AN ORGANIZATION DESIGN TO IMPLEMENT AND MONITOR INTEGRAL SAFETY MANAGEMENT AT THE UNIVERSITY OF TWENTE

J.I.M. Halman

May 1, 2020

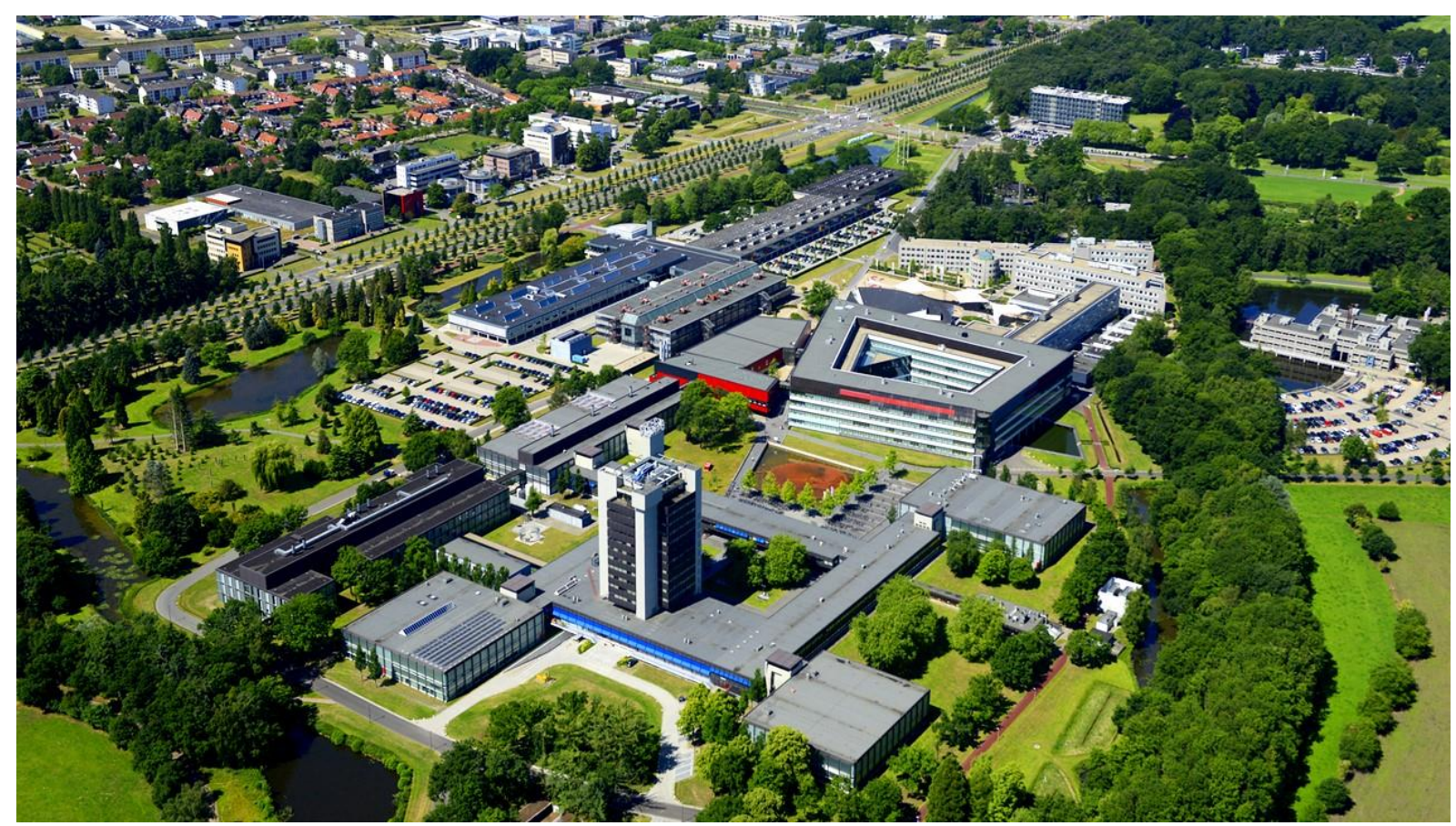


Halman, J.I.M.

An organization design to implement and monitor integral safety management at the University of Twente/ J.I.M. Halman, Faculty Engineering Technology, University of Twente, Enschede, The Netherlands.

ISBN: 978-90-365-5023-9

DOI: $10.3990 / 1.9789036550222$

URL: $\underline{\text { https://doi.org/10.3990/1.9789036550222 }}$

Cover Picture: Campus of the University of Twente 


\title{
AN ORGANIZATION DESIGN TO IMPLEMENT AND MONITOR INTEGRAL SAFETY MANAGEMENT AT THE UNIVERSITY OF TWENTE
}

\author{
Synopsis \\ 1. Introduction \\ Page \\ 2. The Organization of Integral Safety at the University of Twente \\ 2.1. Mission \\ 2.2. Vision \\ 2.3 Additional objectives \\ 2.4 Scope \\ 2.5 The PDCA cycle \\ 2.6. The organization structure \\ 2.7. Budget and resources \\ 3. Recommendations

Appendix I:

The identified potential safety and security risks for universities and campuses Appendix II:

The identified potential risk mitigation strategies for potential safety and security risk issues at universities and campuses

Appendix III:

Incident and accident reporting systems at the University of Twente

Appendix IV:

Expertise input at the University of Twente for each of the distinguished pillars for integral safety

APPENDIX A:

INTERNAL ORIENTATION ABOUT INTEGRAL SAFETY

MANAGEMENT AT THE UNIVERSITY OF TWENTE

APPENDIX B:

EXTERNAL ORIENTATION ABOUT INTEGRAL SAFETY

MANAGEMENT

REFERENCES 


\section{Synopsis}

All universities participating within $\mathrm{VSNU}^{1}$ have agreed with regard to safety to:

- Take responsibility for organizing an integrated safety policy to guarantee a safe living, learning and working environment and safeguard business continuity also in the case of extreme circumstances.

- Compare costs and benefits of safety measures with each other so that only the most sensible ones are given a place.

To implement Integral Safety Management in accordance with the above made agreements, a proposal is being developed for the organization and monitoring of Integral Safety Management at the UT. The following phasing is used:

$1^{\text {st }}$ Phase: Internal orientation: mapping the status quo in the field of safety and security management at the University of Twente

$2^{\text {nd }}$ Phase: External orientation: developing an overview of relevant safety and security risks and risk mitigation strategies based on an extensive review of academic literature and consultation of with external experts

$3^{\text {rd }}$ Phase: A design for implementing and monitoring integral safety at the University of Twente.

The first part of this report provides the results of the $3^{\text {rd }}$ Phase: it includes a design for implementing an Integral Safety Management System at the University of Twente. After a short introduction in section 1, section 2 describes the proposed organization design for implementing an integral safety management system for the University of Twente. Section 3 includes a number of recommendations which are important for a successful implementation of Integral Safety Management at the University of Twente.

Appendix I provides an overview of all the potential risk issues, that were identified during the internal and external orientation studies about Integral Safety Management. They are based on an extensive review of the academic literature about Integral Safety and in-depth interviews with 29 practitioners in the field of safety and security management.

Similarly, Appendix II provides an overview of all potential risk mitigations strategies that were identified during the internal and external orientation studies about Integral Safety Management. Both Appendix I and Appendix II are categorized according to the ten distinguished pillars for Integral Safety Management (These ten pillars are illustrated in figure 1 on page 5).

Appendix III provides a list with the current and proposed incident and accident reporting systems at the University of Twente.

Finally, Appendix IV provides an overview of the available expertise at UT that may be consulted for each of the distinguished pillars for Integral Safety.

Appendix A describes the results of the internal orientation, the $1^{\text {st }}$ phase of this project. This orientation was conducted in 2019 and was reported and approved in October 2019. Fortunately, since the $1^{\text {st }}$ phase of this project, several new initiatives and precautions in the field of Integral Safety Management (such as the registration of hazardous substances via Gros, Mindlab, a nonsmoking UT campus area, the implementation of a UT Privacy policy, the appointment of an ombudsperson and a well-being study among employees) were implemented.

Appendix $B$ describes the results of the external orientation, the $2^{\text {nd }}$ phase of this project.

\footnotetext{
${ }^{1}$ VSNU: Vereniging Universiteiten Nederland; Association of Universities in The Netherlands
} 


\section{Introduction}

On June $6^{\text {th }}, 2018$ the $\mathrm{VSNU}^{2}, \mathrm{VH}^{3}$ and $\mathrm{OCW}^{4}$ signed the "Code of Conduct for an integrated security policy in higher education". This resulted in the Platform Integrale Veiligheid - Hoger Onderwijs (IVHO). As a member of the VSNU, the UT thus committed itself to develop an integral safety and security plan for its organization. The present document fulfills this obligation. In addition, the universities united in the VSNU will investigate on which themes a joint cooperation is feasible and desirable.

One of the highest priorities of the University of Twente is to guarantee a safe education, research, living and working environment for all students and employees. And also, to safeguard the continuity of the university, in the case of extreme circumstances. Increasingly, one may observe that safety or security risks in a specific domain to be intertwined with safety or security risks in other domains. For example, a fire in an ICT-center, not only leads to fire damage, but also potentially leads to failure of ICT-services and the loss of valuable information. Or the spreading of an infectious disease such as Covid-19, will not only potentially affect the health of students and employees, but may also harm the potential continuity of educational and operational processes. This requires a well-coordinated and integrated organization and management of safety and security risks. This note describes a first draft to organize and manage Integral Safety at the University of Twente.

\section{The Organization of Integral Safety at the University of Twente}

Although many safety and security processes at UT are well carried out within the different departments, a coordinated Integral Safety policy, and the integrated monitoring and management of all safety and security aspects is missing. The implementation of an Integrated Safety and Security Management system is therefore required. This will not only ensure a responsible planning, monitoring, realization and evaluation of all required safety and security processes, but will also facilitate a coordinated identification and sharing of well-working local initiatives.

In the following subsections, the mission, vision, objectives, scope, organization structure, and the processes for a UT Integral Safety Management System are described.

\subsection{Mission}

The mission of the Integral Safety Management Organization is to safeguard the continuity of the operational processes of the University of Twente and to realize a substantial contribution to make the UT a safe place and environment for all its students and employees to study, to work, to live, to research, to sport, and to relax.

\subsection{Vision}

The Integral Safety Management Organization aims to realize its mission by:

- Implementing an annual 'plan-do-check-act' program for each of the ten distinguished pillars for Integral Safety Management, which are (see also figure 1): Campus and buildings; Integrity; Privacy; Crisis Management; Cyber risks; Working conditions; Environmental issues; Social safety; Internationalization; and Knowledge development and sharing.

- Identifying, analyzing and mitigating potential safety and security risks which are inextricable intertwined.

\footnotetext{
${ }^{2}$ VSNU: Vereniging Universiteiten Nederland; The Association of Universities in The Netherlands

${ }^{3} \mathrm{VH}$ : Vereniging Hogescholen; The Association of Universities of Applied Sciences

${ }^{4}$ OCW: Ministerie van Onderwijs, Cultuur en Wetenschappen; Ministry of Education, Culture and Science
} 


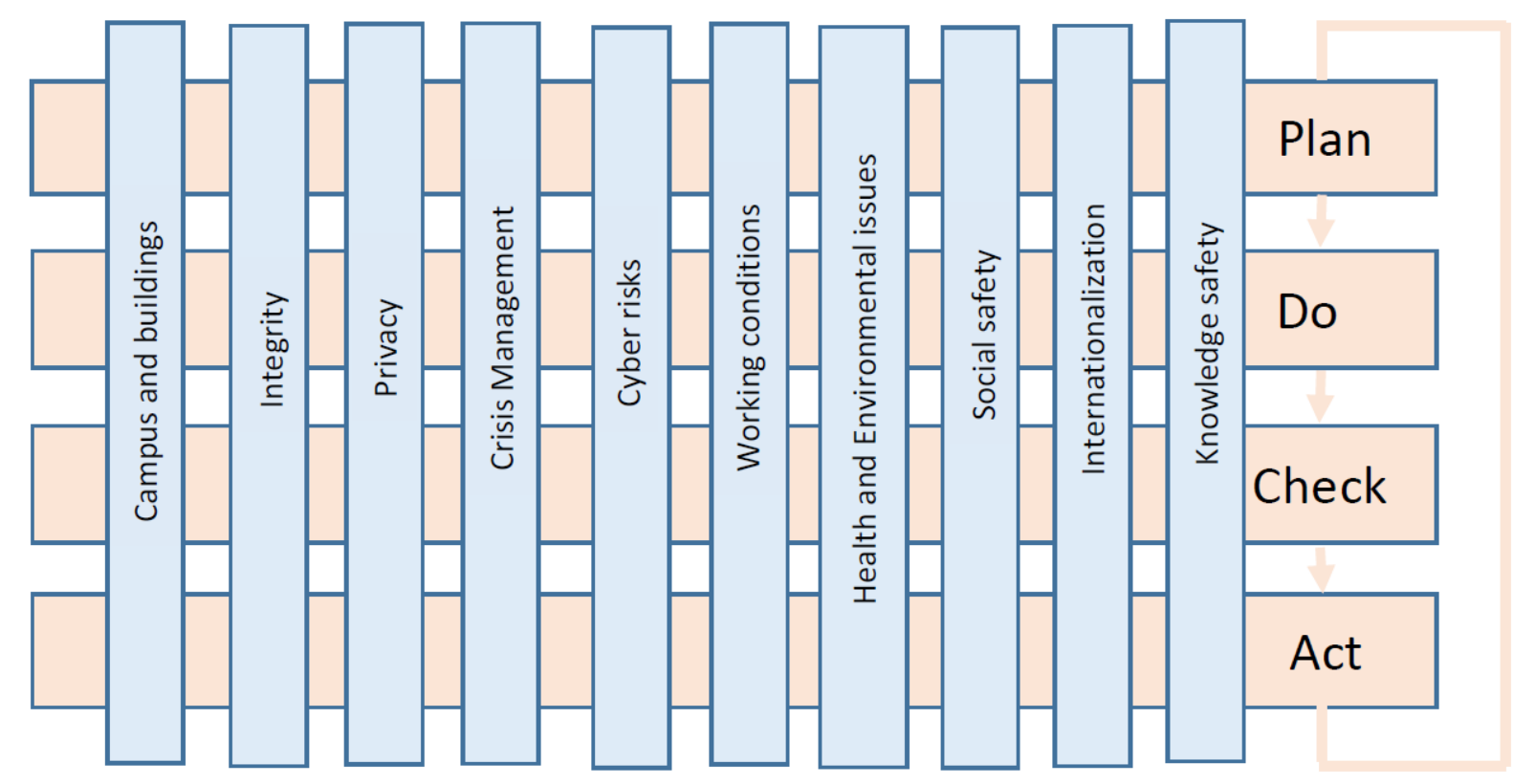

Figure 1. The Integral Safety Management System (Adapted from: Integrale Veiligheid Hoger Onderwijs; Management Systeem Integrale Veiligheid)

- Developing and implementing an annual UT Safety and Security monitor in which the state of safety and security at UT is reported. Systematically collected incidents and accidents and ideas are worked out to further improve the process of Integral Safety Management at UT.

- Promoting and increasing Security and Safety awareness among all students and employees through the development and dissemination of tailored made awareness programs and by integrating awareness for integral safety management in existing leadership courses .

- Playing a coordinating and facilitating role in the process of crisis management and a foresight role by identifying developments and future trends and possible scenarios that may harm the continuity position of the university of Twente.

\subsection{Additional objectives}

While implementing the activities as listed in the vision subsection, the following additional objectives are considered.

- The applied risk, safety and security management methods are state-of-the-art.

- The risk appetite determines the amount and type of risk that UT is prepared to pursue, retain or take. The risk appetite is determined by the Executive Board in consultation with the University council of the University of Twente. The applied risk, safety and security management processes will enable UT to optimally conduct its core activities and to take innovation risks in accordance with the determined risk appetite.

- Knowledge development about risk, safety and security management and pilot testing of new developed methods takes place in close collaboration with UT Faculty research staff.

- Knowledge about and experiences with risk, safety and security management are shared with students.

- Knowledge sharing and learning about risk, safety and security is realized in close cooperation with (inter)national partners. 


\subsection{Scope}

The Integral Safety Management System focuses on the ten distinguished pillars for Integral Safety Management (see figure 1). This means that, although very important, the pillar Financial safety and financial security is not included in the Integral Safety Management System. The description of the organization, procedures and codes of conduct of the Financial Administration and Business control function are outlined in several documents. See also: https://www.utwente.nl/nl/fin/abc/

The University of Twente ensures that its strategy and operational activities are compliant with existing EU and Dutch legislations and also with its own regulations, e.g. with respect to the code of conduct for research integrity. Compliancy can be regarded as an important aspect for each of the ten distinguished pillars for Integral Safety Management.

\subsection{The PDCA cycle}

The Integral Safety Management System is based on the 'Plan-do-check-Act cycle' (PDCA-cycle) principle. As such, the organization and management of Integral Safety can be seen as a continuous process of learning and improving:

Plan: Develop an Integral Safety Management policy, objectives, processes and procedures to achieve results that are consistent with the UT's overall policies and objectives.

Do: Implement the developed Integral Safety Management policy, objectives, processes and procedures.

Check: Monitor and measure the results of the implemented Integral Safety Management policy, objectives, processes and procedures

Act: $\quad$ Take corrective and preventive actions, based on internal audits and management reviews, to achieve continuous improvement

\subsection{Organization structure}

The Supervisory Board is tasked with supervising the Executive Board of the University of Twente, ensuring compliance with the current legal regulations with regard to safety \& security and advises the Executive Board on the integral management of safety and security.

The Executive Board of the University of Twente is ultimately responsible for the safety and security of the University of Twente. The Executive Board appoints an Integral Safety Manager who takes responsibility for implementing and realizing the vision and additional objectives as outlined in this note. The Integral Safety Manager is embedded hierarchically in the Department General Affairs and has a direct reporting line to the portfolio holder for Integral Safety of the Executive Board. In the pursuit of Integral Safety management one may distinguish two levels of Integral Safety: the Strategic level and the Tactical/Operations level (see also figure 2).

\section{Strategic level}

The Strategic level of Integral Safety management has the entire university in mind and covers the desired future and long-term goals at the University of Twente with respect to Integral Safety.

A UT Integral Safety Board determines the UT Integral Safety objectives by which Faculties and Service Departments can create compatible plans that are aligned with those objectives. This Board is chaired by the portfolio holder of Integral Safety of the Executive Board and further consists of: the Integral Safety Manager, the directors General Affairs (GA), Centre for Educational Support (CES); Human Resources (HR); Library, ICT Services \& Archive (LISA), Strategy \& Policy (S\&P), Marketing \& Communication (M\&C), Campus \& Facility Management (CFM), Finance (FIN); and the Operations directors of the Faculties Behavioral, Management \& Social Sciences (BMS); Engineering Technology (ET); Electrical Engineering, Mathematics, \& Computer Science EEMCS; Science \& Technology (TNW); 


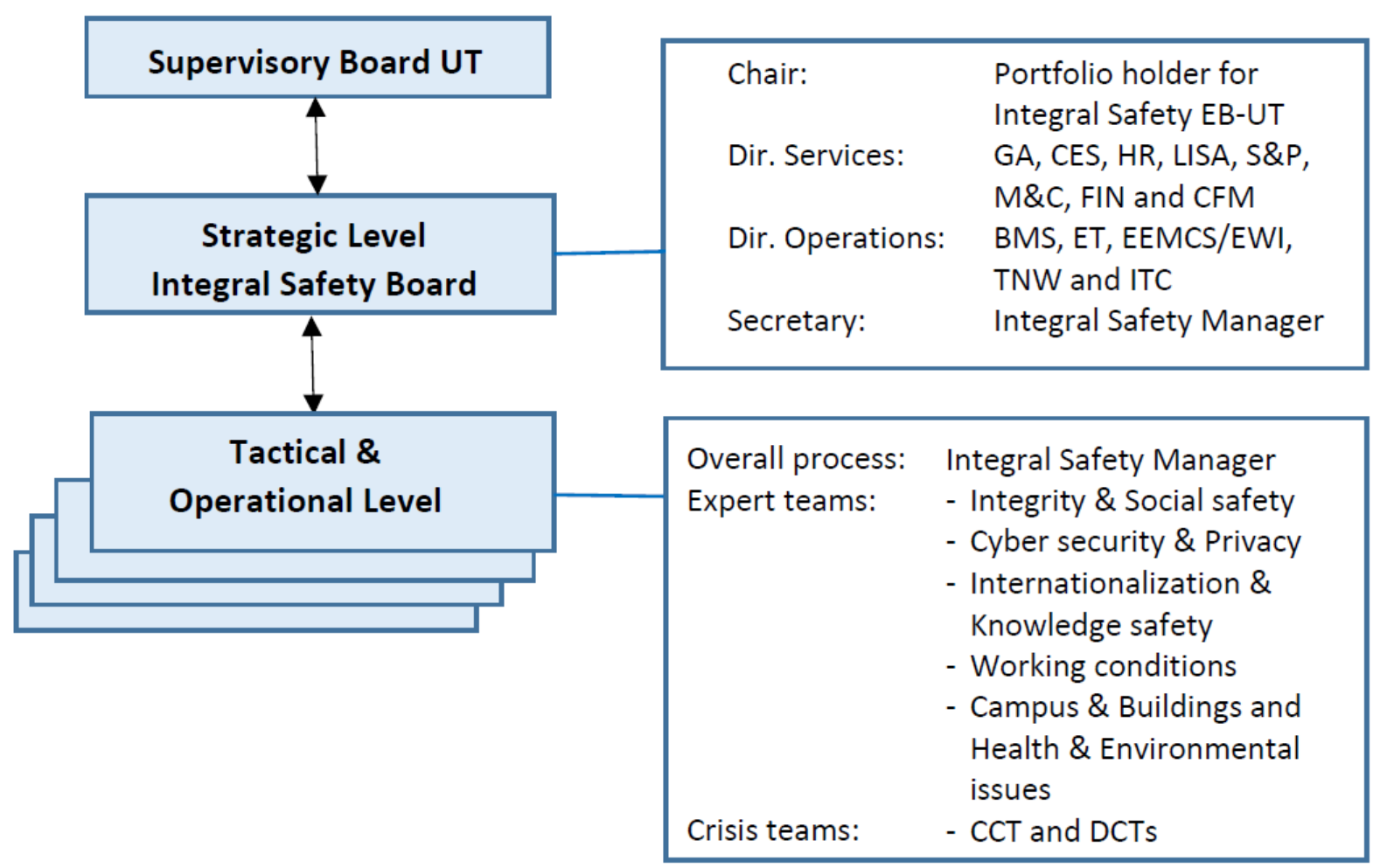

Figure 2: The Integral Safety Governance Structure

and Geo-Information Science and Earth Observation (ITC). With the exception of the inclusion of the Integral Safety Manager, the composition of the UT Integral Safety Board is the same as the existing consultative body UCB. The frequency of consultation on Integral Safety related topics will be about 4 times a year.

The Integral Safety Board takes responsibility for the annual development, realization and evaluation of an Integral Safety UT plan. Input for the Integral Safety UT Plan are the:

- Quarterly reports and annual evaluation and annual plan on Integrity and social safety;

- Quarterly reports and annual evaluation and annual plan on Cyber security and Privacy;

- Quarterly reports and annual evaluation and annual plan on Internationalization and Knowledge safety;

- Quarterly reports and annual evaluation and annual plan on Working conditions issues;

- Quarterly reports and annual evaluation and annual plan on crisis management events, crisis training sessions and operational continuity management;

- Quarterly reports and annual evaluation and annual plan on Campus and Buildings, Health \& Environmental safety and security issues.

The reports will naturally incorporate and not overlap with already existing reporting systems such as RI\&E (Risk Inventory \& Evaluation) for Health and Environment safety, the yearly Fire safety inspection round, quarterly reports about cyber security, the annual report made by confidential advisors, the annual report ombudsperson, the well-being research employees report and the Student well-being report.

In addition, to prepare for possible new safety and security risk events that may happen in the near future, the Integral Safety Board will conduct every 3-5 years an in-depth scenario-analysis.

The Integral Safety Board will also take responsibility to commission an external audit team with safety and security experts to evaluate every three years, the state of Integral Safety at UT. 
UT Annual Integral Safety report and plan

Approval by: Integral Safety Board

Prepared by: Integral Safety Manager

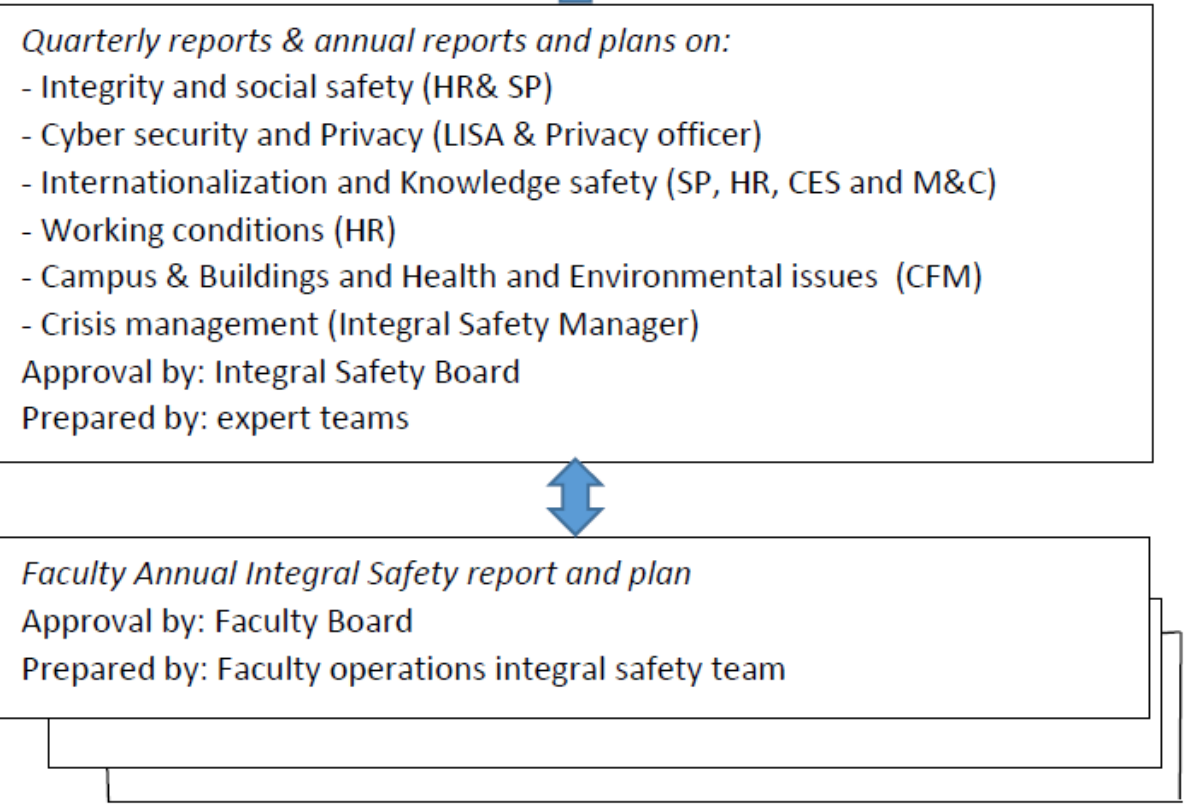

Figure 3: The Integral Safety products and control scheme.

\section{Tactical \& Operational level}

The overall UT process of Integral Safety planning, implementing, monitoring and taking of improvement actions is the responsibility of the Integral Safety Manager.

Each Faculty operations director, casu quo, Service department director, is expected to plan, implement, monitor and improve the state of Integral Safety within his/her own Faculty or Service department and to take appropriate actions to further improve the state of Integral Safety Management. The Faculties and Service departments are supported by domain experts, who are specialized in specific safety and/or security related areas. The following clusters of expertise are distinguished (see also figure 3):

- Integrity and social safety (HR \& SP);

- Cyber security and Privacy (LISA \& Privacy officer);

- Internationalization and Knowledge safety (SP, HR, CES \& M\&C);

- Working conditions (HR);

- Campus \& Buildings safety and Health \& Environmental issues (CFM).

Besides supporting the Faculties and Service departments in implementing Integral Safety within their Faculty or Service department, the expertise teams also take responsibility for writing the respective UT quarterly and annual reports and the annual plans. These reports and plans also cover Faculties and Service departments.

At the Faculty level, an Operational Integral Safety Team is chaired by the Faculty Operations Director and typically consists of the HR manager, the ICT-account manager, HSE-Faculty manager, CFMFaculty team leader, and the Portfolio managers for education and for research. Whenever necessary, the Faculty of operations director is advised by the Integral Safety Manager or by one of the clusters of expertise. Similarly, a Service Department Director takes responsibility for the planning, 
implementation, monitoring and evaluation of Integral Safety Management within his/her own Department.

\section{Crisis management and the crisis team(s)}

Crisis management can be defined as the preparing for and responding to unscheduled, undesirable, urgent and threatening contingencies such as pandemics, infrastructure breakdowns, terrorist attacks and outburst of mass violence (Boin and 't Hart, 2010). Such contingencies are of the low probability but very high impact kind. To respond to such kind of crises, the University of Twente has developed a Crisis Management Policy Plan. The Integral Safety Manager is responsible for the actualization and implementation of the Central Crisis Plan. This Central Crisis Plan is updated every last week of the quarter; The Integral Safety Manager organizes an exercise of the plan at least once a year.

The Executive Board of the University of Twente determines whether there is an emergency and whether the Central Crisis Team (CCT) should be convened. The Central Crisis Team (CCT) is chaired by one of the members of the Executive Board. Depending on the type of crisis, the Executive Board decides who will lead the CCT in a specific crisis. Besides the CCT chair, the central crisis team consists of the secretary of the university, the directors M\&C, HR, CFM, CES and LISA (or their substitutes) and a spokesman/woman of the Executive Board. Depending on the type of crisis, the CCT chair will determine whether these members will be part of the crisis team or whether the team may consist of a smaller or extended formation.

Minor incidents and accidents are dealt with by the BHV teams (emergency response teams). In the case of a more complicated calamity, the local BHV manager alerts the chair of the Decentral Crisis Team (DCT). The DCT is chaired by the dean of the faculty (or the director of operations/ director of the service department or their substitute). The composition of the DCT is similar as the Decentral Operational Safety \& Security Team but depending on the type of crisis, the DCT chair or his deputy will determine whether these members will be part of handling the specific crisis or whether the team may consist of a smaller or extended formation. The DCT chair informs the chair of the CCT about the calamity. If necessary, the chair of the CCT will scale up the handling of the calamity.

\subsection{Budget and resources}

To successfully implement the Integral Safety Management system, it is required to allocate dedicated specialized resources and an additional budget.

It is advised to appoint a full time Integral Safety Manager who is embedded hierarchically in the General Affairs Department and who has a direct reporting line to the portfolio holder for Integral Safety of the Executive Board. The Integral Safety Manager is responsible for implementing and realizing the vision and additional objectives of Integral Safety Management as outlined in this note and takes responsibility for the overall Integral Safety management. The Integral Safety Manager further acts as the secretary of the UT Integral Safety Board, and is a senior advisor on Integral Safety issues for all the Faculties and Service Departments.

The Integral Safety Manager is assisted by a full time Integral Safety advisor, who takes care of the development and implementation of a structural training program on safety \& security for UT employees and students. The Integral Safety advisor assists the Integral Safety Manager in a signaling role on the implementation of Integral Safety Management at the Faculties and Service Departments. In addition, the Integral Safety advisor is expected to develop and implement procedures for those pillars of the Integral Safety Management system that are still in their infancy. The Integral Safety advisor will also contribute in yearly performing an integrated risk assessment about the status of Security and Safety management at the University of Twente. 
Specific additional expertise is required to handle new upcoming internationalization and knowledge development \& sharing issues such as the implementation of sanction policies required by the Dutch government. It is assumed that this will require the expertise of a policy advisor on a $0,5 \mathrm{fte}$ basis.

Besides allocating a budget to appoint a full time Integral Safety manager, a full time Integral Safety advisor and a part time specialized advisor, an additional budget is required to develop and implement a safety and security communication and training program for UT employees and students. It is advised to allocate a yearly budget of $100 \mathrm{~K}$ for training and administrative and supportive activities on Integral Safety Management at the central and local level at the University of Twente.

\section{Recommendations}

To realize the intended Integral Safety Management system at UT it is proposed to:

\section{- Conduct a scenario-analysis every 3-5 years}

College campuses need to change their short-term focus toward a sustainable and resilient approach. Universities often realize that they are preparing for the more recent events in history, which possibly leads to responding to a situation they have not prepared for. Although the preparedness for recurring events is applaudable, it is also necessary to be prepared for possible new events that may happen in the near future

- Develop and implement an annual 'plan-do-check-act' program for each of the ten distinguished pillars included in the Integral Safety Management System (see figure 1)

From the earlier conducted Quick Scan study (Halman, 2019) it became clear that a number of the pillars (i.e. the pillar 'cyber security risks', 'Campus and buildings' and "Health and Environmental safety') have well worked out procedures for safety and security management while the 'plan-do-check-act' control cycle for some other pillars (e.g. the pillars Internationalization and ) are still in their infancy.

- Conduct an analysis of safety and security risk issues that are inextricably intertwined From the bibliographic study but also the conducted interviews for the Quick Scan study, it became clear that besides individual safety or security risks, there are also safety and security risks which are intertwined (e.g. a fire in an ICT-center, not only potentially leads to fire damage but also potentially leads to failure of ICT-services and the loss of valuable information. Or the spreading of an infectious disease which can also harm the continuity of the educational process). Based on a detailed collection of potential safety and security risks per distinguished pillar an analysis can be made of potential mutual interactions.

- Develop and implement an annual UT Security and Safety monitor For the transition towards an Integrated Safety and Security Management System, it is important to systematically collect incidents and accidents and also annually perform an integrated risk assessment about the status of Security and Safety management at the University of Twente. Such a monitor will help to evaluate if risk mitigation actions have been effective and if potential new and/or new intertwined risks are observed or anticipated.

The identified safety and security risks, as categorized in Appendix 1, can be used as input for the integrated risk assessment. Appendix 2 can be used as a reference to evaluate if potential improvements in the process of Integral Safety Management have been implemented. 
- Develop and implement a tailored Integrated Security and Safety training program No safety and security without safety and security awareness and training. Depending on the specific role (student, faculty or staff), the position (management, administrative, research and/or education) and the disciplinary background (e.g. high risk for espionage), a tailored made awareness and safety \& security training program needs to be developed, disseminated and maintained.

- Develop and regularly update a continuity of operations plan

Evaluate the management of the covid-19 university lockdown process and develop on the basis of this evaluation an improved crisis management plan and a continuity of operations plan. Encourage faculty, staff, and students to avail training and education opportunities in crisis management and ensure that key staff and faculty are trained and are participating in regular crisis exercises.

- Conduct an external audit about the state of safety \& security management every 3 years Education programs, research programs and also the financial administration are regularly audited by external experts. Similarly, it is advised to ask external experts to audit every 3 years the state of implementation of integral safety management at the University of Twente.

- Implement the proposed organization structure and resources for Integral Safety Management It is advised to implement the proposed organizational structure for Integral Safety Management and to appoint the proposed Integral Safety Manager, the Integral Safety management assistant and the part time policy advisor on internationalization and knowledge development and sharing. 


\section{APPENDIX I: THE IDENTIFIED POTENTIAL SAFETY AND SECURITY RISKS FOR UNIVERSITIES AND CAMPUSES}

Table 1 provides all the potential risk issues, that were identified during the internal and external orientation interviews about Integral Safety and the reviewed academic literature about Integral Safety at universities and campuses. They are clustered according to the ten distinguished pillars for Integral Safety (see also figure 1). While some of these risks have been addressed at the UT since the start of this inventory, this does, unfortunately, not always guarantee that there is no (perceived) risk anymore.

Table 1. The identified potential safety and security risks for universities and campuses

\begin{tabular}{|c|c|c|}
\hline & Category & Identified potential safety \& security risks \\
\hline 1 & Campus and buildings & 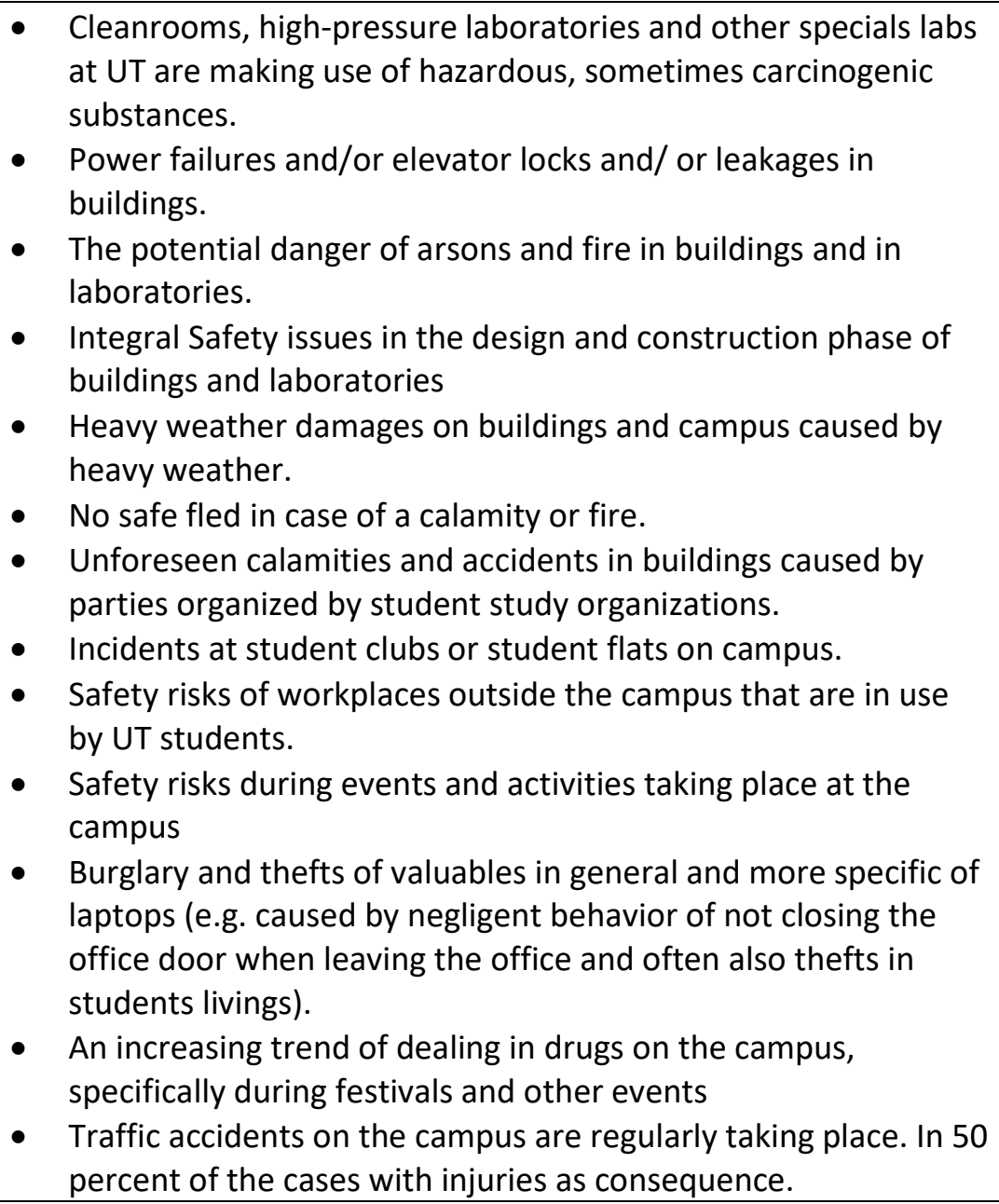 \\
\hline 2 & Integrity & $\begin{array}{l}\text { - The UT and Faculty may suffer reputation damage in case of } \\
\text { violation against scientific integrity (i.e. careful data } \\
\text { management; research ethics; plagiarism; data fraud; diploma } \\
\text { fraud; a student pretending to be someone else during } \\
\text { examination; conflict of interests) } \\
\text { - The UT, Faculty or Service departments may suffer reputation } \\
\text { damage in case of violation against social integrity (i.e. } \\
\text { relationships, manners in the work place) }\end{array}$ \\
\hline
\end{tabular}


Table 1. The identified potential safety and security risks for universities and campuses (continued).

\begin{tabular}{|c|c|c|}
\hline & Category & Identified potential safety \& security risks \\
\hline & Integrity (cont.) & $\begin{array}{l}\text { - The UT may suffer reputation damage in case of violation against } \\
\text { organization integrity (i.e. ensuring a safe working environment } \\
\text { safeguard the privacy of employees and students, financial } \\
\text { fraud) }\end{array}$ \\
\hline 3 & Privacy & $\begin{array}{l}\text { - Employees or students who are threatened via internet and } \\
\text { social media } \\
\text { - Negative fake comments about UT, employees or students on } \\
\text { internet and social media placed by a former employee or other } \\
\text { person } \\
\text { - Privacy violation of students, staff or external stakeholders, } \\
\text { caused by data breaches, different forms of digital fraud and } \\
\text { hacking (GDPR). }\end{array}$ \\
\hline 4 & Crisis Management & $\begin{array}{l}\text { - Disasters affecting humans and/or infrastructure at UT; } \\
\text { - Terroristic action on campus; } \\
\text { - } \text { Fast spreading of infectious disease; } \\
\text { - Outbursts of violence } \\
\text { - Continuity of university in danger; } \\
\text { - Acute situation(s) that have not occurred before and } \\
\text { consequently difficult to protocol. } \\
\text { - Not being prepared for unscheduled, undesirable, urgent and } \\
\text { - } \quad \text { threatening contingencies } \\
\text { - Management inaction and/or neglect } \\
\text { - Inadequate management by e.g. misleading half-truths or lies or } \\
\text { - by assigning blame to others } \\
\text { Lack of training in crisis management }\end{array}$ \\
\hline 5 & Cyber risks & $\begin{array}{l}\text { - Serious IT threats caused by interference from foreign countries } \\
\text { (Iran, Russia, China). } \\
\text { - Security of the data center. } \\
\text { - Network and Wifi outage. } \\
\text { - Misuse of ICT systems (e.g. when a student uses the (digital) } \\
\text { identity of a teacher or staff member, to change his study } \\
\text { results) } \\
\text { - Cyberattacks, data breaches and hacking. } \\
\text { - Ransomware. } \\
\text { - ICT spam. }\end{array}$ \\
\hline 6 & Working conditions & $\begin{array}{l}\text { - An increasing and too heavy workload and work stress } \\
\text { - Employees and students showing psychological vulnerable } \\
\text { behavior (e.g. psychotic behavior, suicide tendency and serious } \\
\text { depression) } \\
\text { - A lack of expertise in dealing with mental crisis situations in the } \\
\text { workplace. } \\
\text { - Not meeting ARBO requirements } \\
\text { - Cleanrooms, high-pressure laboratories and other special labs } \\
\text { at UT are making use of hazardous, sometimes carcinogenic } \\
\text { substances. }\end{array}$ \\
\hline
\end{tabular}


Table 1. The identified potential safety and security risks for universities and campuses (continued).

\begin{tabular}{|c|c|c|}
\hline & Category & Identified potential safety \& security risks \\
\hline & $\begin{array}{l}\text { Working conditions } \\
\text { (cont.) }\end{array}$ & $\begin{array}{l}\text { - Working with flammable and explosive substances in } \\
\text { laboratories } \\
\text { - Potential inadequate emergency response. BHV reports about } \\
75 \text { health accidents per year (e.g. someone becoming unwell, a } \\
\text { suffered cardiac arrest, an epileptic seizure or an injury } \\
\text { sustained by someone). }\end{array}$ \\
\hline 7 & $\begin{array}{l}\text { Health \& } \\
\text { Environmental issues }\end{array}$ & $\begin{array}{l}\text { - Possible fast spreading of an infectious disease such as the } \\
\text { coronavirus Covid-19. } \\
\text { - } \text { Disaster on campus caused by explosions of fire and with } \\
\text { serious health impact } \\
\text { - } \quad \text { Disaster on campus caused by a crashing plane } \\
\text { - } \quad \text { The institution's imports of food, paper, use of fossil fuels, } \\
\text { construction materials, landscaping materials and many other } \\
\text { products that may have a negative environmental impact. }\end{array}$ \\
\hline 8 & Social safety & $\begin{array}{l}\text { - Unwanted sexual touching: between students, between } \\
\text { employees but also between a student and an employee. } \\
\text { - } \quad \text { Psychological harassment: between students, between } \\
\text { employees but also between a student and an employee. } \\
\text { - } \text { Aggressive behavior and bullying between students, between } \\
\text { employees but also between a student and an employee. } \\
\text { - Hiring of new employees with a negative track record. } \\
\text { - Violent loners. } \\
\text { - Robbery of valuables on the campus and in the buildings }\end{array}$ \\
\hline 9 & Internationalization & $\begin{array}{l}\text { - Safety of UT-employees and UT-students who are staying in } \\
\text { foreign countries } \\
\text { - Students or staff at UT with unacceptable norms and values } \\
\text { (e.g. male students who behave in an ill-mannered way } \\
\text { towards female students or female staff). } \\
\text { - Students or staff with radical ideas of extremism. } \\
\text { - Studying as a disguise for gaining a temporary residence permit } \\
\text { to stay in The Netherlands. } \\
\text { - An increased vulnerability for spying. } \\
\text { - Foreign students discriminated in The Netherlands or on the } \\
\text { campus; } \\
\text { - Administrative problems for foreign students: to get a visa, } \\
\text { getting a social security number, bank account, or } \\
\text { accommodation. } \\
\text { - Augmenting stress and psychological problems among foreign } \\
\text { BSc, MSc and PhD students, (caused e.g. by homesickness, } \\
\text { time pressure to finalize the study, the stigma of failure, social } \\
\text { isolation, relationship problems, culture shock, alcohol and } \\
\text { drug abuse }\end{array}$ \\
\hline
\end{tabular}


Table 1. The identified potential safety and security risks for universities and campuses (continued).

\begin{tabular}{|l|l|l|}
\hline & Category & \multicolumn{1}{|c|}{ Identified potential safety \& security risks } \\
\hline (cont.) & $\begin{array}{l}\text { Internationalization } \\
\text { Knowledge safety }\end{array}$ & $\begin{array}{l}\text { Financial problems for foreign students: PhD students lacking } \\
\text { financial resources from home country, BSc and MSc student } \\
\text { not receiving their scholarship from home country }\end{array}$ \\
\hline 10 & $\begin{array}{l}\text { Possible espionage activities through theft of data sets and } \\
\text { blueprints, pending or unpublished patents and scientific } \\
\text { discoveries, in particular by students or staff from sanction } \\
\text { countries such as China, Iran and Russia. }\end{array}$ \\
& $\begin{array}{l}\text { The dual use of specific UT knowledge, patents and innovations } \\
\text { by foreign countries such as China, Iran and Russia which are } \\
\text { on the sanction list of the Dutch government. } \\
\text { Projects with countries on the sanction list of the Dutch } \\
\text { government may jeopardize the continuity position of UT } \\
\text { IT-security of UT staff and students (due to loss/hacking of } \\
\text { confidential information) when travelling to sanction countries } \\
\text { such as China, Iran and Russia. }\end{array}$ \\
\hline
\end{tabular}




\section{APPENDIX II: THE IDENTIFIED POTENTIAL MITIGATION STRATEGIES FOR POTENTIAL SAFETY AND SECURITY ISSUES AT UNIVERSITIES AND CAMPUSES}

Table 2 provides all the potential risk mitigation strategies, that were identified during the internal and external orientation interviews about Integral Safety and the academic literature review about Integral Safety. They are clustered according to the ten distinguished pillars for Integral Safety (see also figure 1).

Table 2: $\quad$ The Identified potential mitigation strategies for potential safety and security risk issues at universities and campuses

\begin{tabular}{|c|c|c|}
\hline & Category & Identified potential mitigation strategies for potential risk issues \\
\hline 1 & Campus and buildings & $\begin{array}{l}\text { - Clear agreements between the Campus \& buildings } \\
\text { organization and the Operational Faculty director about the } \\
\text { issue of keys to access a building, office room and/or } \\
\text { laboratory. The Galaxy authorization system gives people } \\
\text { access to buildings outside office hours. The facility manager of } \\
\text { a faculty or building complex has been mandated to assign the } \\
\text { entrance authorization to an employee, student or external } \\
\text { person. } \\
\text { - A regulated permission is effective to access workspaces and } \\
\text { laboratories which contain hazardous substances. } \\
\text { - Keeping up an up-to-date register of all persons who are in } \\
\text { contact with hazardous substances } \\
\text { Students and new employees who are going to work in } \\
\text { laboratories with an increased safety risk, should in advance be } \\
\text { tested on their knowledge with respect to safety precautions. } \\
\text { Access to the laboratories should only be made possible } \\
\text { through the ARBO (Health, Safety \& Environment) coordinator } \\
\text { of the respective department. } \\
\text { All buildings have a fire alarm system and an evacuation alarm } \\
\text { system. Carré, de Horst, Ravelijn and the Technohal in addition } \\
\text { have a Sprinkler installation. Through the Picasse system, BHV } \\
\text { teams or members of a local crisis team can be called quickly in } \\
\text { case of an emergency. } \\
\text { The quality of Automatic External Defibrillators (AED) in all } \\
\text { buildings, installed to be used in case of a cardiac arrest, and } \\
\text { the installed fire hoses, are regularly tested. } \\
\text { All BHV (emergency response) volunteers and professionals at } \\
\text { Carre and Horst yearly follow an emergency response training } \\
\text { of about } 20 \text { hours. The other BHV teams at the campus follow } \\
\text { an emergency response team training of about } 12 \text { hours per } \\
\text { year. In addition, about } 150 \text { volunteering students yearly } \\
\text { follow the BHV training while about } 150 \text { volunteering students } \\
\text { receive a repeat training. All BHV volunteers and professionals } \\
\text { follow in addition a breathing air training which is given by a } \\
\text { fire brigade instructor. } \\
\text { To better prevent the risk of a fire breaking out in buildings, we } \\
\text { of illegal coffee makers and monitor safety in laboratory } \\
\text { facilities. }\end{array}$ \\
\hline
\end{tabular}


Table 2 The Identified potential risk mitigation strategies for safety and security risk issues at universities and campuses (continued)

\begin{tabular}{|c|c|c|}
\hline & Category & Identified potential mitigation strategies for potential risk issues \\
\hline & $\begin{array}{l}\text { Campuses and } \\
\text { buildings (cont.) }\end{array}$ & $\begin{array}{l}\text { - All BHV (emergency response) teams have a system that each } \\
\text { building has a "buddy building". So if there are too few } \\
\text { emergency responders in a building during an emergency, an } \\
\text { automatic notification for support is sent to the buddy } \\
\text { building. } \\
\text { - For bigger events and activities taking place at the campus of } \\
\text { UT, CFM (Campus and Facility management) makes use of } \\
\text { about } 30 \text { external security guards. } \\
\text { - The boards of study associations need to be aware of what is } \\
\text { and what is not possible during a drink or event organized by } \\
\text { them. To this end, there are regular consultations between the } \\
\text { building manager and the respective study associations. } \\
\text { - Student teams working in workplaces outside the campus (e.g. } \\
\text { solar team), need to be made aware of the possible safety risks } \\
\text { and to be informed whom they contact at the UT for support } \\
\text { to mitigate safety risks. } \\
\text { - Awareness promotion among employees and students about } \\
\text { the possible theft of their laptop or other valuables. } \\
\text { The campus security carefully controls for possible dealing in } \\
\text { drugs (e.g. during festivals and events) and closely works } \\
\text { together to this end with the city Police. } \\
\text { Awareness promotion, and speed limitation are needed to } \\
\text { increase traffic safety on the Campus. }\end{array}$ \\
\hline 2 & Integrity & $\begin{array}{l}\text { - Implementation of the "House of Integrity" through: } \\
\text { (1) promoting awareness among students and employees; } \\
\text { (2) Promoting an integrity culture; } \\
\text { (3) Research data management; } \\
\text { (4) Publication policy; } \\
\text { (5) Ethical norms and procedures } \\
\text { - Including Integrity as a separate course (2 EC) in the PhD and } \\
\text { PDEng education program. } \\
\text { - Screening of new staff (VOG and VGB) that are appointed in } \\
\text { sensitive positions. }\end{array}$ \\
\hline 3 & Privacy & $\begin{array}{l}\text { - At UT this has been formulated in: "Leidraad privacyregels } \\
\text { bescherming van personen in wetenschappelijk onderzoek" } \\
\text { and the appointment at UT of "Privacy Contact Personen" } \\
\text { (PCPs). See also: https://www.utwente.nl/en/cyber- } \\
\text { safety/cybersafety/legislation/ } \\
\text { - Privacy sensitive research needs the approval of the Ethical } \\
\text { committee. } \\
\text { - The "house of integrity" also covers the organization integrity, } \\
\text { i.e. safeguarding the privacy of employees and students }\end{array}$ \\
\hline
\end{tabular}


Table 2 The Identified potential risk mitigation strategies for safety and security risk issues at universities and campuses (continued)

\begin{tabular}{|c|c|c|}
\hline & Category & Identified potential mitigation strategies for potential risk issues \\
\hline 4 & Crisis Management & $\begin{array}{l}\text { - A proper Crisis management and Continuity management plan } \\
\text { which is regularly updated. } \\
\text { - } \quad \text { A well-tuned partnering plan and effective communication with } \\
\text { external key-actors (e.g. Hospital, Municipality, Police etc.). } \\
\text { - A well-tuned cooperation between the UT security guard } \\
\text { organization and the city Police is needed. } \\
\text { - Effective crisis management depends on principles and } \\
\text { processes that assure flexibility and a smooth flow of } \\
\text { information. } \\
\text { - Early warning mechanisms/ rapid response capability; } \\
\text { - The deployment of UT mental crisis experts in the event of a } \\
\text { - } \quad \text { Reguchotic crisis behavior case. } \\
\text { - Evaluation to learn from conducted crisis simulations. } \\
\text { - Extend the current pallet of potential crisis situations. } \\
\text { - Conduct a scenario analysis to anticipate potential future risks } \\
\text { - Awareness creation and training among students, faculty and } \\
\text { - } \text { staff. } \\
\text { - Psychosocial, legal and financial aftercare. }\end{array}$ \\
\hline 5 & Cyber risks & $\begin{array}{l}\text { - The Cert-UT (Computer Emergency Response Team) is } \\
\text { responsible for the UT cyber-security policy and takes security } \\
\text { risk precautions. See also: https://www.utwente.nl/en/cyber- } \\
\text { safety/cybersafety/legislation/ } \\
\text { - UT participates in the CERT-SURF network. } \\
\text { - UT makes use of “Quarantine-net", an advanced software to } \\
\text { detect suspicious computer behavior by employees and } \\
\text { students. } \\
\text { - } 24 / 7 \text { security monitoring is of vital importance. } \\
\text { - UT cooperates with the "Twente Hackers squad" to detect } \\
\text { possible leaks in the UT computer network. } \\
\text { - UT has a "responsible disclosure procedure" to report leaks in } \\
\text { the UT-computer network and software applications. } \\
\text { - Participation in cyber crisis exercises, organized by SURF, such } \\
\text { as OZON and NOZON } \\
\text { Cyber-security awareness and training among all students and } \\
\text { employees is of vital importance. }\end{array}$ \\
\hline 6 & Working conditions & $\begin{array}{l}\text { - An UT-taskforce has been installed to monitor workload at UT } \\
\text { and to makes suggestions how to reduce an unacceptable level } \\
\text { of workload. } \\
\text { - TGS (Twente Graduate School) offers courses for PhD students } \\
\text { how to deal with work stress. } \\
\text { - VSNU has outlined rules to promote a healthy work practice for } \\
\text { PhD students. } \\
\text { - The hiring of 1-2 professionals to deal with mental crisis } \\
\text { situations at UT. }\end{array}$ \\
\hline
\end{tabular}


Table 2 The Identified potential risk mitigation strategies for safety and security risk issues at universities and campuses (continued)

\begin{tabular}{|c|c|c|}
\hline & Category & Identified potential mitigation strategies for potential risk issues \\
\hline & $\begin{array}{l}\text { Working conditions } \\
\text { (cont.) }\end{array}$ & $\begin{array}{l}\text { - Awareness creation among executives, department chairs, and } \\
\text { employees how to reduce work overload and to prevent } \\
\text { burnout. }\end{array}$ \\
\hline 7 & $\begin{array}{l}\text { Health and } \\
\text { Environmental issues }\end{array}$ & $\begin{array}{l}\text { - Create a continuity plan in case of the spreading of a serious } \\
\text { infectious disease } \\
\text { - The VGM (Safety, Health \& Environmental) organizations has } \\
\text { outlined the tasks and responsibilities of all actors in the field of } \\
\text { Safety, Health and Environmental issues (report nr. VGM TVB's } \\
\text { 372.447/PA\&O) } \\
\text { - Create a strong chemical safety culture in laboratories. } \\
\text { - Maintain a chemical incident reporting \& learning system. } \\
\text { - Deploy a sustainable policy with regard to purchasing green } \\
\text { products, circular designs and circular construction. }\end{array}$ \\
\hline 8 & Social safety & $\begin{array}{l}\text { - New students and new employees must be extensively } \\
\text { informed about the view of the UT with regard to an inclusive, } \\
\text { - } \quad \text { Stufe and healthy working environment. } \\
\text { what is expected from them with respect to an inclusive, safe } \\
\text { and healthy study and working environment at UT. } \\
\text { - An UT aggression protocol outlines the procedures and } \\
\text { sanctions which are effective with regard to physical } \\
\text { aggression, but also less visible aggressive behavior such as } \\
\text { bullying. } \\
\text { - A careful screening of new employees (e.g. taking references } \\
\text { from past employers serious and ask for a certificate of good } \\
\text { conduct (VOG) and also VGB in case of sensitive positions). } \\
\text { Employees and students can inform a UT-confidant or the UT- } \\
\text { ombudsperson if they want to confidentially report e.g. } \\
\text { unauthorized financial transactions, incorrect assessments, and } \\
\text { complaints regarding unwanted touching or psychological } \\
\text { harassment. } \\
\text { - Identify worrying behavior in an early phase. } \\
\text { Include a safety and security awareness training in student } \\
\text { orientation programs } \\
\text { Include a safety and security awareness training for new } \\
\text { employees. }\end{array}$ \\
\hline 9 & Internationalization & $\begin{array}{l}\text { - Provide relevant information to foreign students and foreign } \\
\text { employees about the administrative side of staying in the } \\
\text { Netherlands. } \\
\text { - Inform foreign students about the prevailing norms, values and } \\
\text { manners in Dutch society. Student mentors and study advisors } \\
\text { may a constructive role to this end. } \\
\text { - Also in the case of foreign employees, the introduction } \\
\text { program should draw attention about the prevailing norms, } \\
\text { values and manners in Dutch society. }\end{array}$ \\
\hline
\end{tabular}


Table 2 The Identified potential risk mitigation strategies for safety and security risk issues at universities and campuses (continued)

\begin{tabular}{|c|c|c|}
\hline & Category & Identified potential mitigation strategies for potential risk issues \\
\hline & Internalization (cont.) & $\begin{array}{l}\text { - Involve the international PhD community at UT. They may play } \\
\text { a significant role by paying attention to each other as a } \\
\text { community and warning when one is worried about a PhD } \\
\text { student. } \\
\text { - Adopt at all Faculties the current ITC practice where foreign } \\
\text { students can approach two study affairs officers with a range of } \\
\text { (also non-study related) problems. Due to an accessible open } \\
\text { door policy the study affairs officers quickly hear when a } \\
\text { potential problem arises and they can take proactive actions. } \\
\text { Like ITC, start with a homologation year for foreign PhD } \\
\text { students. This is to ensure that a PhD student has the required } \\
\text { knowledge and skills to successfully complete a promotional } \\
\text { project. } \\
\text { For foreign students, a buddy system, the organization of social } \\
\text { events and - if needed - psychic support are effective measures } \\
\text { that can be taken. } \\
\text { Exit interviews are helpful to improve the process of } \\
\text { accommodating foreign students in The Netherlands. } \\
\text { Travel advises provided by Ministry of Foreign Affairs, Radio } \\
\text { Netherlands Worldwide and SOS international are helpful for } \\
\text { UT students when planning for a travel, stay and study abroad. } \\
\text { A as complete as possible overview of all students, faculty and } \\
\text { staff travelling abroad is needed to communicate with them in } \\
\text { case of a calamity (e.g. a tsunami, flood, attack or revolt). }\end{array}$ \\
\hline 10 & Knowledge safety & $\begin{array}{l}\text { - Actively strengthen the awareness among faculty and staff in } \\
\text { particular on the risk of espionage and the sanction rules. } \\
\text { Identify and pay particular attention to the protection of core } \\
\text { interests of the UT } \\
\text { - A clear UT-protocol how to deal with foreign countries that are } \\
\text { listed on the sanction list of the Dutch government. } \\
\text { The general Intelligence and security service (AIVD) has } \\
\text { developed an e-learning module about laptop and website use } \\
\text { when travelling in foreign countries such as China, Russia and } \\
\text { Iran. Important is to travel with an "empty laptop". } \\
\text { A UT protocol that UT students and UT employees are required } \\
\text { to follow when travelling to countries which have been labelled } \\
\text { as "unsafe" by the Ministry of Foreign affairs. } \\
\text { A UT travel app "CHUBB", to contact and inform UT students } \\
\text { and UT employees in case a risky situation has occurred in a } \\
\text { country they are staying. }\end{array}$ \\
\hline
\end{tabular}




\section{APPENDIX III: INCIDENT AND ACCIDENT REPORTING SYSTEMS AT THE UNIVERSITY OF TWENTE}

\section{Existing incidents and accidents reporting systems at UT}

- A cyber-security and privacy report is made on a quarterly basis

- Each BHV (emergency response) coordinator keeps a record of all emergency accidents that have occurred.

- Traffic accidents: the security guard department keeps a registration of all traffic incidents on the campus.

- The security guard department keeps a record of incidents (burglary, thefts, vandalism, aggression etc.) that have occurred on the campus and in the buildings. These data are shared with all Facility managers of the respective buildings.

- VGM (Safety, Health and Environment) yearly publishes an annual report including all incidents that happened in the past year with respect to Safety, Health and Environmental issues. .

- CES keeps track of serious calamities such as Tsunami's, floods, attacks, or revolts (this to warn students about unsafe foreign countries and to contact UT-students possibly staying in these unsafe foreign countries).

- An annual report of the confidential advisors

- An annual report of the ombudsperson

- $\quad$ The well-being of employees report

\section{Not yet available but required reporting systems:}

- We need an overview and insight of the contact pattern per employee with hazardous substances in laboratories (as requested by law). The Executive Board has decided to replace the current registration system GROS.

- The Security Department has a good cooperation with the police. For example, the police recently reported an increase in the number of burglaries in student houses. The Head of Security would like to see immediately at which locations the burglaries occurred (on UT grounds or in the city, etc.).

\section{Security guard related installed security systems}

- Sky-walker. With this software the Security department can save all kinds of malfunctions and incidents that have occurred at UT. Camera images from observations by security guards (for example, when someone is unauthorized in a building or room) can be saved with Sky-walker.

- Milestones. This system combines all camera surveillance images of all buildings

- A fire detection system. The UT has the ASCOM fire detection system. The different detection devices are connected to each other and can be operated as a whole. There are, however, a number of stand-alone systems (from Siemens) that are not connected to the ASCOM system. The security officers make a specific report of each incident in "word". This is then processed in "excel" into a management report.

- Picasse. This is a calling system that is used by the emergency response (BHV) teams. Team members receive a message via a tablet about the nature of the incident and where they should take action.

- Galaxy. This authorization system gives people access to buildings outside office hours. An officer has been appointed for each building who is responsible for assigning the authorization to an employee, student or external person.

- Remote opening/closing system. The security can remotely activate or deactivate access to buildings. 
APPENDIX IV: EXPERTISE INPUT AT THE UNIVERSITY OF TWENTE FOR EACH OF THE DISTINGUISHED PILLARS FOR INTEGRAL SAFETY.

\begin{tabular}{|c|c|c|c|c|c|}
\hline & $\begin{array}{l}\text { Strategic } \\
\text { (CvB + }\end{array}$ & Tactic & operational & Other at UT & $\begin{array}{l}\text { Other } \\
\text { external }\end{array}$ \\
\hline $\begin{array}{l}\text { Knowledge } \\
\text { safety }\end{array}$ & $\mathrm{SP}+\mathrm{HR}$ & $\begin{array}{l}\text { Directors LISA, } \\
\text { CES, HR, M\&C }\end{array}$ & $\begin{array}{l}\text { Contact } \\
\text { persons } \\
\text { Faculties, } \\
\text { Institutes, } \\
\text { Service } \\
\text { Departments }\end{array}$ & $\begin{array}{l}\text { Secretariats, } \\
\text { Lawyers }\end{array}$ & $\begin{array}{l}\text { Travel } \\
\text { agency }\end{array}$ \\
\hline $\begin{array}{l}\text { Internatio- } \\
\text { nalization }\end{array}$ & SP (intern) & $\begin{array}{l}\text { SP Head cluster } \\
\text { Internationali- } \\
\text { zation, Head } \\
\text { CES }\end{array}$ & HR, CES, M\&C & $\begin{array}{l}\text { FAINCO's } \\
\text { Lawyers }\end{array}$ & $\begin{array}{l}\text { Travel } \\
\text { agency }\end{array}$ \\
\hline $\begin{array}{l}\text { Campus \& } \\
\text { Buildings }\end{array}$ & CFM, UCB & $\begin{array}{l}\text { Directors } \\
\text { Service } \\
\text { Departments }\end{array}$ & $\begin{array}{l}\text { CFM, BVN, HSE } \\
\text { coordinators }\end{array}$ & Lawyers & \\
\hline Integrity & $\mathrm{SP}, \mathrm{HR}, \mathrm{FIN}$ & $\begin{array}{l}\text { SP and HR, } \\
\text { Deans }\end{array}$ & $\begin{array}{l}\text { Portfolio- } \\
\text { holders } \\
\text { Faculties and } \\
\text { Service } \\
\text { departments }\end{array}$ & Lawyers & \\
\hline Privacy & LISA & FG team & $\begin{array}{l}\text { FG team }+ \\
\text { Privacy contact } \\
\text { persons }\end{array}$ & Lawyers & \\
\hline $\begin{array}{l}\text { Crisis } \\
\text { Management }\end{array}$ & CCT & $\begin{array}{l}\text { Project team } \\
\mathrm{CCT} \text {, education } \\
\text { team }\end{array}$ & $\begin{array}{l}\text { Faculties, } \\
\text { Service } \\
\text { departments, } \\
\text { Institutes, } \\
\text { Security } \\
\text { officers } \\
\end{array}$ & $\begin{array}{l}\text { Representa- } \\
\text { tives in } \\
\text { national } \\
\text { consultation }\end{array}$ & \\
\hline Cyber risks & LISA & & & & \\
\hline $\begin{array}{l}\text { Working } \\
\text { conditions }\end{array}$ & $C \& F M \& H R$ & $\begin{array}{l}\text { HR \& Service } \\
\text { Departments }\end{array}$ & & & \\
\hline $\begin{array}{l}\text { Health \& } \\
\text { Environment }\end{array}$ & $\mathrm{HR}$ & CFM, Labs & & & \\
\hline Social safety & & & $\begin{array}{l}\text { Ombuds- } \\
\text { person; } \\
\text { Confidential } \\
\text { couselors }\end{array}$ & & \\
\hline
\end{tabular}


APPENDIX A

INTERNAL ORIENTATION ABOUT INTEGRAL SAFETY

AT THE UNIVERSITY OF TWENTE

By: J.I.M. Halman

11 October 2019 


\section{CONTENTS OF APPENDIX A: INTERNAL ORIENTATION}

Section

Page

A1 Synopsis $r$

$\begin{array}{ll}\text { A2 Introduction } & 26\end{array}$

$\begin{array}{lr}\text { A3 Cyber security } & 27\end{array}$

$\begin{array}{lr}\text { A4 Buildings and labs } & 27\end{array}$

A5 Campus and terrains $r$

A6 Employees and students $\quad 30$

$\begin{array}{ll}\text { A7 Integrity and ethical behavior } & 31\end{array}$

A8 Internalization $\quad 31$

A9 Reputational damage $\quad 32$

A10 Political safety $\quad 32$

A11 Systems to monitor safety and security at UT 33

A12 Organization of Integral Safety $\quad 34$

A13 Awareness on Integral Safety among employees and students 35

$\begin{array}{lll}\text { A14 Training of crises } & 36\end{array}$

$\begin{array}{lll}\text { A15 Other suggestions made on Integral Safety } & 37\end{array}$

$\begin{array}{ll}\text { A16 Conclusion. } & 37\end{array}$

Table A1. Potential risk issues identified during the internal orientation 39

Table A2. Potential risk solutions identified during the internal orientation 41

Reporting systems $\quad 45$ 


\title{
APPENDIX A \\ PLAN TO IMPLEMENT INTEGRAL SAFETY AT UNIVERSITY OF TWENTE $1^{\text {st }}$ PHASE: INTERNAL ORIENTATION REPORT
}

\author{
By: J.I.M. Halman
}

11 October 2019

\section{A1. Synopsis}

All universities participating within VSNU have agreed with regard to safety to:

- Take responsibility for organizing an integrated safety policy to guarantee a safe living, learning and working environment and safeguard business continuity also in the case of extreme circumstances.

- Compare costs and benefits of safety measures with each other so that only the most sensible ones are given a place.

To implement Integral Safety Management in accordance with the above made agreements, a proposal is being developed for the organization and monitoring of Integral Safety Management at the UT. The following phasing is used:

$1^{\text {st }}$ Phase: Internal orientation: mapping the status quo in the field of safety and security management at the University of Twente

$2^{\text {nd }}$ Phase: External orientation: developing an overview of relevant safety and security risks and risk mitigation strategies based on an extensive review of academic literature and consultation of with external experts

$3^{\text {rd }}$ Phase: A design for implementing and monitoring integral safety at the University of Twente.

This part of the report provides the 1st Phase: the internal orientation. Interviews were taken with 26 professionals at the UT who are responsible for safety and/or security.

The interviews show that there is broad support for the implementation of Integral Safety at the University of Twente. The subject is seen as of particular importance to the University of Twente. On the basis of this internal orientation, I conclude that the following topics should in any case be addressed with priority for the follow-up process:

- Developing continuity plans for the operations process of the University of Twente (UT). In the event that Osiris breaks down due to a calamity or cyberattack, an important part of the education will be canceled;

- An integrated approach to security by more explicitly considering and developing the relationship between cyber security and the other security and safety aspects;

- Work out a protocol and the organize for safety and security risks caused by employees or students who are in mental distress;

- Raising awareness on safety and security issues among staff and students;

- Elaborate on the implications of internationalization for the successful implementation of Integral Security at the UT;

- Increasing road safety on the UT campus;

- Increasing the anticipatory capacity for hard-to-foresee safety issues by periodically performing a future scenario analysis;

- Embedding Integral Safety by including this in the UT's Planning \& Control cycle. 


\section{A2. Introduction}

As a university, we strive to be an "open science" and "open access" institution. As an area of attention, safety has grown in importance and size in recent years. Important developments at the UT such as an increasing degree of digitization and internationalization and the fact that there have been a few serious incidents in the field of physical and / or psychological safety in the past period have contributed to this. Increasing internationalization keeps creating new platforms. All this makes it increasingly easier to work together on a global scale. However, we will also have to be able to guarantee safety with this increasing transparency. Matters such as safeguarding privacy, open data policy, the management of patents and the interaction with the business community play a role here. An important principle in the implementation of Integral Safety at the UT should be: How do you promote awareness and adequate action of the organization, staff and students with regard to integral safety, without paralyzing it?

In the period July 22, 2019 - September 4, 2019, interviews were held with important portfolio holders for safety and/or security management at the UT.

In total, interviews were held with 26 professionals within the UT community: The members of the Executive Board; the Secretary of the Executive Board; David Korringa, director of Operations ET; Marion Kamp director of BMS Operations; Christy Schoonheijt-Oude Veldhuis, Director of Operational Management TNW; Stephan Maathuis, director of EEMCS Operations; Ton Veldkamp and Annemarie Arets of the Faculty ITC; Joost Sluijs, director HR; Jan Laurens Lasonder, director of LISA; Pim Fij, director Campus \& Facility Management; Hans Oeloff director of CES; Benno Kiers, head of Security at UT; Henk Swaters, Head of Demand Supply Management; Richard Sanders, Safety officer HRM; Henk Bleijerveld, Emergency response coordinator UT; Peter Peters, Security management LISA; Bertus Dierink HSE-TNW; Nancy Heijnekamp (VGM-ET) and Herman Kuiper (CFMET); Andries Klijnstra Facility team leader of the Vrijhof, Ravelijn, Cubicus and Citadel buildings; Marco Boevink (CFM), Ellen Giebels of BMS and Rogier Jansen of the AIVD East Netherlands. $A$ report was made of each conducted interview. The report was sent back to the interviewee with a request for correction and / or addition.

The aim of the interviews was to map out the views of the portfolio holders in the field of safety and security management. The interviewees were asked to reflect on the various aspects of safety and security: what according to their opinion is going well and what needs further improvement. In addition the interviewees were asked to explain how the respective processes of safety and/or security monitoring are conducted and what aspects need to be expanded and/or integrated. This report examines the main results of the conducted interviews. 


\section{A3. Cyber security}

For Integral Safety it is important to analyze the relationship between cyber security and the other safety aspects. After all, nowadays a lot is done via the ICT network. We have built up a huge dependence on ICT. In the event of an "attack" in which the security of the UT is endangered, there is a real chance that it will be a double attack (also disabling the ICT network) with a double risk. There are clear interfaces between the various aspects of safety. This necessitates an integrated approach to safety. The physical security of, for example, the BMS lab is intended to protect the IT equipment and privacy-sensitive data in this lab. Likewise, the security of our data center is both an IT security matter and a physical one to prevent burglary and theft of the equipment and data stored there. During one of the crisis exercises by the Central Crisis Team, an accident was practiced in which a potential physical serious malfunction in a fume hood was initiated via the network. The physical and the digital are increasingly intertwined.

There is a CERT-UT (Computer Emergency Response Team) in the field of Cyber Security. In addition, the UT also actively participates in security for the SURF network in CERT-SURF. At Cybersecurity it is very important to continuously monitor trends and possible threats. China, Russia and Iran are also advanced. As a UT, we must be alert for possible internal as well as external espionage activities. The UT uses the "Quarantine network" with advanced software that can detect strange computer behavior by staff and students. The quarantine network was developed in the past by "Tesorion" (www.tesorion.nl), a HTSUp of the UT. In addition, LISA collaborates with the "Twente Hackers squad" a group of UT students and PhD students who are interested in detecting leaks in the computer network. The UT has a procedure for "responsible disclosure" with which leaks in the UT's computer network and applications can be reported. The reporter can receive an honorable mention if he / she wants to. The resolution of the identified vulnerabilities is monitored in the security quarterly report. Within the surfnet context, the UT actively participates in cyber crisis exercises such as OZON (https://www.surf.nl/ozon-oefen-hoe-je-bij-een-cybercrisis-reageert) and smaller trainings such as NOZON (https://www.surf.nl/agenda/voorbereidingsbijeenkomst-cybercrisisoefening-nozon$\underline{2019)}$.

As an organization, we may be too focused on the types of (in)safety and (in)security we are already familiar with. Due to the increasing digitization, new issues are also emerging, such as the personal safety of employees, for example due to threats via the internet and social media. An external person or former employee can post negative comments about an employee on the internet (facebook, instagram, twitter etc.). This not only has a huge impact on the employee concerned, but indirectly also on the UT as a whole. How to act adequately and expeditiously is an issue, as UT we do not yet have this in order.

\section{A4. Buildings and laboratories}

A question that is important when it comes to the physical safety of buildings and laboratories: Is access to work areas and all laboratories properly arranged? The access to the building and the access system to the building are managed from the facility organization. It is essential that there are clear agreements between the facility organization and the director of operations (casus quo the person who has been delegated by the director of operations) regarding the issue of keys to access the building, to access office rooms and other spaces and whether or not to lend out a master key.

Some areas on the campus, such as the clean-rooms, the high-pressure lab, other special labs and gas storage, etc. deserve extra attention because of the hazardous substances that are used. Some of the chemicals in the laboratories can be characterized as dangerous, sometimes also carcinogenic substances. It is important to keep a register of people who come into contact with these substances. One researcher is in frequent contact with these hazardous substances, while another researcher 
only comes into contact 1-2 times a year. There is now no insight into the contact pattern per employee with these hazardous substances. At the moment, as UT, we do not comply with the current legislation and we are in a "gray area" which applies to all Universities. For the UT, there is an area for improvement here.

When appointing doctoral students and employees to work in laboratories with an increased safety risk, their knowledge about safety must also be established in advance. At TNW, PhD students are trained per department in how to handle hazardous chemicals. Access to the laboratories is only possible through the ARBO / Environmental health coordinator of the department concerned. In addition, there is an introduction four times a year, for employees of TNW, which also focuses on safety in the handling of toxic chemicals. The turnout of the introductory sessions is reasonable, with around $60-70 \%$ employees taking part.

All buildings have a BMI (Fire Reporting Installation) and an OAI (Evacuation Alarm Installation). In addition, some of the buildings (Carre, de Horst, Ravelijn and the Technohal) have an SMI (SprinklerMeldInstallatie). With the UT's Picasse system, members of the emergency response teams or members of the (local and central) crisis teams can be called quickly by telephone.

BHV - emergency response - teams of the respective buildings at UT are on strength. These BHV teams also have a "buddy-system", i.e. each BHV-team has a buddy BHV-team of another building. So if there are too few emergency response officers in a building during an emergency, an automatic notification for support is sent to the buddy building. The teams have enough resources to perform their duties. Cutbacks have not yet been applicable at the UT because there is enough awareness about the importance of emergency response teams at the Executive Board, the service directors and deans. The emergency response teams Horst and Carré practice an accident situation 10 times a year for two hours under the supervision of two instructors. Evaluation takes place afterwards: what went well, what could be better. The other teams practice 6 times a year. The emergency response coordinator keeps an accident register. About 75 accidents occurred in 2018. The most common accidents are: an employee or student becoming unwell, an epileptic seizure or an injury to someone. An emergency response team was able to provide assistance three times because someone suffered cardiac arrest. The AED (Automatic External Defribillator) devices installed in the respective buildings, that can restore the heart rhythm after cardiac arrest are regularly checked. After a serious accident, the person who has suffered the accident will be transported by ambulance to the hospital for a further check-up.

The emergency response officers at the teams Carre and Horst follow about 20 hours of training per year, excluding the breathing air training with a fire brigade instructor. For the other teams, 12 hours of training per year applies to the employees. Every year, about 150 students also follow the emergency response training and about 150 students a receive repeat training. The students register as a volunteer. Students at the UT who work behind the bar at their student association receive a training in how to serve alcohol responsibly. This course also teaches how to deal with drunken visitors. Both courses take place regularly because there are annual changes among the students.

To avoid the danger of a fire breaking out in one of the buildings, we must deal more responsibly with facilities such as turning off stoves after working hours, not using illegal coffee machines and monitoring safety in laboratory facilities. We will have to "shake each other up" periodically. Some time ago, a fire broke out in the Horst building due to overheating of a 3D printer. Against the prevailing rules, the Lab with the 3D printer was unoccupied during printing. As a result of this incident, extra attention is again being paid to monitoring safety in the laboratories.

Building rounds take place on a regular basis, checking the operation of the fire hoses and whether there are any blockages in the buildings that could form an obstacle in the provision of assistance in the event of an emergency or crisis situation.

The permission of the building manager is required for organizing activities in buildings. The boards of the study associations are aware of what can and cannot be done during a drink or event 
organized by them. To this end, consultations are held on a regular basis with the building manager and the relevant study associations.

In the city, the "Pakkerij" is used by four student associations. These four spaces are the responsibility of the Student Union. CFM is responsible for the general entrance area. Cameras have been installed in all rooms so that it can be subsequently determined in case of an incident which persons were involved. Monthly meetings take place within the "Management Committee for Pakkerij (BCP)" about the maintenance and safety of the Pakkerij, the organization of in-house emergency responders (BHVers), parties that will take place and any incidents that have occurred. The Bakery Management Committee is composed of members of the board of the four Bakery Associations, a Facility Team Leader of the CFM, the Student Union's portfolio holder for Accommodation and a coordinator Health and Safety and Head of Emergency Response at the UT. The BCP publishes an annual report every year.

Students also work outside the campus in their own workshops. For example, there is a workplace where students experiment with hydrogen and the UT solar team also has a workplace outside the campus. Should an accident occur in such a workplace, the media will certainly also discuss whether the UT has failed in taking safety precautions. It is therefore important to make student teams working in these types of workshops aware of the potential risks and to announce where they can go to get UT support.

\section{A5. Campus and terrains}

CFM is responsible for ensuring safety and security at events and activities that take place on campus. One of the biggest events is the annual Batavierenrace. In 2019, more than 8.500 students participated in the Batavierenrace, a large part of whom also spend the night in the sports center and in tents on campus. About 12,000 students participate in the closing party. The CFM department hires around 30 security guards for such an event. But absolute safety, even with these extra security guards, cannot be guaranteed.

The employees of the service desks at the entrances to the buildings have been trained to see who comes in. Due to carelessness (leaving the office room open and your own room in student residences), burglaries and laptops, etc. can easily be stolen. This is done regularly. During the "Kick in" days, new students are alerted to the possibility of theft, but also the danger of fire. The police and fire brigade participate in the information during the annual Kick in. However, you will only see a change in behavior if a theft or other incident has occurred in the immediate vicinity of a student or of an employee. The increasing crime as a result of drug trafficking, which also takes place on the UT campus (at festivals, for example) is also a concern. Many of the criminals are known to the police. Security is carefully monitored here. Within this framework, there must be good coordination between the security guards of the UT and the Police, so that rapid escalation can also take place when a potential crisis situation arises. The relationship between security and the Police is currently good, the Police is easily accessible and quickly on the spot

A point of attention concerns road safety on campus. On the UT campus, traffic accidents regularly occur at difficult traffic points (crossings of cyclists and cars). There is an increasing trend. According to Security data, 130 accidents were registered between January 2013 - February 2019, approximately 20 accidents per year. In $50 \%$ of the cases, one of the people involved was injured. Flashing triangles have been installed at dangerous intersections, but the priority of cyclists does not necessarily lead to a safer situation. Fast bicycles and e-bikes can suddenly unexpectedly appear in front of a crossing car. Keypoint has been asked to issue advice on how to increase road safety on campus. This investigation is still ongoing. 


\section{A6. Employees and students}

In addition to care for physical safety, social safety is also an important topic for Integral Safety. Matters such as how to deal with sexual harassment, psychological harassment and how to make these types of issues open to discussion are relevant in this context.

When a new employee is introduced, he will have to be extensively informed about the UT's view with regard to the care for an inclusive, safe and healthy working environment and what can be expected of an employee or manager within this framework. The same must also be done during the Kick-in that is organized to familiarize new students with the UT. Although positive and certainly important during the introduction, this is insufficient for awareness and internalization. The UT's view with regard to an inclusive, safe and healthy working environment must be brought to the attention of the Netherlands on a regular basis.

Following the \#MeToo discussion and recommendations of the labor inspectorate, an aggression protocol has been developed for the UT. This document describes what behavior the university does and does not tolerate and what the procedures and sanctions are in these cases. The new measures focus not only on physical aggression, but also on forms that are less easy to recognize, such as bullying. The protocol was drawn up by the Service department HR.

The concern for creating a safe and healthy working environment must also be recognizable in our personnel policy. When hiring employees, we must seriously check through references how the person in question has behaved in other organizations. This by performing a background check. Not only ask for references, but also seriously question these referees. For financial positions a protocol is already available.

We must be able to offer a safe working environment in which mutual expectations are clearly communicated and clear agreements are made with regard to the roles to be filled. This applies to both students and employees. Employees and students will have to feel sufficiently safe to report, if necessary, the experience of excessive work pressure or undesirable behavior.

Within the context of dealing with complaints about sexual harassment, the question is whether our instruments and establishing a confidential advisor are sufficient. What are good rules to use? How do we discuss a reported case with the victim or the alleged perpetrator? Should direct colleagues also be consulted? And what are the consequences for the perpetrator if the complaint turns out to be justified? Giving a "yellow card" or already a "red card"? Unwanted intimacies can occur between students, but also between a student and an employee or manager and between an employee and a manager. A clear protocol is not yet available .

Confidential advisors cannot share everything with the organization. The UT has therefore decided to appoint an ombudsperson in addition to confidential advisers. Initially it concerns a two-year pilot. Employees and students may report unjustified assessments and redeployments to the ombudsman when they experience undesirable behavior by colleagues or supervisors (such as a supervisor conducting unauthorized financial transactions). The ombudsperson can also mediate in conflicts and conduct his/her own investigations.

Increasing workload can lead to dangerous situations. In the past few years, the number of burnout complaints from UT employees has clearly increased. In such cases, staff and students can themselves pose a security risk. In most cases it concerns a combination of work and private life.

It is important to be alert to possible deviant behavior that can arise under increasing work pressure. The manager plays an important role in the identification of this. The UT has now set up a workload management task force that advises the Executive Board on work pressure management. This task force initiates, coordinates and supports a UT-wide approach and proposes improvements. 
What we as the UT are not yet sufficiently prepared for is dealing with employees who are in psychological distress. It is wise if the UT learns how to communicate with a person who is in a mental crisis situation. The police have experienced negotiators who are trained to ask the right questions. Philippe Huinen and Heidi Nieboer provide training in this area and have gained extensive experience as police negotiators. It is also recommended to involve the UT's confidential advisers and security officers in such training.

\section{A7. Integrity and ethical behavior}

Integrity and ethical conduct is of strategic importance because of the possible reputation damage that the UT may incur in the event of a breach of integrity or unethical conduct.

A new Integrity code has been drawn up from the VSNU. This will be rolled out within the UT next year. Within this framework, a note was drawn up by the Service department HR about the integrity policy to be pursued by the UT and the implementation of a "House of Integrity". The memorandum was discussed on 11 July 2019 within the Council of Deans and the Executive Board and it was decided to implement the proposed actions. The "House of Integrity" encompasses three dimensions of integrity: scientific integrity (e.g. careful data management and research ethics), social integrity (relationships and manners in the workplace) and organizational integrity (ensuring a safe working environment and safeguarding the privacy of Staff members). Five projects are underway for the implementation of the House of Integrity:

(1) Promote awareness among staff and students;

(2) Promoting a culture of integrity

(3) Research Data management

(4) Publication policy

(5) Ethical standards and procedures.

Integrity is a compulsory part (2 EC) in the training programs of PhD students and will also apply to external PhD students. One question is how much time we can ask for topics such as Integrity and Ethical Conduct. The obviousness to demand attention and time here will only grow in the coming years. Preventing and combating plagiarism, for example, is self-evident and standard nowadays and can be checked through a simple process.

\section{A8. Internationalization}

The internationalization of the university is accompanied by the arrival of foreign employees and students, and with it also divergent standards and values. For example, depending on the country of origin, there is a different relationship with women. Female students, but also employees can suffer from this. International students and staff will have to be familiarized with the prevailing manners in the Netherlands. Perhaps student mentors and study advisers can play a constructive role in this. And in the case of employees, we as an organization will have to be alert and respond adequately to this. But as a university with the aim to be an international university, we should also become more aware of different cultures and styles and trained how to interact with diversity.

Several of the interviews showed that the number of psychological complaints has increased, partly due to the internationalization of the UT. Homesickness, the pressure to graduate or obtain a doctorate within the prescribed time, a visa that can expire when the student or doctoral candidate is not ready within the prescribed time and the stigma of failure within their own culture, cause increasing stress among foreign students and doctoral candidates. Foreign students and doctoral candidates are also less inclined to reach out for help. It is therefore important to be alert to tutors about identifying worrying behavior. In the case of foreign PhD students, the family situation often plays a role as well: partner and children are often only slightly involved. As UT we have a special responsibility for this. In addition, the international PhD community at the UT could also play a 
significant role by paying more attention to each other as a community and if they are concerned about a fellow PhD student, to share this concern e.g. with the student counselor.

TGS now offers workshops on how to deal with this stress. The rules for a PhD program will also be adjusted: two supervisors are assumed in the future and the supervisors are expected to become more involved in the qualifier process. The whole must lead to a secure basis for the PhD students. Rules have been drawn up within VSNU for healthy promotion practice. The intention is now to implement these rules within the UT.

In the recent past period, a few psychological crises have also arisen with foreign PhD students. These types of incidents are expected to increase in the near future. The emergency response teams are not properly trained to deal with this adequately. The orange overalls of the emergency response teams may even work up agitation. Perhaps setting up a UT-wide "Intervention Group" with expert knowledge about psychologically vulnerable behavior and how to deal with this could be a solution. The Intervention Group can then be called up via the Picasse system when a psychotic incident occurs. It is sensible if the UT invests in hiring 1-2 experts in this field, because it will occur again in the coming years. Ideally, these experts are always present to deal with crisis situations and to prevent them from getting worse. At the moment we are dependent on Mediant and that is not always at the pace that we need.

Faculties within the UT may learn from two working methods followed by ITC for foreign students and doctoral candidates:

The ITC faculty has two study affairs officers for students. Foreign students can approach these officers with a range of problems (which may also be non-study related). There is an accessible, open door policy. When a potential problem arises, officers quickly hear it and can take proactive action. ITC starts with a homologation year for foreign PhD students. This is to ensure that a PhD student has the required knowledge and skills to successfully complete a PhD project.

\section{A9. Reputation risk}

A good reputation of the UT is essential to be able to close contracts with third parties and to be attractive as an organization for employees who want to join or continue to work at the UT and for students to study here.

\section{A10. Political safety}

As UT, we will have to become more aware of the risk of espionage. International students and doctoral candidates can be encouraged to do so from their home state. Political security includes knowledge that is insufficiently secured by the UT and the sharing of this knowledge with countries such as Iran, Russia or China can damage the UT. For example, the Cabinet is increasingly concerned about Iran's ballistic missile program. For that reason, supervision of students and researchers who may have a link to the Iranian ballistic missile program has been tightened. For the 2019-2020 academic year and beyond, the Cabinet will tighten the supervision of new students and researchers who wish to develop activities in one of the relevant fields of education and research by testing this group before they start teaching or research. A complicating factor here is the possibility of dual use (developed, for example, as an application within health, but ultimately also applicable for defense purposes) and the increasing coherence between ICT, materials, product and production technology. The Government's choice for a specific number of educational and research areas is therefore somewhat ad hoc in nature. The imposed restriction places the university as an open institution for education and research for new dilemmas on how to deal with this. We lack a clear protocol in this area. So we will have to develop policy ourselves. Perhaps we can learn from what TNO (which has a strong defense arm) and TU Delft (where a great deal of knowledge is developed that is important for military organizations and for space and aviation) have developed protocols in this area. 
There is a chance of access to various systems (via students but also via employees) and there is no overall contact point within the organization to supervise this. Good coordination is required between the external organization and the internal organization and a clear overview of activities that could potentially harm the strategic interests of the UT. For example, working on projects that can benefit Iran can ultimately harm our relationship with the USA with which we as a knowledge institution have a lot of exchange. This may jeopardize the continuity of the UT as an organization.

A point of attention when traveling to countries such as China, Russia, Iran and the USA concerns IT security. The AIVD has developed an e-learning module that can be followed by employees. It is important to take an "empty" laptop with you to the intended country and certainly not to log in to the UT website or data at the UT.

Students and staff often go abroad for education and research. Identify in advance in which countries they may be exposed to major security risks and address people about their responsibility with regard to these risks. As a faculty, you must have a protocol on the course of action to follow if an employee or student is in an unsafe country or intends to go there. This includes informing about the unsafe situation, advising against it and also retrieving it. And in case of refusal, place the responsibility completely with the employee or student.

The ITC faculty always checks the advice of BUZA when traveling abroad by students or staff: The journey cannot be continued under "code red". With "code orange", it will be checked on a case-bycase basis whether there are good reasons to make the trip.

CES keeps track of calamities worldwide (such as tsunamis, floods, attacks or riots, such as recently in Hong Kong). This is important in order to subsequently determine whether any students or UT employees are at risk. The Ministry of Foreign Affairs operates a free downloadable travel app that can provide students or employees who travel with important information about the country in question. This is especially important when a potentially risky situation arises. In addition, the UT itself is also developing a travel app (CHUBB) that enables the UT to contact students and / or UT employees in the event that a risky situation threatens or has arisen in a particular country. in this country. Or vice versa, that students and staff can make contact with the UT. The UT's travel app is still in an experimental phase. The evaluation of the UT's travel app will follow.

\section{A11. Systems to monitor safety and security at UT}

- Sky walker. With the help of this software, all kinds of malfunctions and incidents that have occurred can be saved. Camera images of observations by security guards (when someone is unauthorized in a building or space, for example) can also be saved with Sky-walker.

- Milestone. This bundles all camera images. Benno Kiers uses this.

- Fire detection systems. The UT has the ASCOM fire detection system. The different detection devices are connected to each other and can be operated as a whole. However, there are a number of stand-alone systems (from Siemens) that are not connected to the ASCOM system. The security guards make a specific report of each incident in "word". This is then processed in "Excel" into a management report.

- Picasse. A paging system using a tablet that has been used by the various emergency response teams for a year now. Team members are informed via the tablet about the nature of the incident and where to take action. 
- Galaxy. This is an authorization system that gives people access to buildings outside office hours. An official has been appointed per building who is responsible for allocating the authorization to an employee, student or external person.

- Messaging systems. The security guard can activate or deactivate a system per building remotely.

- Burglaries. The Security Department has good standing cooperation with the police. For example, the police recently reported an increase in the number of burglaries in student houses. The Head of Security would like to see immediately at which locations the burglaries occurred (on UT grounds or in the city, etc.).

- Traffic incidents: these are registered. A separate form has now been developed for the registration of traffic incidents.

- Cyber security. LISA draws up a quarterly report on all aspects of Cyber Security at the UT. This is discussed in the Executive Board and shared with senior management. Two employees within LISA are responsible for publishing this report. It would be good to integrate this form of reporting into a yet to be developed and implemented regular report on Integral Safety at the UT.

- Reports of incidents by Security. The Security group of CFM makes reports of all incidents that occur on campus and in the buildings. The facility team leaders receive these reports. It is also good to share this kind of information with the dean and the director of operations. Then they will also get a better sense of what important actions to take in the field of security.

- VGM reports. VGM reports every year on the incidents that have occurred. This is important in order to be able to analyze afterwards whether there is a pattern that can be identified. We must then build a culture so as not to downplay accidents, but to always report them. Not all accidents are reported. We need to build a culture that we feel jointly responsible for building a safe working environment. This applies not only to the prevention of physical accidents, but also in the care for the way in which we manage our data management, for example. The experiences with data leaks can be shared upon reporting and can be used to learn from this.

\section{A12. Organization of Integral Safety}

To date UT still lacks an integrated risk management policy. That is an important reason for this study. It is important for the organization and organization of risk management that potential internal and external risks are identified in a structural and systematic manner, that annual evaluations and improvement plans are drawn up and that the extent to which the implemented improvements prove to be effective is subsequently examined. to be.

An important observation made during the interviews was the lack of continuity plans for the primary process of the UT. In the event that Osiris breaks down due to a calamity or cyberattack, an important part of the education will be canceled.

Within faculties, a distinction can be observed between HR activities and ARBO matters. This also applies at central level. This split makes it more difficult to keep control. Direction within the faculty is mainly via the Portfolio Holder for Operations. The control function is less visible at central level. For Integral Security it is essential that there is a good lateral connection between these two areas of attention. This is an important condition for achieving Integral safety. Persons with responsibility in the field of Integra Security must meet regularly to exchange experiences. This increases alertness and a greater chance of pattern recognition when a special situation arises.

A point of attention in the implementation of Integral Safety is the organization of the responsibility for Integral Safety. There is a risk that this will be placed with a "central coordinator for Integrated Safety" and that this will then become separate from the line organization and the scientists. A similar risk exists for other emerging transcending new themes such as "integrity", 
"Internationalization" and "Inclusivity". When coordinating between the central organization and the decentralized (faculty) organizations, it is important to have a good balance between trust and transparency in mind. When delegating, trust is given to a decentralized organization. From a decentralized organization, this must be accompanied by a transparent way of working, which will maintain confidence. This interaction in turn leads to a reliable way of working. In the coming period it is important to develop an effective modus operandi for the organization and organization of Integral Security.

It is important to monitor the follow-up of areas for improvement with regard to Integral Safety and to achieve continuous attention for integral safety. In this context, it is recommended to also include Integral Safety in the UT's Planning \& Control cycle.

\section{A13. Awareness about Integral Safety among employees and students}

Essential to increasing safety on campus and in the buildings is a shared sense of responsibility for safety. This means that we are all alert. A red alarm light at a disabled toilet requires action, a van that reports for "maintenance to beamers" and then runs off with the beamers, requires stricter control of companies that work for the university. Registration of (sub) contractors who carry out work in the buildings is important in this context, also in the event of an emergency occurring. Employees and students should know who to report a potentially unsafe situation to.

The UT already has many regulations in the field of social safety, such as dealing with aggression and relationships in the workplace. However, an important question is how do you also get this on the minds of employees and students? The awareness about Integral Safety among employees and students is still low. It is important that an employee or student takes action when something happens to him / her or when he / she sees that the social safety of a colleague or of a fellow student is at stake. We will therefore have to develop a policy that makes us more aware of this within the organization. The important question then is how to roll out Integrated Security within the UT? The culture at the UT can be characterized as informal, both students and staff feel safe. When implementing Integrated Safety at the UT, a "principle-based approach" fits better with the culture of the organization than a "rule-based approach". Ideally formulated principles are ideally derived from the identity that an organization pursues and the values that underlie it. When drafting principles, it often works well to describe not only what you do, but also what you don't. However, as more excesses arise in the future, we may need to shift more towards a rule-based approach.

In the past, the ARBO visited a new employee to provide information about safe and healthy work and how and what to do in problem situations. This should be reintroduced.

As stated in the section "A4. Employees and students", it is important to point out the importance of Integrated Safety when new employees are introduced and afterwards. In addition to the national emergency number 112, every employee should also know the UT's emergency number 053-489 2222 and know how to act when an emergency occurs. The UT emergency number should be on every employee's cell phone. Every effort is made to bring the emergency number to the attention of visitors, employees and students. This is done on the billboard at the entrance of the UT and also on the screens within the buildings. In the event of an emergency, it is important to be able to reach everyone inside a building. Every building now has a public address system for this purpose. Ideally, employees should also be able to be reached via their mobile in the event of a crisis situation.

To raise employees' awareness of ethical behavior, Ellen Giebels, in collaboration with Utrecht University, has taken the initiative to develop a theater performance, as was previously successfully done for the top hospitals, police and defense. Developing a theater performance in the field of Integral Security could also work excellently within universities. 
(Fun) actions are regularly taken to increase awareness of internet dangers among staff and students. An example of this is increasing awareness of the danger of "Phishing mails". In the recent past, BMS, together with LISA, has conducted an investigation into these "Fishing mails" by issuing a "Phishing mail" itself: who steps in and why / when does this happen? Other examples that were used to raise awareness were a wooden horse (Trojan Horse) on campus, stickers to stick the camera on your laptop, the presence of LISA during the kick-in of new students at the start of the academic year with the slogan: Treat your passwords like your underwear; Do not share with your friends, do not let it swing and change regularly".

A similar action carried out with access passes to workspaces and laboratories showed that employees issued their access passes in good faith for verification.

It is important to raise awareness by including this in the various training programs such as the leadership program and the introduction of new employees. It is important for employees to be able to evaluate the various options via the intranet, for example (consultation with the ombudsman, confidential adviser, etc.).

Dr. Saskia Kelders has developed a plan to let students increase their learning performance via interactive tools with game elements. This could also be used to increase awareness in the field of Integral Safety among students and staff

\section{A14. Rehearsals of potential crisis situations}

There is a general tendency to develop protocols for dealing with security situations. However, acute situations that have never happened before are difficult to log. As an organization, you must also be able to deal adequately with the unexpected. Building a sufficient level of resiliency is crucial in this. By performing scenario analyzes, we can anticipate future developments and subsequently prepare ourselves better for them.

Crisis exercises are carried out regularly. It is recommended to expand the range of possible crisis situations that may arise during the exercises. Recently, the national emergency number 112 has led to unforeseen emergencies. We must also continuously look for good coordination between the various crisis teams.

The crisis management exercises are satisfactory in themselves. But it is recommended to also consider upscaling involving larger target groups. The Van Gogh Museum recently held an exercise in which a terrorist attack was simulated.

It is important to conduct a crisis exercise regularly. The more team members have experienced an exercise, the more they respond to each other. A point of attention is who / when a crisis team convenes. For example, when a major storm hit the campus, one of the members of the central crisis team spontaneously came up with the idea that physical security on campus could be endangered and the crisis team was convened. These kinds of potential risks should actually be embedded as a standard repertoire.

An important point is the learning ability of the UT as an organization. How can we learn from calamities when they occur and what can we learn from crisis exercises? With regard to Integral Security, we will have to make our websites more accessible to the various target groups. Also make use of the expertise available at the various researchers at the UT. And put together an annually changing external expert group a "Council of Others" who can question the organization and make suggestions in the field of Integral safety. 
As UT we also have a central telephone number. Chances are that if a bomb threat occurs, this central number will be called. There must be a protocol on how to handle such a call and the operator on duty must know it well.

\section{A15. Additional suggestions that were made integral safety}

Privacy-sensitive research must now be submitted to an Ethics Committee at the UT. It would be good if this committee was also given the task of investigating whether safety monitoring might be an issue for the research in question and what should be done about it. At the time of the evaluation of the MH17 study that was carried out by a research group of the BMS faculty, external efforts were made via the internet to find out data about this study.

The accessibility and findability of information in the field of integral security (on the website) needs to be improved. When searching, the desired information should be easy to find and organized for the various target groups.

Regarding security monitoring, it is important to mention the "Cyber Reporting" which is published every quarter. Two employees within LISA are responsible for publishing this report. It would be good to integrate this form of reporting into a yet to be developed and implemented regular report on Integral Safety at the UT.

To increase safety on the UT internet, it is important to also consider developing and implementing fallback options in the event of an emergency within the context of Integral Safety. For example, from fixed line connections to switch effortlessly to mobile connections and for communication the use of face time as an option.

In addition to incidents occurring and dealing with them, it is also good to think about what structural risks may arise at the UT. For example, how to act with structural growth or with structural shrinkage? As an organization, we often have a tendency to move quickly "to the order of the day" within our own functional tube, while a structural risk requires an integrated analysis and approach, whereby it is also clearly agreed who has the leading role in this.

An improvement point at the UT with regard to the organization of ARBO / Environmental issues is the lack of a policy at the central level. At faculty level, implementation is adequately addressed, but budget cuts in the past have largely eliminated the policy function in the health, safety and environment area at central level.

\section{A16. Conclusion and continuation}

In this report, the views of the portfolio holders in the field of Integral Security at the UT have been mapped out. The interviews held show that there is widespread support for the implementation of Integrated Safety. The subject is seen as of great importance to the UT. It is a first step to arrive at a plan for the implementation of Integrated Safety Management at the UT. This internal orientation will be continued with an external orientation, which will examine which external developments are important for the implementation of Integrated Safety Management at the UT and what the UT may possibly learn from other companies and knowledge institutions.

This internal orientation has confirmed that integral safety management is considered by all interviewed as an important topic for the UT to implement. Also, that a lot of work is already effective in this area. Important topics to be addressed now are to: 
- Develop continuity plans for the primary process of the UT. In the event that Osiris breaks down due to a calamity or cyberattack, an important part of the education will be canceled

- Explicitly consider and develop the relationship between cyber security and the other safety aspects

- Elaborate on a protocol and the organization of safety risks caused by employees or students who are in mental distress

- $\quad$ Raise awareness in the field of Integral Safety among staff and students

- Elaborate on the implications of internationalization for the successful implementation of Integral Security at the UT

- Increase the anticipatory capacity for hard-to-foresee safety issues by periodically performing scenario analyzes

- Embed Integral Safety by including this in the UT's Planning \& Control cycle

- Increase road safety on the UT campus 
Table A1 provides all the potential risk issues, that were mentioned during the internal orientation interviews about Integral Safety at UT.

Table A1.

\begin{tabular}{|c|c|c|}
\hline & Category & Identified potential risk issues \\
\hline 1 & Campus and buildings & $\begin{array}{l}\text { - Cleanrooms, high-pressure laboratories and other specials labs } \\
\text { at UT are making use of hazardous, sometimes carcinogenic } \\
\text { substances } \\
\text { - } \\
\text { - } \text { becout } 75 \text { accidents are registered per year (e.g. someone } \\
\text { seizure or an injury sustained by someone). } \\
\text { - The potential risk of fire in buildings and in laboratories } \\
\text { - Unforeseen calamities and accidents caused by parties } \\
\text { - Safety risks of workplaces outside the campus that are in use } \\
\text { by UT students. } \\
\text { - Safety risks during events and activities taking place at the } \\
\text { campus } \\
\text { - The theft of Laptops and other valuables (e.g. caused by } \\
\text { negligent behavior of not closing the office door when leaving } \\
\text { the office and often also thefts in students livings). } \\
\text { - An increasing trend of dealing in drugs on the campus, } \\
\text { specifically during festivals and other events } \\
\text { Traffic accidents on the campus are regularly taking place. In } 50 \\
\text { percent of the cases with injuries as consequence. }\end{array}$ \\
\hline 2 & Integrity & $\begin{array}{l}\text { - The UT and Faculty may suffer reputation damage in case of } \\
\text { violation against scientific integrity (careful data management } \\
\text { and research ethics) } \\
\text { - The UT, Faculty or Service departments may suffer reputation } \\
\text { damage in case of violation against social integrity (relationships } \\
\text { and manners in the work place) } \\
\text { - The UT may suffer reputation damage in case of violation against } \\
\text { organization integrity (ensuring a safe working environment and } \\
\text { safeguard the privacy of employees and students) }\end{array}$ \\
\hline 3 & Privacy & $\begin{array}{l}\text { - Employees or students who are threatened via internet and } \\
\text { social media } \\
\text { - Negative fake comments about UT, employees or students on } \\
\text { internet and social media placed by a former employee or other } \\
\text { person }\end{array}$ \\
\hline 4 & Crisis Management & $\begin{array}{l}\text { - Acute situations that have not occurred before are difficult to } \\
\text { protocol. }\end{array}$ \\
\hline 5 & Cyber risks & $\begin{array}{l}\text { - Serious IT threats caused by interference from foreign countries } \\
\text { (Iran, Russia, China) } \\
\text { - Security of the data center } \\
\text { - } \quad \text { Cyberattacks and hacking } \\
\text { - Misuse of ICT systems }\end{array}$ \\
\hline 6 & Working conditions & $\begin{array}{l}\text { - An increasing and too heavy workload } \\
\text { - Employees and students showing psychological vulnerable } \\
\text { behavior (e.g. psychotic behavior, suicide tendency and } \\
\text { depressions) }\end{array}$ \\
\hline
\end{tabular}




\begin{tabular}{|c|c|c|}
\hline & & $\begin{array}{l}\text { - The lack of expertise in dealing with mental crisis situations in } \\
\text { the workplace. }\end{array}$ \\
\hline 7 & Environmental issues & $\begin{array}{l}\text { - Cleanrooms, high-pressure laboratories and other specials labs } \\
\text { at UT are making use of hazardous, sometimes carcinogenic } \\
\text { substances. }\end{array}$ \\
\hline 8 & Social safety & $\begin{array}{l}\text { - Unwanted sexual touching: between students, between } \\
\text { employees but also between a student and an employee. } \\
\text { - Psychological harassment: between students, between } \\
\text { employees but also between a student and an employee. } \\
\text { - Aggressive behavior and bullying between students, between } \\
\text { employees but also between a student and an employee. } \\
\text { - Hiring of new employees with a negative track record. }\end{array}$ \\
\hline 9 & Internationalization & $\begin{array}{l}\text { - Safety of UT-employees and UT-students who are staying in } \\
\text { foreign countries } \\
\text { - Foreign students with different norms and values (e.g. male } \\
\text { students with divergent manners with female students or staff) } \\
\text { may show behavior which is considered as unacceptable in The } \\
\text { Netherlands } \\
\text { - Augmenting stress among foreign BSc, MSc and PhD students, } \\
\text { (caused e.g. by homesickness, time pressure to finalize the } \\
\text { study, an expiring visa and the stigma of failure) lead to } \\
\text { psychological problems. }\end{array}$ \\
\hline 10 & Knowledge safety & $\begin{array}{l}\text { - Possible espionage activities by (foreign) students and (foreign) } \\
\text { employees, in particular by sanction countries such as China, } \\
\text { Iran and Russia. } \\
\text { - The dual use of specific UT knowledge, patents and innovations } \\
\text { by foreign countries such as China, Iran and Russia which are } \\
\text { on the sanction list of the Dutch government. } \\
\text { - Projects with countries on the sanction list of the Dutch } \\
\text { government may jeopardize the continuity of UT } \\
\text { IT-security when travelling to sanction countries such as China, } \\
\text { Iran and Russia. }\end{array}$ \\
\hline 11 & $\begin{array}{l}\text { Multiple pillars } \\
\text { involved }\end{array}$ & $\begin{array}{l}\text { - Datacenter: IT-Security \& Fire safety \& burglary and theft of } \\
\text { equipment and stored data. } \\
\text { - Serious Physical failure in a fume cupboard, caused through the } \\
\text { internet }\end{array}$ \\
\hline
\end{tabular}


Table A2 provides all the potential risk solutions, that were identified during the internal orientation. Depending on their content, each solution was categorized into one or more of the ten distinguished pillars for Integral Safety Management.

Table A2. Identified potential risk mitigation strategies for potential risk issues, categorized per distinguished pillar of Integral Safety

\begin{tabular}{|c|c|c|}
\hline & Category & Identified potential risk mitigation strategies \\
\hline 1 & Campus and buildings & $\begin{array}{l}\text { - Clear agreements between the Campus \& buildings organization } \\
\text { and the Operational Faculty director about the issue of keys for } \\
\text { access to the building, office rooms and laboratories. The Galaxy } \\
\text { authorization system gives people access to buildings outside } \\
\text { office hours. An officer has been appointed for each building } \\
\text { who is responsible for assigning the authorization to an } \\
\text { employee, student or external person. } \\
\text { - A regulated permission access to workspaces and laboratories } \\
\text { which contain hazardous substances } \\
\text { - Keeping up an up-to-date register of all persons who are in } \\
\text { contact with hazardous substances } \\
\text { - Students and new employees who are going to work in } \\
\text { laboratories with an increased safety risk, should in advance be } \\
\text { tested on their knowledge with respect to safety } \\
\text { - Access to the laboratories should only be made possible through } \\
\text { the ARBO (Health, Safety \& Environment) coordinator of the } \\
\text { respective department. } \\
\text { All buildings have a fire alarm system (BMI), and an evacuation } \\
\text { alarm system. Carré, de Horst, Ravelijn and the Technohal also } \\
\text { have a Sprinkler installation. BHV teams or members of local } \\
\text { crisis team can be called quickly by telephone in case of an } \\
\text { emergency. } \\
\text { - The quality of Automatic External Defribilators (AED) in all } \\
\text { buildings, installed to be used in case of a cardiac arrest and the } \\
\text { installed fire hoses, need to be regularly tested. } \\
\text { - All BHV (emergency response) volunteers and professionals at } \\
\text { Carre and Horst on a yearly basis follow an emergency response } \\
\text { training of about } 20 \text { hours training on a yearly basis. The other } \\
\text { BHV teams at the campus follow an emergency response team } \\
\text { training of about } 12 \text { hours per year. In addition, about } 150 \\
\text { students yearly follow the BHV training while about } 150 \\
\text { emergency responders in a building during an emergency, an } \\
\text { students receive a repeat training. And a fire brigade instructor } \\
\text { gives a breathing air training to all BHV volunteers and } \\
\text { professionals. } \\
\text { illegat coffer prevent the risk of a fire breaking out in buildings, we } \\
\text { - entification for support is sent to the buddy building. }\end{array}$ \\
\hline
\end{tabular}




\begin{tabular}{|c|c|c|}
\hline & & $\begin{array}{l}\text { - For bigger events and activities taking place at the campus of } \\
\text { UT, CFM (Campus and Facility management) makes use of } \\
\text { about } 30 \text { external security guards. } \\
\text { - The boards of study associations need to be aware of what is } \\
\text { and what is not possible during a drink or event organized by } \\
\text { them. To this end, there are regular consultations with the } \\
\text { building manager and the relevant study associations. } \\
\text { - Student teams working in workplaces outside the campus (e.g. } \\
\text { solar team), need to be made aware of the possible the } \\
\text { possible safety risks and to be informed whom they contact at } \\
\text { the UT for mitigating safety risks support. } \\
\text { - Awareness promotion among employees and students about } \\
\text { the possible theft of their laptop or other valuables. } \\
\text { - The campus security carefully controls for possible dealing in } \\
\text { drugs (e.g. during festivals and events) and closely works } \\
\text { together with the city Police. } \\
\text { - Awareness promotion, and speed limitation are needed to } \\
\text { increase traffic safety on the Campus. }\end{array}$ \\
\hline 2 & Integrity & $\begin{array}{l}\text { - Implementation of the "House of Integrity" through: } \\
\text { (1) promoting awareness among students and employees; } \\
\text { (2) Promoting an integrity culture; } \\
\text { (3) Research data management; } \\
\text { (4) Publication policy; } \\
\text { (5) Ethical norms and procedures } \\
\text { - Including Integrity as a separate course (2 EC) in the PhD and } \\
\text { PDEng education program. }\end{array}$ \\
\hline 3 & Privacy & $\begin{array}{l}\text { - Privacy sensitive research needs the approval of the Ethical } \\
\text { committee } \\
\text { - The "house of integrity" also covers the organization integrity, } \\
\text { i.e. safeguarding the privacy of employees and students }\end{array}$ \\
\hline 4 & Crisis Management & $\begin{array}{l}\text { - A good coordination between the security guard organization } \\
\text { and the police is needed } \\
\text { - The deployment of mental crisis experts in case of a psychotic } \\
\text { crisis behavior case } \\
\text { - Regular trainings in crisis management and evaluation of } \\
\text { conducted crisis simulations } \\
\text { - Extend the current pallet of potential crisis situations } \\
\text { - Conduct a scenario analysis to anticipate potential future risks }\end{array}$ \\
\hline 5 & Cyber risks & $\begin{array}{l}\text { - The Cert-UT (Computer Emergency Reponse Team) } \\
\text { - Participation in CERT-SURF network. } \\
\text { - UT makes use of "Quarantainenet", advanced software to } \\
\text { detect suspicious computer behavior by employees and } \\
\text { students } \\
\text { - Collaboration with "Twente Hackers squad" to detect possible } \\
\text { leaks in the UT computer network. } \\
\text { - UT has a "responsible disclosure procedure" to report leaks in } \\
\text { the UT-computer network and software applications. } \\
\text { - Participation in cyber crisis exercises, organized by SURF, such } \\
\text { as OZON and NOZON }\end{array}$ \\
\hline
\end{tabular}




\begin{tabular}{|c|c|c|}
\hline 6 & Working conditions & $\begin{array}{l}\text { - An UT-taskforce workload to monitor workload at UT and to } \\
\text { make suggestions to reduce an unacceptable level of workload. } \\
\text { - TGS offers courses for PhD students how to deal with work } \\
\text { stress. } \\
\text { - VSNU has outlined rules to promote a healthy work practice for } \\
\text { PhD students. } \\
\text { - The hiring of 1-2 experts to deal with mental crisis situations at } \\
\text { UT. }\end{array}$ \\
\hline 7 & Environmental issues & $\begin{array}{l}\text { - The VGM (Safety, Health \& Environmental) organizations has } \\
\text { outlined the tasks and responsibilities of all actors in the field of } \\
\text { Safety, Health and Environmental issues (report nr. VGM TVB's } \\
\text { 372.447/PA\&O) } \\
\text { - The need to hire of } 1-2 \text { experts to deal with mental crisis } \\
\text { situations at UT. }\end{array}$ \\
\hline 8 & Social safety & $\begin{array}{l}\text { - New students and new employees must be extensively } \\
\text { informed about the view of the UT with regard to an inclusive, } \\
\text { safe and healthy working environment. } \\
\text { Students, employees and management must be made aware of } \\
\text { what is expected from them with respect to an inclusive, safe } \\
\text { and healthy study and working environment at UT. } \\
\text { - An UT aggression protocol outlines the procedures and } \\
\text { sanctions which are effective with regard to physical } \\
\text { aggression, but also less visible aggressive behavior such as } \\
\text { bullying. } \\
\text { A careful screening of new employees (e.g. taking references } \\
\text { from past employers serious and certificate of good conduct } \\
\text { (VOG) and also VGB in case of sensitive positions). } \\
\text { Employees and students can inform an UT-confidant or the UT- } \\
\text { ombudsperson if they want to confidentially report e.g. } \\
\text { unauthorized financial transactions, incorrect assessments, and } \\
\text { complaints regarding unwanted touching or psychological } \\
\text { harassment. }\end{array}$ \\
\hline 9 & Internationalization & $\begin{array}{l}\text { - Inform foreign students about the prevailing norms, values and } \\
\text { manners in Dutch society. Student mentors and study advisors } \\
\text { may a constructive role to this end. } \\
\text { In the case of foreign employees the introduction program for } \\
\text { foreign employees should also include attention about the } \\
\text { prevailing norms, values and manners in Dutch society. } \\
\text { Involve the international PhD community at UT. They may play } \\
\text { a significant role by paying attention to each other as a } \\
\text { community and warning when one is worried about a PhD } \\
\text { student. } \\
\text { Adopt at all Faculties the current ITC practice where foreign } \\
\text { students can approach two study affairs officers with a range of } \\
\text { (also non-study related) problems. Due to an accessible open } \\
\text { door policy the study affairs officers quickly hear when a } \\
\text { potential problem arises and they can take proactive actions. } \\
\text { Like ITC, start with a homologation year for foreign PhD } \\
\text { students. This is to ensure that a PhD student has the required } \\
\text { knowledge and skills to successfully complete a promotional } \\
\text { project. }\end{array}$ \\
\hline
\end{tabular}




\begin{tabular}{|l|l|l|}
\hline 10 & Knowledge safety & $\begin{array}{l}\text { A clear UT-protocol how to deal with foreign countries that are } \\
\text { listed on the sanction list of the Dutch government. } \\
\text { The general Intelligence and security service (AIVD) has } \\
\text { developed an e-learning module about laptop and website use } \\
\text { when travelling in foreign countries such as China, Russia and } \\
\text { Iran. Important is to travel with an "empty laptop". } \\
\text { A UT protocol that UT students and UT employes are required } \\
\text { to follow when travelling to countries which have been labelled } \\
\text { as "unsafe" by the Ministry of Foreign affairs. } \\
\text { A UT travel app "CHUBB", to contact and inform UT students } \\
\text { and UT employees in case a risky situation has occurred in a } \\
\text { country they are staying. }\end{array}$ \\
\hline
\end{tabular}




\section{REPORTING SYSTEMS}

\section{Existing incidents and accidents reporting systems at UT}

- A cyber-security report is made on a quarterly basis

- Each BHV (emergency response) coordinator keeps a record of all emergency accidents that have occurred.

- Traffic accidents: the security guard department keeps a registration of all traffic incidents on the campus.

- The security guard department keeps a record of incidents (burglary, thefts, vandalism, aggression etc.) that have occurred on the campus and in the buildings. These data are shared with all Facility managers of the respective buildings.

- VGM (Safety, Health and Environment) yearly publishes an annual report including all incidents that happened in the past year with respect to Safety, Health and Environmental issues. .

- CES keeps track of serious calamities such as Tsunami's, floods, attacks, or revolts (this to warn students about unsafe foreign countries and to contact UT-students possibly staying in these unsafe foreign countries).

- An annual report of the confidential advisors

- An annual report of the ombudsperson

- $\quad$ The well-being of employees report

\section{Not yet available but required reporting systems:}

- We need an overview and insight of the contact pattern per employee with hazardous substances in laboratories (as requested by law)

- The Security Department has a good cooperation with the police. For example, the police recently reported an increase in the number of burglaries in student houses. The Head of Security would like to see immediately at which locations the burglaries occurred (on UT grounds or in the city, etc.).

\section{Security guard related installed security systems}

- Sky-walker. With this software the Security department can save all kinds of malfunctions and incidents that have occurred at UT. Camera images from observations by security guards (for example, when someone is unauthorized in a building or room) can be saved with Sky-walker.

- Milestones. This system combines all camera surveillance images of all buildings

- A fire detection system. The UT has the ASCOM fire detection system. The different detection devices are connected to each other and can be operated as a whole. There are, however, a number of stand-alone systems (from Siemens) that are not connected to the ASCOM system. The security officers make a specific report of each incident in "word". This is then processed in "excel" into a management report.

- Picasse. This is a calling system that is used by the emergency response (BHV) teams. Team members receive a message via a tablet about the nature of the incident and where they should take action.

- Galaxy. This authorization system gives people access to buildings outside office hours. An officer has been appointed for each building who is responsible for assigning the authorization to an employee, student or external person.

- Remote opening/closing system. The security can remotely activate or deactivate access to buildings. 
APPENDIX B

EXTERNAL ORIENTATION OF INTEGRAL SAFETY

Made by: J.I.M. Halman

March 2020 


\title{
CONTENTS OF APPENDIX B: EXTERNAL ORIENTATION
}

\author{
B1. SYNOPSIS \\ $B 2$. \\ The identified safety and security risks based on an extensive literature \\ review and consultations with external experts \\ B3. The identified solutions for risk issues based on an extensive literature \\ review and consultations with external experts \\ B3. RECOMMENDATIONS
}

Page

\section{APPENDIX 1}

A summary of the reviewed academic literature about integral safety at universities and campuses

B-A1.1. Fletcher, P \& Bryden, P.J. (2009)

Preliminary Examination of Safety Issues on a University Campus: Personal Safety Practices, Beliefs \& Attitudes of Female Faculty \& Staff, College Student Journal, Vol. 43 (1), pp 181-195.

B-A1.2. Kapucu, N. \& Khosa, S. (2012)

Disaster Resiliency and Culture of Preparedness for University and College Campuses, Administration \& Society 45(1) pp 3-37.

B-A1.3. Williams, B.N., LePere-Schloop, M., Silk, P.D. \& Hebdon, A. (2016) The co-production of campus safety and security: a case study at the University of Georgia, International Review of Administrative Sciences, Vol 82 (1) pp 110 - 130.

B-A1.4. Helsloot, I., Vlagsma J. \& Kraaijenbrink, S. (2017) Risk analysis higher education institutions; An integral analysis of the risks for higher educational institutions, Program IV-HO, 31pp.

B-A1.5. Platform IV-HO (2018), Advies over Veiligheid in het Hoger Onderwijs,

B-A1.6. Focke-Bakker, E.G.A., Kaouass, A., Koning, R.W.J. de \& Mansvelt, W.M. (2012) Integrale Veiligheid in governance en bedrijfsvoering in het hoger onderwijs, Handleiding voor de implementatie van integrale veiligheid, Ministerie OCW, $50 \mathrm{pp}$.

B-A1.7. Hutter, J. and Spit, M. (2014) Integrale Veiligheid Hoger Onderwijs; Management Systeem Integrale Veiligheid Ministerie OCW, Platform Integrale veiligheid Hoger Onderwijs, 62 pp.

B-A1.8. Platform IV-HO, Integrale Veiligheid Hoger Onderwijs, Handboek Integraal Veilig internationaliseren. Veiligheid bij interne- en externe mobiliteit van studenten en medewerkers in het hoger onderwijs, 24 pp.

B-A1.9. Platform IV-HO (2019) Integrale Veiligheid Hoger Onderwijs, Handreiking voorbereiding op een ernstig geweldsdelict op instellingen van hoger onderwijs, $22 \mathrm{pp}$.

B-A1.10. Damme, P. van \& Remrev, M., Handreiking Crisisorganisatie, Platform Integrale Veiligheid in het Hoger Onderwijs, 23 pp.

B-A1.11. Boin, A. and Hart, Paul 't (2010) Organising for effective emergency management: Lessons from research, Australia Journal of Public Management, Vol. 69 (4), pp. 357-371. 
B-A1.12. Garcia, H.F. (2006) Effective leadership response to crisis, Strategy \&

Leadership, Vol. 34 (1), pp. 4-10.

B-A1.13. Sapriel, C. (2003) Effective crisis management: Tools and best practice for the new millennium, Journal of Communication Management, Vol. 7 (4), pp. 1-8.

B-A1.14. European Confederation of Institutes of Internal Auditing, Risk in Focus 2020, Hot topics for internal auditors, $68 \mathrm{pp}$.

B-A1.15. García Herreo, S., Mariscal Saldaña, M.A., Manzanedo del Campo, M.A. \& Ritzel, D.O. (2002) From the traditional concept of safety management to safety integrated with quality, Journal of Safety Research, Vol 33, pp 1-20.

B-A1.16. Stafford, D. \& Rittereiser, S. (2007) Community policing, crime prevention and comprehensive trainings programs: Key ingredients to reducing risk in campus public safety, In: Stetson College of Law, proceedings of the $28^{\text {th }}$ Annual National Conference on Law and Higher Education, February 17-21, 2007.

B-A1.17. Ministerie van Binnenlandse Zaken en Koninkrijksrelaties, Algemene Inlichtingen- en Veiligheidsdienst, Kwetsbaarheidsanalyse spionage, Spionagerisico's en de nationale veiligheid (2010), 56 pp.

B-A1.18 Ministerie van Binnenlandse Zaken en Koninkrijksrelaties, AIVD Jaarverslag 2018, 28 pp.

B-A1.19 Van Gelder, P. and Focke-Bakker, E., TU Delft, TBM/Dsys \& Delft Safety and Security Institute, Veiligheidsprofiel (VP 2019) TU Delft 2019, $22 \mathrm{pp}$.

B-A1.20 Universiteit Utrecht, (CIRM) Centraal Integraal Risicomanagement Integrale Veiligheid, Overzicht (2020), 11 pp.

APPENDIX 2

A Summary of the consultations with external experts on safety and security

B-A2.18. TNO, Linda Krom, Director Security

B-A2.19. THALES, Ronald Brinkman, Tactical Information Security Officer and

B-A2.20. TU Delft, Ron Massink, Manager Integral Safety TU Delft and with Paul Hillman, Director $\mathrm{ClO} \&$ Facilities 


\title{
PLAN TO IMPLEMENT INTEGRAL SAFETY AT UNIVERSITY OF TWENTE $2^{\text {ND }}$ PHASE: REPORT OF THE EXTERNAL ORIENTATION
}

\author{
Made by: J.I.M. Halman
}

March 2020

\section{B1. SYNOPSIS}

All universities participating within VSNU have agreed with regard to safety to:

- Take responsibility for organizing an integrated safety policy to guarantee a safe living, learning and working environment and safeguard business continuity also in the case of extreme circumstances.

- Compare costs and benefits of safety measures with each other so that only the most sensible ones are given a place.

To implement Integral Safety Management in accordance with the above made agreements, a proposal is being developed for the organization and monitoring of Integral Safety Management at the UT. The following phasing is used:

1st Phase: Internal orientation: mapping the status quo in the field of safety and security management at the University of Twente

$2^{\text {nd }}$ Phase: External orientation: developing an overview of relevant safety and security risks and risk mitigation strategies based on an extensive review of academic literature and consultation of with external experts

$3^{\text {rd }}$ Phase: A design for implementing and monitoring integral safety at the University of Twente.

This report provides the results of the $2^{\text {nd }}$ Phase: the external orientation on Integral Safety. This external orientation consisted of a systematic bibliographic study about Integral Safety as applied at Higher Education Institutes (HEIs) around the world. In addition to this extensive literature review, indepth interviews were conducted with a number of experts in the field of Safety and Security. Purpose of these consultations has been to learn from the experiences that organizations such as Thales, TNO and TU Delft have built up with respect to Safety and Security and to be informed by the General Intelligence and Security Service (AIVD) about their intelligence and security concerns for HEls in The Netherlands.

The bibliographic study has been made after a search in academic databases for relevant studies, papers and reports about Integral Safety at universities and campuses. Based on a first search, 15 reports and 11 academic papers were selected and reviewed. After a relevance review, a summary was written for 12 reports and 5 academic papers. The interviews were conducted with directors and with managers with a leading position in safety and security. A summary of the interviews is also included in this report.

After a content analysis, the reports, papers and the outcome of the interviews were categorized into one or more of the ten distinguished pillars for Integral Safety Management which are (see also figure 1): Campus and buildings; Integrity; Privacy; Crisis Management; Cyber risks; Working conditions; Health \& Environmental issues; Social safety; Internationalization; and Knowledge development and sharing. 


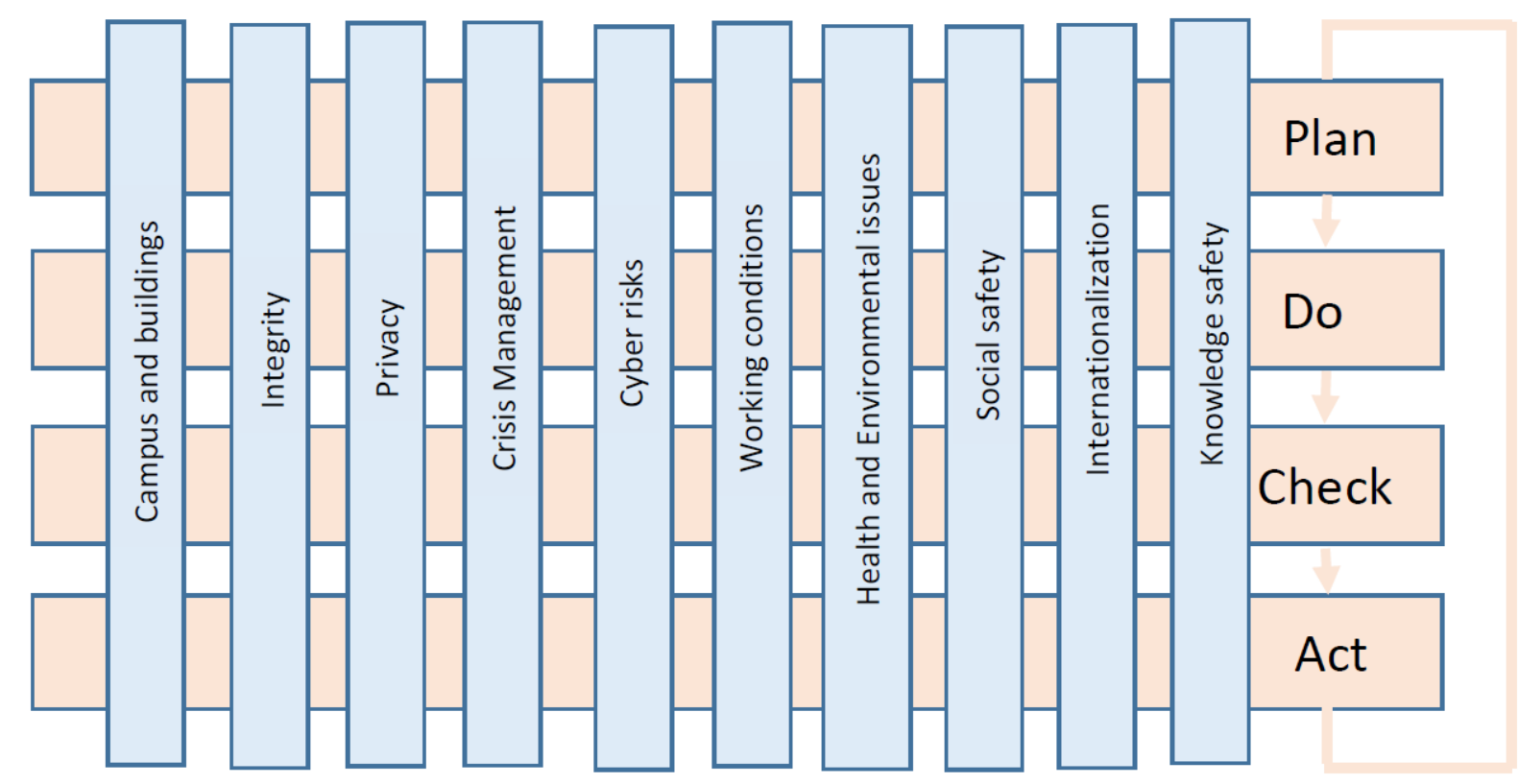

Figure 1. The Integral Safety Management System (Adapted from Hutter and Spit, 2014)

Section 1.1. provides a systematic overview of all the potential risk issues, that were identified in the reviewed literature or that were mentioned by the consulted external experts. And similarly, section 1.2. provides all the potential risk mitigation strategies, that were identified in the reviewed literature or that were mentioned by the consulted external experts.

Based on the bibliographic study and the consultations with external experts, a number of recommendations are made in section 2 for the implementation of Integral Safety at the University of Twente.

Appendix 1 provides a summary of 11 reports and 5 academic papers about relevant literature on safety and security at universities and campuses. Finally, appendix 2 provides a summary of the consultations with external experts in the field of safety and security management. 


\section{B2. The identified potential safety and security risks based on an extensive literature review and consultations with external experts}

Table 1 provides all the potential risk issues, that were identified in the reviewed literature or that were mentioned during the interviews with the external experts. Depending on the content, each risk issue was categorized into one or more of the ten distinguished pillars for Integral Safety Management.

Table B-1. Potential safety and security risk issues categorized per distinguished pillar of Integral Safety

\begin{tabular}{|c|c|c|c|}
\hline & Category & Sources & Identified potential risk issues \\
\hline 1 & Campus and buildings & $\begin{array}{l}\text { Williams et al (2016); Van } \\
\text { Gelder \& Focke-Bakker } \\
\text { (2019); Van Gelder et al } \\
\text { (2019); Helsloot et al } \\
\text { (2017). }\end{array}$ & $\begin{array}{l}\text { Fire and Arson, Traffic accidents; } \\
\text { elevator locks; Power failures; } \\
\text { Leakages; Incidents at student clubs or } \\
\text { student flats on campus; Lab unsafety; } \\
\text { No safe fled in case of a calamity; } \\
\text { Heavy weather damages; Burglary and } \\
\text { thefts in general and more specific of } \\
\text { Lap tops; Alcohol and drug use on } \\
\text { campus. }\end{array}$ \\
\hline 3 & Privacy & $\begin{array}{l}\text { Helsloot et al (2017); } \\
\text { Platform IV-HO (2018); } \\
\text { Hutter \& Spit (2014) }\end{array}$ & $\begin{array}{l}\text { The risk of privacy violation is a threat } \\
\text { for the openness of the university and } \\
\text { of course this has large potential } \\
\text { effects on the trust in universities. } \\
\text { Data breaches, different forms of } \\
\text { digital fraud and hacking, may violate } \\
\text { the privacy of staff and students. }\end{array}$ \\
\hline 4 & Crisis Management & $\begin{array}{l}\text { Kapucu \& Khosa (2012); } \\
\text { Van Damme \& Remrev; } \\
\text { TU Delft; Boin \& 't Hart } \\
\text { (2010); Sapriel (2003); } \\
\text { Garcia (2006). }\end{array}$ & $\begin{array}{l}\text { Disasters affecting humans and/or } \\
\text { infrastructure; Infrastructure } \\
\text { breakdowns; Fast spreading of } \\
\text { infectious diseases; Terrorist attacks; } \\
\text { Outbursts of violence; Continuity of } \\
\text { university in danger; Lack of } \\
\text { information to manage crisis. Not } \\
\text { being prepared for unscheduled, } \\
\text { undesirable, urgent and threatening } \\
\text { contingencies; Management inaction } \\
\text { and/or neglect. Misleading half-truths } \\
\text { or lies by management; Management } \\
\text { assigning blame to others; Lack of } \\
\text { training in crisis management. }\end{array}$ \\
\hline 5 & Cyber risks & $\begin{array}{l}\text { Helsloot et al (2017); } \\
\text { European confideration } \\
\text { of Internal Auditors } \\
\text { (2020); } \\
\text { Van Gelder \& Focke- } \\
\text { Bakker (2019); Van } \\
\text { Gelder et al. (2019); } \\
\text { Thales, Brinkman \& } \\
\text { Schutte, 2019. }\end{array}$ & $\begin{array}{l}\text { ICT failure; Data breaches; Misuse of } \\
\text { ICT systems; Network and wifi outage; } \\
\text { Cyberattack and hacking; ICT spam; } \\
\text { Ransomware; When a student uses the } \\
\text { (digital) identity of a teacher or staff } \\
\text { member, it can be abusively used to } \\
\text { see or change for example study } \\
\text { results. }\end{array}$ \\
\hline
\end{tabular}


Table B-1. Potential safety and security risk issues categorized per distinguished pillar of Integral Safety (continued)

\begin{tabular}{|c|c|c|c|}
\hline & Category & Sources & Identified potential risk issues \\
\hline 6 & Working conditions & $\begin{array}{l}\text { Helsloot et al (2017); } \\
\text { Hutter \& Spit (2014); } \\
\text { Adelerhof (2018) }\end{array}$ & $\begin{array}{l}\text { Psychosocial problems; Work stress; } \\
\text { Working with toxic, flammable and } \\
\text { explosive substances in laboratories; } \\
\text { Mental health; Risk of not meeting } \\
\text { ARBO requirements; }\end{array}$ \\
\hline 7 & $\begin{array}{l}\text { Health and } \\
\text { Environmental issues }\end{array}$ & $\begin{array}{l}\text { Platform IV-HO internat.; } \\
\text { European confideration } \\
\text { of Internal Auditors } \\
\text { (2020); Van Gelder \& } \\
\text { Focke-Bakker (2019); } \\
\text { American Chemical } \\
\text { Society (2012). Adelerhof } \\
\text { (2018); Clarke and Kouri } \\
\text { (2009). }\end{array}$ & $\begin{array}{l}\text { Environment and climate change; } \\
\text { Natural disasters; Health issues; Heavy } \\
\text { weather damages; Safety issues (toxic, } \\
\text { flammable and explosive substances) } \\
\text { in laboratories; The institution's } \\
\text { imports of food, paper, fossil fuels, } \\
\text { construction materials, landscaping } \\
\text { materials and many other products } \\
\text { can have a negative environmental } \\
\text { impact. }\end{array}$ \\
\hline 8 & Social safety & $\begin{array}{l}\text { Fletcher \& Bryden (2009); } \\
\text { Helsloot et al (2017); } \\
\text { Platform IV-HO internat.; } \\
\text { Stafford \& Rittereiser } \\
\text { (2007) }\end{array}$ & $\begin{array}{l}\text { Unwanted sexual touching; sexually } \\
\text { transmitted diseases; various forms of } \\
\text { harassment; violent loners; Robbery; }\end{array}$ \\
\hline 9 & Internationalization & $\begin{array}{l}\text { Helsloot et al (2017); } \\
\text { Platform IV-HO internat.; }\end{array}$ & $\begin{array}{l}\text { Radical ideas and extremism; Studying } \\
\text { as a disguise; Increased vulnerability } \\
\text { for spying; Health problems; Mental } \\
\text { health; fast spreading of infectious } \\
\text { diseases; malaria; Discrimination; } \\
\text { Administrative problems; Medicines; } \\
\text { Financial problems; }\end{array}$ \\
\hline 10 & Knowledge safety & $\begin{array}{l}\text { AIVD (2010); AIVD (2019); } \\
\text { TU-Delft, Massink\& } \\
\text { Hillman, (2020). TNO, } \\
\text { Krom ,(2019). }\end{array}$ & $\begin{array}{l}\text { Espionage, through theft of data sets } \\
\text { and blueprints, pending or } \\
\text { unpublished patents and scientific } \\
\text { discoveries; Biggest threat of } \\
\text { economic espionage comes from } \\
\text { China; China is particularly interested } \\
\text { in High-tech, energy, maritime, life } \\
\text { sciences \& health. } \\
\text { Risk of dual use perspective and risk of } \\
\text { not complying with sanction policy } \\
\text { rules; Loss of confidential information } \\
\text { caused by university employees. }\end{array}$ \\
\hline
\end{tabular}




\section{B3. The identified potential solutions for potential risk issues based on an extensive literature review and consultations with external experts}

Table 2 provides all the potential solutions, that were identified in the reviewed literature or that were mentioned during the interviews with the external experts. Depending on their content, each solution was categorized into one or more of the ten distinguished pillars for Integral Safety Management.

Table B-2. Identified potential solutions for potential safety and security risk issues categorized per distinguished pillar of Integral Safety

\begin{tabular}{|c|c|c|c|}
\hline & Category & Sources & Identified risk mitigation strategies \\
\hline 1 & Campus and buildings & Williams et al (2016) & $\begin{array}{l}\text { Implement reactive, proactive and co- } \\
\text { active strategies for campus security } \\
\text { police personnel. }\end{array}$ \\
\hline 2 & Integrity & $\begin{array}{l}\text { TNO, Krom, 2019; } \\
\text { Integrity policy UT (2019); } \\
\text { UT policy (2020) }\end{array}$ & $\begin{array}{l}\text { Screening of new staff (VOG and VGB) } \\
\text { that are appointed in sensitive } \\
\text { positions; A 'house of integrity' as an } \\
\text { approach to structure and organize } \\
\text { the various integrity-related policies, } \\
\text { regulations and practices. }\end{array}$ \\
\hline 3 & Privacy & $\begin{array}{l}\text { Algemene Verordening } \\
\text { Gegevensbescherming } \\
\text { (2018); Schermer et al } \\
\text { (2018); Borgman (2018); } \\
\text { Orrick (2018); Neufelft } \\
\text { (2009); Gilley (2006); } \\
\text { Dowding (2011); Radboud } \\
\text { University (2019). }\end{array}$ & $\begin{array}{l}\text { Develop and implement a privacy } \\
\text { policy; At UT: "Leidraad privacyregels } \\
\text { bescherming van personen in } \\
\text { wetenschappelijk onderzoek" and the } \\
\text { appointment at UT of "Privacy } \\
\text { ContactPersonen" (PCPs); }\end{array}$ \\
\hline 4 & Crisis Management & $\begin{array}{l}\text { Kapucu \& Khosa (2012); } \\
\text { Focke-Bakker et al (2012); } \\
\text { Platform IV-HO (2019); } \\
\text { Van Damme \& Remrev; } \\
\text { Boin \& 't Hart (2010); } \\
\text { Sapriel (2003); Garcia } \\
\text { (2006). }\end{array}$ & $\begin{array}{l}\text { A proper Crisis management and } \\
\text { Continuity management plan which is } \\
\text { regularly updated; Situation report; A } \\
\text { well performing crisis team and } \\
\text { organization; Awareness creation and } \\
\text { training among students, faculty and } \\
\text { staff. Psychosocial, legal and financial } \\
\text { aftercare; } \\
\text { Develop early warning mechanism/ } \\
\text { rapid response capability; Designate a } \\
\text { senior executive as responsible for } \\
\text { crisis preparedness and response; } \\
\text { Organize for resilience; Scenario } \\
\text { analyses; Partnering with key actors; } \\
\text { Correct mistakes early; Regular } \\
\text { workshops for Crisis management } \\
\text { team; Effectively communicate with } \\
\text { all stakeholders; Effective crisis } \\
\text { management depends on principles } \\
\text { and processes that assure flexibility } \\
\text { and a smooth flow of information. } \\
\text { Prepare for the post-crisis phase. }\end{array}$ \\
\hline
\end{tabular}


Table B-2. Identified potential solutions for potential safety and security risk issues categorized per distinguished pillar of Integral Safety (continued)

\begin{tabular}{|c|c|c|c|}
\hline 5 & Cyber risks & $\begin{array}{l}\text { Thales, Brinkman \& } \\
\text { Schutte (2019); TNO, } \\
\text { Krom (2019); Helsloot et } \\
\text { al. (2017); }\end{array}$ & $\begin{array}{l}\text { Develop and implement a cyber- } \\
\text { security policy and take security risk } \\
\text { precautions; } 24 / 7 \text { security monitoring } \\
\text { is of vital importance; Intensify the } \\
\text { collaboration in safety and security } \\
\text { networks; Implement cyber awareness } \\
\text { and training policy program. }\end{array}$ \\
\hline 6 & Working conditions & $\begin{array}{l}\text { Focke-Bakker et al (2012); } \\
\text { TNO, Krom, (2019) }\end{array}$ & $\begin{array}{l}\text { Awareness creation; Take Burnout } \\
\text { preventive measures. }\end{array}$ \\
\hline 7 & $\begin{array}{l}\text { Health and } \\
\text { Environmental issues }\end{array}$ & $\begin{array}{l}\text { American Chemical } \\
\text { Society (2012); Adelerhof } \\
\text { (2018); Clarke and Kouri } \\
\text { (2009). }\end{array}$ & $\begin{array}{l}\text { Create strong chemical safety culture } \\
\text { in laboratories; Maintain chemical } \\
\text { incident reporting and learning system. } \\
\text { The negative environmental impact } \\
\text { can be mitigated by purchasing green } \\
\text { products, reducing the volume of } \\
\text { consumption and circular designs and } \\
\text { circular construction. }\end{array}$ \\
\hline 8 & Social safety & Platform IV-HO (2019) & $\begin{array}{l}\text { Screening of new staff (VOG and VGB) } \\
\text { to be appointed in sensitive positions; } \\
\text { Identify worrying behavior in an early } \\
\text { phase; Cooperate with the local care } \\
\text { and safety chain; Campus public safety } \\
\text { and security involved in student } \\
\text { orientation programs, work with } \\
\text { housing and student affairs } \\
\text { representatives; A rape awareness } \\
\text { and education program; A crime } \\
\text { prevention orientation program; A } \\
\text { personal safety oriented program; }\end{array}$ \\
\hline 9 & Internationalization & Platform IV-HO internat.; & $\begin{array}{l}\text { Adequate briefing of Faculty, staff and } \\
\text { students; Information about the } \\
\text { administrative side of staying in the } \\
\text { Netherlands; A buddy system; } \\
\text { Organizing social events; Psychic } \\
\text { support; Exit interviews; Travel } \\
\text { advises by Ministry of Foreign Affairs, } \\
\text { Radio Netherlands Worldwide and } \\
\text { SOS international; A complete as } \\
\text { possible overview of all students, } \\
\text { faculty and staff travelling abroad. }\end{array}$ \\
\hline 10 & Knowledge safety & AIVD (2020) & $\begin{array}{l}\text { Actively strengthen the awareness } \\
\text { among faculty and staff in particular } \\
\text { on the risk of espionage and the } \\
\text { sanction rules; Work on a cultural } \\
\text { change in the field of security; Pay } \\
\text { particular attention to the protection } \\
\text { of core interests. }\end{array}$ \\
\hline
\end{tabular}




\section{B4. Recommendations}

Based on the conducted bibliographic study and the consultations with external experts in the field of safety and security management, I would like to make the following recommendations for the implementation of Integral Safety at the University of Twente.

\section{Conduct a scenario-analysis every 3-5 year}

College campuses need to change their short-term focus toward a sustainable and resilient approach (Zdziarski et al, 2007). Universities often realize that they are preparing for the more recent events in history, which possibly leads to responding to a situation they have not prepared for. Although the preparedness for recurring events is applaudable, it is also necessary to be prepared for possible new events that may happen in the near future.

2. Develop and implement an annual 'plan-do-check-act' program for each of the ten distinguished pillars included in the Integral Safety Management System (see figure 1)

From the earlier conducted Quick Scan study (Halman, 2019) it became clear that a number of the pillars (i.e. the pillars 'Cyber security risks', 'Campus and buildings' and Health and environmental safety) have well worked out procedures for safety and security management while the 'plan-docheck-act' control cycle for some other pillars (e.g. the pillar Internationalization) are still in their infancy.

3. Conduct an analysis of safety and security risk issues that are inextricably intertwined From the bibliographic study but also the conducted interviews for the Quick Scan study, it became clear that besides individual safety or security risks, there are also safety and security risks which are intertwined (e.g. a fire in an ICT-center, not only potentially leads to fire damage but also potentially leads to failure of ICT-services and the loss of valuable information. Or the spreading of an infectious disease which can also harm the continuity of the educational process). Based on a detailed collection of potential safety and security risks per distinguished pillar an analysis can be made of potential mutual interactions.

4. Develop and implement an annual UT Security and Safety monitor

For the transition towards an Integrated Safety and Security Management System, it is important to systematically collect incidents and accidents and also annually perform an integrated risk assessment about the status of Security and Safety management at the University of Twente. Such a monitor will help to evaluate if risk mitigation actions have been effective and if potential new and/or new intertwined risks are observed or anticipated.

\section{Develop and implement a tailored Integrated Security and Safety training program}

No safety and security without safety and security awareness and training. Depending on the specific role (student, faculty or staff), the position (management, administrative, research and/or education) and the disciplinary background (e.g. high risk for espionage), a tailored made awareness and safety \& security training program needs to be developed and disseminated. 
6. Develop and regularly update a continuity of operations plan

Evaluate the management of the covid-19 university lockdown process and develop on the basis of this evaluation an improved crisis management plan and a continuity of operations plan.

Encourage faculty, staff, and students to avail training and education opportunities in crisis management and ensure that key staff and faculty are trained and are participating in regular crisis exercises. 


\title{
APPENDIX B1
}

\section{A SUMMARY OF THE REVIEWED LITERATURE ABOUT INTEGRAL SAFETY AT UNIVERSITIES AND CAMPUSES}

\author{
B-A1.1. Paula Fletcher and Pamela J. Bryden (2009) \\ Preliminary Examination of Safety Issues on a University Campus: Personal \\ Safety Practices, Beliefs \& Attitudes of Female Faculty \& Staff \\ In: College Student Journal, Vol. 43 (1), pp 181-195.
}

Fletcher and Bryden examined issues that female faculty and staff members working at a university in Central Ontario in Canada have about safety on and around the campus, including concerns about safety, personal safety precautions, and issues involving victimization. 229 female faculty and staff completed a questionnaire sent via inter-campus mail. Participants were dissatisfied with the following safety features on campus: lighting, signage and the availability of emergency phones. More faculty members than staff members, reported being victimized on campus, although both groups reported similar types of victimization (i.e. unwanted sexually touching and various forms of harassment). The authors conclude that despite the small sample contained within their exploratory study, the results provide undeniable evidence of the existence of compromised safety on a university campus. Further research is needed to draw conclusions to what extent these findings can be generalized. However, steps toward making campuses safe havens for students, staff, faculty and administration should definitely be considered a priority for Higher Education Institutions (HEls).

\section{B-A1.2. Naim Kapucu and Sana Khosa (2012) Disaster Resiliency and Culture of Preparedness for University and College Campuses. In: Administration \& Society 45(1) pp 3-37.}

In the United States, more than 4000 public and private institutions of higher education (HEls) are involved in developing policies, procedures, and strategies to maintain a safe campus life and environment (U.S. Department of Education [DOE], 2009). Campus safety and security issues have gained momentum over time since the nature of campus crimes and campus threats have evolved. Due to the difficult nature of preparing for all risks and threats, campuses often realize that they are preparing for the more recent events in history, which possibly leads to responding to a situation they have not prepared for. College campuses therefor need to change their short-term focus toward a sustainable and resilient approach. To guard the campus community against threats, a Disaster Resilient University (DRU) has to be created to ensure that an overall culture of preparedness is developed and that the campus community is properly prepared for all dangers that are unique to it. Universities play many roles in a community, and apart from academic services, they provide many research and partnership opportunities for the community in which they reside. In the wake of a disaster, the ability of an institution to continue its operations is not only important to the faculty, staff, and students but also to the community at large.

Although campuses across the United States are laying emphasis on creating comprehensive emergency management plans (CEMPs), cultivating a deeper sense of executing and understanding these plans among the campus communities may be missing at large. Along with building a culture of preparedness through awareness campaigns, training exercises and information dissemination about emergency plans through websites and posters, a healthy campus culture of openness between staff, faculty and students needs to be encouraged and developed. 
A well-prepared university and campus has a disaster management program with at least four main features. It:

- Caters to and prepares for various types of disasters and crises;

- Has methods and systems that collect cues signaling early warnings of potential crises;

- Has a multidepartment and interdisciplinary disaster management team and;

- Encourages and ensures buy-in and support from a number of internal and external stakeholders.

Early signs of weaknesses within the current crisis-management system or in current safety and security plans should result in improving current systems. A culture of preparedness will be cultivated throughout the campus when a multi-departmental and multi-divisional disaster management team is formed that is supported by the campus leadership. In addition, this team should be the result of numerous meetings and simulations to ensure that the capacity of managing emergencies is being addressed rather than simply forming a list of people from different departments and bunching them together to form a team. Disaster management needs to be an integral element in the strategic governance of colleges and universities. Thus, the concepts of resiliency and culture of preparedness are at the heart of creating DRUs and colleges.

Ideally, a Crisis Management Plan is composed of the following six components:

- A plan activation component which deciphers when a plan needs to be activated

- Clear lines of authority that depict a hierarchy of roles that lead to the campus president

- Action steps that give campus officials the roadmap of what to do depending on the nature of a crisis, and identification of key responsibility modes that help campus emergency staff to take appropriate actions depending on the level of disaster

- Established communication methods including a communications center that will ensure effective information exchange

- Redundancy of critical staff to make sure staff is available in disasters; clarified media responsibilities to avoid misinformation that would endanger lives and delay proper response

- A clarified role for campus security and outside agencies and a plan for business resumption such as a detailed Continuity of Operations Plan (COOP) that will help to restore operations.

\section{Continuity Planning}

Continuity Planning is positively related to the perceived level of disaster resiliency and the level of preparedness within a university. For creating a Disaster Resilient University, it is important that campus operations such as teaching, research, and other auxiliary services are not disrupted for too long and an overall continuity plan is in place. Continuity planning can help to lessen the impact of a crisis and, more importantly, to allow an institution to continue operating during a crisis. Without a proper continuity plan, a university risks extending classes, suspending semesters, and delaying crucial research. A Continuity of Operations Plan (COOP) defines the roles, functions, and priorities for faculty and staff following an emergency as a means to quickly restore a university to a functional status and involves key academic affairs personnel, departmental heads, and other important contacts that have stakes involved in ensuring instructional continuity.

Ideally a Continuity of Operations Plan ( COOP):

- Identifies the critical operations and functions and the minimum requirements to perform them;

- Identifies the Internal and external dependencies;

- Determines alternative methods and redundancies;

- Identifies steps for recovery and restoration in addition to goals and timelines;

- Examines assumptions; 
- Examines communication methods;

- Tracks incident-related expenses/financial components, and;

\section{Partnering with Key Community Actors}

Partnerships with key community actors contribute positively to the perceived level of resiliency and helps to create a culture of preparedness. A Disaster Resilient University (DRU) has to develop a nd maintain strong working relationships with its surrounding community, not only during response and recovery from a disaster but also in its preplanning and preparedness efforts. There are a variety of strong relationships that have to be developed prior to an emergency, such as fire and rescue units, public safety, and police departments; and medical and health services. Nonprofits such as Red Cross and Salvation Army are also important partners in the crisis management process and help to provide temporary housing and food to displaced students and employees during emergencies. The private sector can also help provide assistance to colleges and universities during a disaster or crisis. In 2005, during Hurricane Katrina, Verizon Wireless provided technical assistance by donating mobile cell towers, generators, and portable transmission sites to assist with additional coverage in the hardest hit areas.

To establish proper collaboration between outside agencies and the campus, two things are very helpful: pre-crisis network building and establishing mutual aid agreements. Pre-crisis network building involves developing relationships with agencies for information sharing and exchange prior to a crisis and by involving them in campus training exercises and drills. This type of networking helps to familiarize first responders and local agencies to campus structures and culture. Moreover, campus officials are also able to delineate which resources and skills outside agencies bring to the emergency management and planning table (Zdziarski et al., 2007).

\section{Crisis Information Management and Risk Communication}

Creating and implementing a risk communication plan and managing crisis information are positively related to the perceived level of preparedness and resilience in universities.

Crisis communication is different from risk communication as it is event specific, reactive, and takes place during or after a crisis, whereas effective risk communication is proactive, future-oriented, and mitigates the impacts of a crisis. Risk communication is interactive as it involves stakeholders who identify and assess risks and plan for and support the creation of emergency information management systems. Thus, along with crisis communication, effective risk communication is integral for mitigation and resiliency.

Effective and timely communication is an important element for the safety of faculty, staff, and students immediately prior to, during, and following a disaster. It can positively affect how the community perceives an institution's ability and capacity for handling a crisis. The death toll from the Virginia Tech campus shootings may also be attributed to the lack of timely campus communication.

\section{Training and Certification}

Overall, a campus crisis training program has to be well planned, regularly implemented and updated, and evaluated to ensure that the campus community has developed readiness and resiliency to cope with a disaster. As such, it will develop disaster resiliency and a culture of preparedness within a university.

An educational institution is recommended to encourage faculty, staff, and students to avail training and education opportunities in crisis management and ensure that key staff and faculty are trained 
in the $\operatorname{ICS} 1^{5}$ and are participating in annual crisis exercises and continuous professional development programs. ICS courses provide a guideline for campus officials to act proactively in emergencies. In addition, training activities can be carried out on campus to prepare individuals for crises. Tabletop exercises are "discussion-based activities that can be used in crisis-management training to assess the effectiveness of a plan while handling operational and communication challenges" aimed at solving problems collaboratively (Zdziarski et al., 2007, p. 192). During a tabletop exercise, participants are presented with a scenario and are required to chalk out their response and actions to these scenarios. Through tabletop exercises, participants learn how to allocate resources during crises and this helps to gauge whether an educational institution has the ability to carry out the respective phases of emergency management.

\section{Conclusion}

Results from the study conducted by Kapucu and Khosa across university and college campuses in the United States, show that an all-hazards plan, conducting regular training and exercises and developing strong community partnerships to be the most important elements for creating a disaster-resilient university, well prepared to tackle any calamity.

\section{B-A1.3. Brian N. Williams Megan LePere-Schloop, P. Daniel Silk \& Alexandra Hebdon (2016) The co-production of campus safety and security: a case study at the University of Georgia In: International Review of Administrative Sciences Vol 82 (1) pp 110 - 130.}

This article describes the views of university police personnel and students regarding a coproduction of safety and security at the University of Georgia in de USA. The university police personnel has evolved from being reactive or simply reacting to calls for service, to being more proactive as officers independently act upon the knowledge, technical skills, and abilities that they have. They currently also face the challenge of being more co-active, by partnering with students to solve problems and deliver services. Community oriented policing (COP) is an operating philosophy that reflects and supports the values of student engagement and participation in public safety, order and security. At its core, COP leverages community partnerships to prevent crime and solve problems. A specific challenge for building up such partnerships is the fact that the majority of the student body is almost completely new every four or five years.

\section{B-A1.4. Helsloot, I., Vlagsma J. \& Kraaijenbrink, S. (2017) Risk analysis higher education institutions; An integral analysis of the risks for higher educational institutions, Program IV-HO, https://integraalveilig- ho.nl/wp-content/uploads/Risk-analysis-HEls.pdf 31pp.}

Important values for Higher Education Institutions (HEIs) are their openness, accessibility and transparency. The crucial but complex question is how HEls on the one hand cherish the values of openness, accessibility and transparency, while on the other hand take care of safety and security and deal with classical, new and intertwined risks in a proportional way.

The higher educational system is (and always has been) confronted by different types of risks. 'Classical' risks, such as fire, are known by HEls and there are plenty of measures in place to reduce

\footnotetext{
${ }^{5}$ ICS: Incident Command System, a standardized approach to the command, control, and coordination of crisis response providing a common hierarchy within which responders from multiple organizations can be effective.
} 
these type of risks (preventive measures, e.g. fire compartmentation) or to reduce the impact (repressive, e.g. fire extinguishers). In the past decennium, new risks emerged due to developments such as globalization and digitalization. These new risks are present in society as a whole, and thus in the educational system as well.

Another noticeable aspect is the intertwining of classical and new risks within the HEls. This means that the new risks interfere with the classical risks. Classical and new risks combined result in what we call 'intertwined risks'. Intertwined risks are a combination of new and classical risks. They amplify certain effects or give new effects. An integral approach to risks is therefore necessary.

\section{Classical safety and security risks}

Classical safety and security risks have been present in HEls since decades. Although they may change over time, these risks are known by HEls. Four examples of specific classical safety and security risks are psychosocial problems, violent extremism, and violent loners.

Psychosocial problems can affect students studying in their home country as well as international students abroad. International students have to adjust to their new environment when starting at a new $\mathrm{HEl}$ in a different country. Psychosocial problems are primarily a concern of students themselves, but HEls deal with the effects of the problems. In some cases, students with psychosocial problems may develop extremist thoughts or show aggressive or violent behavior. It is therefore not only in the student's interest but also in the HEl's interest to prevent or minimize psychosocial problems of students in general and in particular international students visiting the HEl. In some cases, it is difficult for international students to adapt to their new environment, for example because of language difficulties, homesickness or (academic) demands that are higher than expected. The new environment and the contrast with the original background of an international student can clash and can result in negative feelings or behavior. It can cause stress, depression and other types of psychosocial problems, which can have a severe impact on the study results of international students. Ultimately, psychosocial problems can lead to suicide or violence (e.g. violent loners). When international students come to visit HEls in the EU, it is also possible that already existing psychosocial complaints become more severe and develop into a problem. When certain groups of international students from two states that are for example at war are confronted with each other, this can cause social tensions. For example, these tensions can occur between students from Bosnia and Serbia, Turkey and Armenia and many other countries that have a conflict.

The reason why radical ideas and extremism deserve the attention of HEls is because of the potentially large effects and consequences of the use of violence. Because of the recent terrorist attacks in Europe (Berlin, Brussels and Paris), the attention for violent extremism has increased. It is presumed that extremists go through a radicalization process before they commit an attack. Some faculties can be particularly vulnerable when it comes to radicalization, because of the type of research that is conducted there. New knowledge that is developed can be especially dangerous when it gets into wrong hands. This is a specific risk for HEls when it comes to risks of extremism.

A violent loner can be defined as a person that operates alone and causes a threat for the security of $\mathrm{HEls}$. Shootings at educational institutions are an example of violence caused by loners. Although there are no known shootings at HEls, in the last few years a couple of serious shooting threats were present in HEls in the Netherlands. Leiden University for example, took extra security measures (such as extra police surveillance at the entrance of the University buildings) because of a threat post of someone on the forum site 4Chan. Eventually and fortunately nothing happened. In the EU school shootings are fortunately a rarity, whereas in the USA school shootings are much more common. 


\section{New safety and security risks}

Examples of new safety and security risks are ICT security risks, Data breach, misuse of ICT facilities, Diploma fraud, Studying as a disguise, and Privacy violation.

Nowadays an educational system without ICT infrastructure is totally unthinkable. Failure of the ICT infrastructure is therefore problematic for the continuity of educational processes. The full integration of ICT in higher education results in new risks. Generally, ICT structures are not completely managed or owned by the HEls using them. This means that there is interdependency and shared responsibility between ICT service delivery companies and HEIs. Cooperation between HEls in the field of ICT also results in shared responsibilities. Use of open sources on the internet raises questions about responsibility as well. The control on ICT environments is divided between HEls and different parties. This makes it more difficult to define ownership.

There is an obligation for Dutch HEls to report data breaches. A data breach is the release of confidential information, for example personal data or research data. Continuity of services (research and education) is threatened by internet risks. When HEls decide to collaborate in the field of ICT, data-sharing or applications, these systems can become intertwined. This means that a cyberattack on the shared system can have much larger (potentially even international) effects. It is therefore important that HEls consider taking safety measures in order to protect their shared systems. The interdependency of digital chains increases as a consequence of the 'Internet of Things'. More and more equipment and sensors are connected to internet and linked to networks. By doing so, these networks become more vulnerable for cyberattacks. The effects of a cyberattack are potentially larger. The business continuity is at stake when these cyberattacks can result in large financial damage and damage to reputation.

The online access to material and data of HEls results in more accessibility for HEls and it creates more freedom for students and staff members, for example to have access to data worldwide. The downside of the intensive use of internet is that it is vulnerable to different types of threats from outside the HEls. Electronic learning environments are gaining in popularity and, if possible, have to be accessible worldwide. With this growing penetration of ICT systems, however, the vulnerability of institutions also increases. This in turn creates increasing demands on security requirements for authorization, authentication and protection, including encryption.

Misuse of ICT systems by students and staff, is in the perception of most higher education institutions a serious risk for ICT systems. This misuse can include the dissemination of seditious messages or pornographic images, but it also covers the deliberate deletion or corruption of files, the disabling of systems, the illegal downloading of intellectual property (e.g. films) and the unauthorized use of access codes. The extent of possible misuse is closely linked to the degree of security applied to the system.

Diploma fraud is a big issue for HEls. The quality and value of education depends on the value of diplomas. Only a presumption of diploma fraud can do damage to the reputation of a HEl. Diploma fraud has negative effects for both students (their diploma loses value) as well as for teachers (their credibility is questioned) and the higher education sector as a whole (their reputation is damaged). When a student pretends to be someone else during examination, the integrity of all study results is jeopardized. When a student uses the (digital) identity of a teacher or staff member, it can be abusively used to see or change for example study results. This can have large consequences for the reputation of the $\mathrm{HEl}$.

Studying as a disguise for gaining a temporary residence permit is a reason to pretend being a student. Foreign people (especially from outside the EU) can easily pretend to be students, while they come to the EU for other reasons. In this case, an educational institution is used as a gateway to Europe. Research conducted by the University of Applied Sciences Saxion concludes that this 
phenomenon is present in the Netherlands. Other research by the Dutch educational inspection proved several cases where students 'disappeared' from HEls where they were registered.

The violation of privacy can be a risk for HEls, because HEls have access to large amounts of personal information from staff and students. In the mentioned risks of data breaches, different forms of digital fraud and hacking, the privacy of staff and students can be violated. The risk of privacy violation is a threat for the openness of HEls and of course this has large potential effects on the trust in HEls.

\section{Intertwined risks: classical risks with new aspects}

Classic risks and new risks become more and more intertwined due to digitalization. An example is a fire in an ICT-center, which not only potentially leads to the loss of information (as is comparable to a fire in old-fashioned archives), but also potentially leads to failure of ICT-services. This can threaten the continuity of the educational processes, and can make lectures unavailable and can make studying from home impossible. Other examples of intertwined risks are a fast spreading of infectious diseases and data loss through spying.

The mobility of people (students and staff) enables a fast spreading of infectious diseases (especially from outside the EU). Traditionally, mobility plays an important role in the large scale spreading of infectious diseases. This principle is not new, but the large scale, intensity, frequency and speed of travelling makes the risks connected to mobility more pressing. The new development of more global traffic, more exchange between universities and more mobility combined with the classical risk of infectious diseases results in an intertwined risk that potentially causes more damage than the original risk of infectious diseases. The risk of infectious diseases therefore threatens the continuity of processes in HEls.

Certain policy decisions in the past have led (unintentionally) to an increased vulnerability for spying activities. The promotion of knowledge migration has as unwanted side effect that intelligence officers can relatively easily infiltrate and hide in a student population. The Dutch intelligence office has indications that foreign students are used by their country of origin to gather intelligence. Scientific and technological knowledge generated by HEls can be highly valuable for other countries. Because of the openness of scientific research, spying is relatively easy. In practice, sensitive information in HEls is poorly protected. The leaking of scientific information can cause damage to the economic wellbeing of a state.

\section{Specific recommendations for risk management at HEls}

The developments regarding the rise of the internet, and the trend towards more and more globalization have created new opportunities for HEl's to perform their core mission of spreading knowledge. At the same time these developments created new risks for HEls. Since openness, accessibility and transparency are values that we do not want to give up in our HEls, it is inevitable that absolute safety at HEls is not possible. Incidents cannot be excluded at the cost of everything. Risk management for HEls is therefore a complex balancing act that requires strategic decisions at the board level of HEls and at the level of national and European safety and security networks. Identifying and prioritizing risks helps in this balancing act, as well as comparing risks, gaining insight in costs and benefits, and being aware that risks are shared with other actors. The report also provides some general principles for risk management by HEls. These principles are: Organize for resilience; Conduct an integral risk analysis; Collaborate in Safety and Security networks;

\section{Organize for resilience}

The context in which HEls function is one that is diverse and constantly subject to change. Flexibility in response to unforeseen incidents increases the capacity to deal with these incidents. A strategy of 
resilience requires reliance on experience with adverse consequences once they occur. This strategy goes hand in hand with accepting the fact that something could go wrong. It is useful for HEls to make a general crisis management plan in advance, so that the HEl can deal with the (re)occurring facets of an incident, no matter what incident the HEI faces.

\section{Conduct an integral risk analysis}

The risks at HEIs are diverse and are traditionally categorized in different domains, each with their own risk governance. However, in order to conduct a useful risk analysis on the level of the $\mathrm{HEI}$, the risk analysis should consider all risks and their potential interactions and compare the costs and benefits of risk mitigation and preparation. The risk analysis needs, in other words, to be integral in order to be able to decide upon a balanced risk policy

\section{Intensify the collaboration in safety and security networks}

$\mathrm{HEls}$ are part of a society in which numerous actors are working to ensure safety and security. HEls should therefore try to collaborate with these actors instead of trying to come up with measures of their own. This way, all participants in the resulting safety and security networks can take their own responsibility. This principle firstly applies to the local, regional and national networks of HEls in which actors such as municipalities and local or national safety and security agencies participate. Secondly HEls are well advised to actively join national and European networks of comparable HEls in order to exchange knowledge and pool resources.

Competition between HEls exists. However, in the field of safety and security it is in many cases more beneficial to collaborate, for example as HEls within the EU. Sharing experiences and successful protection and prevention methods can help increase the safety of HEls as a system.

The operational processes of HEls are essentially the same: providing education and conducting scientific research. Therefore, HEls experience largely the same risks that derive from these primary processes. Besides that, HEls benefit from the continuity of other institutions (e.g. scientific fraud damages the educational system as a whole). This means that there are shared interests, which make it possible and necessary to learn from each other on the field of safety, for example through sharing best practices. Collaboration between HEls asks for effort and investment.

\section{B-A1.5. Platform IV-HO (2018)}

\section{Advies over Veiligheid in het Hoger Onderwijs, Raad van Advies, kenmerk}

\section{B.07.06B https://integraalveilig-ho.nl/wp-content/uploads/Advies-RvA.pdf}

\section{4 pp.}

The program for implementing Integral Safety in higher education institutions distinguishes nine safety themes. These are:

- Working conditions (ARBO and Environment)

- Social safety and security (including worrying behavior)

- Integrity

- Information safety

- Privacy

- Knowledge safety

- Internationalization

- Safety on campus and in buildings

- Crisis management

To implement Integral Safety, the Platform for Integral Safety advises to follow five successive process steps: Risk management; Integral Safety Policy; Organization; Awareness creation; Continuity management. 
The appendix provides an overview of several reports that have been published by the platform for Integral Safety IV-HO:

- Management Systeem Integrale Veiligheid (Managamenet System for Integral Safety)

- Handreiking crisisorganisatie (Crisis organization guide)

- Deskundigheidsbevordering zorgwekkend gedrag (Expertise promotion of worrying behavior)

- Escalatieladder zorgwekkend gedrag (Escalation ladder of worrying behavior)

- Risk Analysis Higher Education Insitutions

- Integraal Veilig Internationaliseren (Internalization from a Integral Safety perspective)

A summary of each report is provided in this literature review.

B-A1.6. Focke-Bakker, E.G.A., Kaouass, A., Koning, R.W.J. de \& Mansvelt, W.M. (2012) Integrale Veiligheid in governance en bedrijfsvoering in het hoger onderwijs, Handleiding voor de implementatie van integrale veiligheid Ministerie OCW, https://integraalveilig-ho.nl/wp-content/uploads/Integraleveiligheid-in-governance-en-bedrijfsvoering-ho.pdf $\mathbf{5 0} \mathbf{p p}$.

Integral Safety is defined in this report as: "an approach to get a grip on all incidents and safety risks in conjunction with each other and to take appropriate measures in conjunction and by cooperation. Integral safety uses common processes, so that a common overall picture of the safety situation is created, regardless of whether there are health, safety, security or IT risks. Integral safety improves control and control of all safety functions and provides competitive advantage."

Depending on the occurrence of an incident, a fire can be a safety risk (spontaneous short-circuit resulting in a fire) and / or a security risk (conscious attempt by a person to start a fire).

The report provides a blueprint and an action plan for the organization and implementation of Integral Safety at universities and other higher education schools. Within the scope of Integral Safety, three organizational perspectives are distinguished:

- Organizing from a crisis management perspective

Crisis management is the phase within the safety chain in which calamities, disasters and crises are dealt with. In its nature, crisis management is responsive. This often manifests itself in the form of a crisis organization that works incident-oriented and is activated by scaling up after an incident has occurred. An incident is seen as a "residual risk" that has become a potential event.

- Organizing from a technical safety and safe working conditions perspective This perspective has its basis in laws, regulations and permits.

- Organizing from a perspective of social safety and security Social safety and security comprises safety issues such as bullying, threatening, blackmailing, bribing and fraud. The number and type of social safety incidents often determine the attention within a knowledge institution.

Knowledge development and knowledge sharing are generally considered as the purpose of existence of a university. A potential lack of safety and/or security in the process of knowledge development and/or knowledge sharing is therefore recognized as a serious risk to the continuity of a knowledge institution. Due to the increase in the number of incidents, safety and security have taken now a much more prominent place in the organization and management process of a university than it used to be.

The report makes a distinction in five successive maturity phases towards Integral Safety at universities and other knowledge institutions: 
- Functional Safety

In this phase the organization manages safety from the different safety functions (IT-security, Environmental safety, Physical safety etc.). The organization lacks formal procedures for safety management.

- Process based Safety

For each safety function there is a clear prescription in terms of tasks and responsibilities available to manage the safety process of the respective safety functions.

- Systemic Safety

An organization-wide policy has been drawn up for each of the safety functions. The functional coordinators working at of different organizational units have a similar functional safety approach. This requires coordination and training within each of the functional columns. This coordination and cooperation makes it possible to report organization-wide about the safety situation in the functional column.

- Controlled Safety

In this phase, line management is responsible for the safety situation. Line management will be confronted with all functional safety areas and will set requirements with regards to safety information. The person responsible for a specific safety function, reports incidents, registers safety performance based on predefined safety indicators.

- Integral Safety Integral safety is based on similar processes within all safety functions. This creates clarity and comparability across the safety functions. Line management focuses on integral risks. Students and staff are aware of integral safety. Management is able to realize continuous improvements with respect to safety. The implemented safety indicators makes it possible for an institution to compare its own performance achievements with the ones realized by competitive institutions.

To realize the transition towards a state of Integral Safety, the authors identified six safety development categories. These are:

- Category 1: Integral safety policy (strategic level)

This category includes the formulation of a safety strategy and associated plans that are in line with the vision and mission of the knowledge institution and how to structure a safety organization for this purpose. In addition attention should be paid attention to whether the intended safety objectives are being achieved. The role in particular with regard to safety decision-making is important here.

- Category 2: Organization (tactical and operational level) The organization concerns the assignment of roles responsibilities and instruments at the tactical and operational level. It focuses on the method of organization so that strategic objectives are achieved.

- Category 3: Risk identification and risk management process (tactical and operational level) Two important activities that need to be conducted are the identification of possible risk scenario's and assessment of the probabilities and consequences of these scenario's.

- Category 4: Performance measurement and evaluation (accountability and supervision) The proper and manageable organization of safety cannot be achieved without critical measurement and evaluation. This is the fuel for the improvement cycle. Internal supervision provides insight into compliance with legal obligations, and strategic, tactical and operational goals.

- Category 5: Crisis management and continuity management (tactical/operational level) Within Integral Safety, a proper crisis management plan is a requirement. A contingency plan 
(also called emergency plan) is a basic requirement. The emergency plan provides the organizational structures, procedures and agreements for emergency situations. The plan describes who has what tasks and powers in the event of an emergency and how coordination with other organizations takes place. Continuity management guarantees the continuation of the most critical processes in the educational institution. The continuity plan enables the organization to continue or restore core activities. The plan describes how the organization will respond to an actual disruption of the most critical processes.

- Category 6: Awareness

No safety without safety awareness among the people in the organization. Integral safety can only flourish based on a fertile safety culture. A safety culture is a socially responsible attitude of all employees with regard to safety in the organization.

For each of the six distinguished categories a list of questions was developed to assess in which phase of safety development (Functional Safety; Process based safety; Systemic safety; Controlled Safety; Integral Safety) the organization can be placed. This ranking provides the necessary input to discuss the further development of the organization in terms of safety management and the time frame to realize the ambition.

B-A1.7. Hutter, J. and Spit, M. (2014) Integrale Veiligheid Hoger Onderwijs; Management Systeem Integrale Veiligheid Ministerie OCW, Platform Integrale veiligheid Hoger Onderwijs, https://www.integraalveilig-ho.nl/instrument/managementsysteem-integraleveiligheid-mivh/, 62 pp.

This report provides general verifiable criteria to establish, control, maintain and improve a management system for universities to improve the level of prevention, readiness, mitigation, response, continuity and recovery from disruptive incidents. Implementation of such a management system requires the necessary time and sufficient management attention and involvement. It is useless to want to have such a system fully implemented in one go.

Core elements for successfully implementing Integral Safety at a university are:

- Top management commitment and vision

The University Board is expected to formulate their vision and the Integral Safety policy the institution and to monitor the implementation. The implementation will only succeed with the visible support by the University Board and their preparedness to make sufficient resources sufficient capable manpower and financial resources available for it.

- Clear rules of engagement Many safety incidents have a cause in human actions. Negligence, organizational or human failures, unfamiliarity with a risk or with safety measures, can cause and exacerbate a safety event. In an (impending) security incident, humans can be the weakest link. However, they can also be a very strong link in combating that incident. Clear rules of engagement are needed with respect to common safety and integrity issues such as: fraud, conflicts of interests, scientific integrity, knowledge security and information security and to whom employees and students can turn with specific questions related to such issues. It is important to realize a situation in which employees contribute to Integral Safety to the best of their ability.

- Monitoring and evaluating the progress of implementing Integral Safety To be able to follow and evaluate the progress of implementing the integral safety policy and 
management system, it is important to implement and to monitor the implementation progress in a systematic way. Based on the collected monitoring information, it will be possible to evaluate to what extent goals are being achieved or whether adjustments are necessary.

- Taking incidents seriously

Addressing violations against shared rules of engagement, sends a signal that value is attached to compliance and exemplary behavior. It ratifies existing standards and reduces the risk of future violations. Setting up an enforcement policy is therefore an essential part of integral safety policy. This includes, among other things, rules concerning the detection, investigation, sanctioning and communication of (suspected) abuses. Provisions such as reporting schemes, confidential advisers, and investigation protocols form part of an integrated safety management approach at universities.

- Accountability

The University Board and the respective management teams of faculties, are not only integral responsible for delivering high quality education and research, but also for the organization and monitoring of integral safety aspects. At all levels and in almost all departments of the institution, employees must be charged with tasks and responsibilities for managing safety risks. This requires the allocation of sufficient capable manpower and financial resources.

The establishment of Integral Safety will follow a natural growth, which can be expressed in so called maturity steps. Such a maturity development approach requires an audit reference model. Three useful tools are already available:

- SURF has a standards framework and benchmark model based on ISO27002 information security, continuity of company data and privacy. This helps to determine the level of information security maturity of the institution.

- ASIS International has developed a manual and standards framework with six maturity levels to determine the NEN 7131 Organizational Resilience Management Resilience level (ANSI/ASIS SPC.4-2012, Maturity Model for the Phased Implementation of the Organizational Resilience Management System).

- Hutter \& Spit (2014) also provide a self-assessment tool consisting of 272 questions, to evaluate the state of Integral Safety at a knowledge institution.

The management of Integral Safety needs to be part of the entire risk management organization, also known as Enterprise Risk Management (ERM). A safety risk analysis provides insight into the type of safety risks and provides a basis for an evaluation of possible measures that have to be taken and the justification of the choices that need to be made. It is important at the start of such a risk analysis, to take the objectives of an institution, the interests of the main stakeholders, and the purpose and the scope of the risk analysis as point of departure. This provides the basis to identify and assess the most important risks that an institution is facing. Table 3 provides an example of an inventory of safety risks for a university. Based on such an inventory an assessment can be made of the probability and the impact of specific incidents. A Safety-risk Matrix visualizes the dispersion of risks and based on this visualization a prioritization of risks can be made. Table 4 provides an example of such a Safety-risk Matrix.

Remark:

Notably table 3 does not pay attention to health risks (such as MERS-CoV, SARS-CoV or COVID-19) that can seriously affect the health of students and employees and possibly also the continuity of a educational and operational processes of a university. 
Table B-3. Example of a high-level inventory of safety \& security risks for a university ( Based on Hutter \& Spit, 2014).

\begin{tabular}{|c|c|c|c|c|c|c|c|c|c|c|c|c|}
\hline & 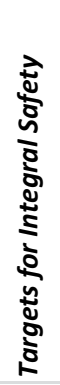 & 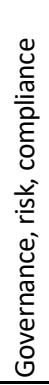 & 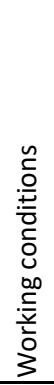 & 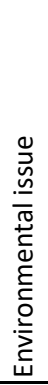 & 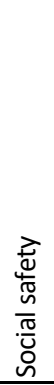 & 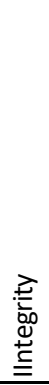 & 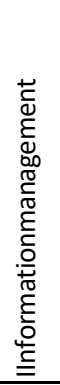 & 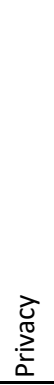 & 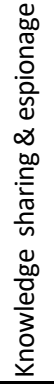 & 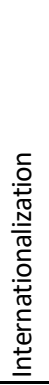 & 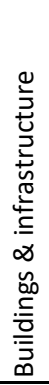 & 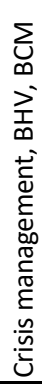 \\
\hline What to protect against & & & & & & & & & & & & \\
\hline & & & & & & & & & & & & \\
\hline \multicolumn{13}{|l|}{ Organizational/technical failures } \\
\hline Fire & & $\mathrm{x}$ & $\mathrm{x}$ & $\mathrm{x}$ & & & $\mathrm{x}$ & & & & $\mathrm{x}$ & $\mathrm{x}$ \\
\hline \multicolumn{13}{|l|}{ Outages } \\
\hline Energy outage & & $\mathrm{x}$ & & & & & $\mathrm{x}$ & & & & $\mathrm{x}$ & $\mathrm{x}$ \\
\hline ICT outage & & $\mathrm{x}$ & & & & & $\mathrm{x}$ & & & & & $\mathrm{x}$ \\
\hline \multicolumn{2}{|l|}{ Failures waste, chemical radiological handling } & $\mathrm{x}$ & $\mathrm{x}$ & $\mathrm{x}$ & & & & & & & $\mathrm{x}$ & $\mathrm{x}$ \\
\hline Failures installation equipment & & $\mathrm{x}$ & $\mathrm{x}$ & & $\mathrm{x}$ & & & & & & $\mathrm{x}$ & $\mathrm{x}$ \\
\hline Failures traffic handling & & $\mathrm{x}$ & & & $\mathrm{x}$ & & & & & & $\mathrm{x}$ & $\mathrm{x}$ \\
\hline Failures events/crowd control & & $\mathrm{x}$ & & & $\mathrm{x}$ & & & & & & $\mathrm{x}$ & $\mathrm{x}$ \\
\hline Failures food handling & & $\mathrm{x}$ & $\mathrm{x}$ & & & & & & & & & $\mathrm{x}$ \\
\hline & & & & & & & & & & & & \\
\hline \multicolumn{13}{|l|}{ Intentionally acts } \\
\hline \multicolumn{13}{|l|}{ Robbery } \\
\hline Creep and burglary (physical \& digital) & & $\mathrm{x}$ & $\mathrm{x}$ & & $\mathrm{x}$ & & $\mathrm{x}$ & & $\mathrm{x}$ & $\mathrm{x}$ & $\mathrm{x}$ & $\mathrm{x}$ \\
\hline Thefts of goods and information & & $\mathrm{x}$ & $\mathrm{x}$ & & $\mathrm{x}$ & & $\mathrm{x}$ & $\mathrm{x}$ & $\mathrm{x}$ & $\mathrm{x}$ & $\mathrm{x}$ & $\mathrm{x}$ \\
\hline Fraud & & $\mathrm{x}$ & & & & $\mathrm{x}$ & $x$ & & $\mathrm{x}$ & & & $\mathrm{x}$ \\
\hline Espionage & & $\mathrm{x}$ & & & & & $\mathrm{x}$ & & $\mathrm{x}$ & $\mathrm{x}$ & & $\mathrm{x}$ \\
\hline Cyber attacks & & $\mathrm{x}$ & & & $\mathrm{x}$ & & $\mathrm{x}$ & & $\mathrm{x}$ & & & $\mathrm{x}$ \\
\hline \multicolumn{13}{|l|}{ Violence } \\
\hline Bullying behavior & & $\mathrm{x}$ & $\mathrm{x}$ & & $\mathrm{x}$ & & & $\mathrm{x}$ & & $\mathrm{x}$ & & $\mathrm{x}$ \\
\hline Threats and intimidation & & $\mathrm{x}$ & $\mathrm{x}$ & & $\mathrm{x}$ & & & $\mathrm{x}$ & & $\mathrm{x}$ & & $\mathrm{x}$ \\
\hline Extortion and blackmail & & $\mathrm{x}$ & $\mathrm{x}$ & & $\mathrm{x}$ & & & $\mathrm{x}$ & & $\mathrm{x}$ & & $\mathrm{x}$ \\
\hline Serious (physical) threats & & $\mathrm{x}$ & & & $\mathrm{x}$ & & & & & $\mathrm{x}$ & & $\mathrm{x}$ \\
\hline Hostage and kidnapping & & $\mathrm{x}$ & $\mathrm{x}$ & & $\mathrm{x}$ & & & & & $\mathrm{x}$ & & $\mathrm{x}$ \\
\hline \multicolumn{13}{|l|}{ Public Order } \\
\hline Occupation, blockade, protest & & $\mathrm{x}$ & & & & & & & & & $\mathrm{x}$ & $\mathrm{x}$ \\
\hline \multicolumn{13}{|l|}{ Sabotage } \\
\hline Minor vandalism & & $\mathrm{x}$ & & & $\mathrm{x}$ & & & & & & $\mathrm{x}$ & $\mathrm{x}$ \\
\hline Fire-raising & & $\mathrm{x}$ & & & & & & & & & $\mathrm{x}$ & $\mathrm{x}$ \\
\hline Molest on building & & $\mathrm{x}$ & & & & & & & & & $x$ & $\mathrm{x}$ \\
\hline \multicolumn{13}{|l|}{ Miscellaneous } \\
\hline Blow up and shooting & & $\mathrm{x}$ & $\mathrm{x}$ & & & & & & & & $\mathrm{x}$ & $\mathrm{x}$ \\
\hline (Fake) Hum letter & & $x$ & $x$ & & & & & & & & $\mathrm{x}$ & $\mathrm{x}$ \\
\hline \multicolumn{13}{|l|}{ Negligence and non-discipline } \\
\hline Serious negligence & & $\mathrm{x}$ & $\mathrm{x}$ & $\mathrm{x}$ & $\mathrm{x}$ & $\mathrm{x}$ & $\mathrm{x}$ & $\mathrm{x}$ & $\mathrm{x}$ & $\mathrm{x}$ & $\mathrm{x}$ & $\mathrm{x}$ \\
\hline Ignoring smoking ban & & $\mathrm{x}$ & $x$ & & & & & & & & $\mathrm{x}$ & $\mathrm{x}$ \\
\hline Ignoring parking regulations & & $\mathrm{x}$ & & & & & & & & & $\mathrm{x}$ & $\mathrm{x}$ \\
\hline & & & & & & & & & & & & \\
\hline \multicolumn{13}{|l|}{ External threats } \\
\hline Extreme weather conditions (cold, hot) & & $\mathrm{X}$ & & & & & & & & & & \\
\hline Extreme weather conditions (storm) & & $\mathrm{X}$ & & & & & & & & & & \\
\hline
\end{tabular}


Table B-4: Example of a Safety-risk Matrix (Based on Hutter \& Spit, 2014; SRM BOK, 2009)

\begin{tabular}{|c|c|c|c|c|c|c|c|c|}
\hline & & & & \multicolumn{5}{|c|}{ Impact } \\
\hline & & & \multirow[t]{2}{*}{ People } & $\begin{array}{l}\text { Minor impact } \\
\text { on core } \\
\text { competences }\end{array}$ & $\begin{array}{l}\text { Small } \\
\text { impact on } \\
\text { core compe- } \\
\text { tences }\end{array}$ & $\begin{array}{l}\text { Unavaila- } \\
\text { bility of core } \\
\text { competences }\end{array}$ & $\begin{array}{l}\text { Unavaila- } \\
\text { bility of core } \\
\text { compe- } \\
\text { tences or } \\
\text { personnel }\end{array}$ & $\begin{array}{l}\text { Long lasting } \\
\text { unavailability } \\
\text { of core } \\
\text { competences } \\
\text { or personnel }\end{array}$ \\
\hline & & & & Minor injuries & $\begin{array}{l}\text { Injury with } \\
\text { treatment } \\
\text { by medical } \\
\text { doctor }\end{array}$ & $\begin{array}{l}\text { Serious } \\
\text { injury/ } \\
\text { hospitaliza- } \\
\text { tion }\end{array}$ & $\begin{array}{l}\text { Death and/ } \\
\text { or multiple } \\
\text { serious } \\
\text { injuries }\end{array}$ & $\begin{array}{l}\text { Multiple } \\
\text { deaths }\end{array}$ \\
\hline & & & Information & $\begin{array}{l}\text { Compromise } \\
\text { of } \\
\text { information } \\
\text { otherwise } \\
\text { available in } \\
\text { the public } \\
\text { domain }\end{array}$ & $\begin{array}{l}\text { Compromise } \\
\text { of } \\
\text { information } \\
\text { sensitive to } \\
\text { internal or } \\
\text { subunits } \\
\text { interests }\end{array}$ & $\begin{array}{l}\text { Compromise } \\
\text { of } \\
\text { information } \\
\text { sensitive to } \\
\text { operation of } \\
\text { organization }\end{array}$ & $\begin{array}{l}\text { Compromise } \\
\text { of } \\
\text { information } \\
\text { sensitive to } \\
\text { interests of } \\
\text { organization }\end{array}$ & $\begin{array}{l}\text { Compromise } \\
\text { of } \\
\text { information } \\
\text { with } \\
\text { significant \& } \\
\text { ongoing } \\
\text { impact }\end{array}$ \\
\hline & & & $\begin{array}{l}\text { Property \& } \\
\text { equipment }\end{array}$ & $\begin{array}{l}\text { Minor } \\
\text { damage or } \\
\text { vandalism to } \\
\text { asset }\end{array}$ & $\begin{array}{l}\text { Damage or } \\
\text { loss of } \\
\text { organization } \\
\text { assets up to } \\
€ 100 \mathrm{~K}\end{array}$ & $\begin{array}{l}\text { Damage or } \\
\text { loss of } \\
\text { organization } \\
\text { assets up to } \\
€ 1 \mathrm{M}\end{array}$ & $\begin{array}{l}\text { Damage or } \\
\text { loss of } \\
\text { organization } \\
\text { assetss up } \\
\text { to } € 10 \mathrm{M}\end{array}$ & $\begin{array}{l}\text { Damage or } \\
\text { loss of } \\
\text { organization } \\
\text { assets } \\
\geq € 10 \mathrm{M}\end{array}$ \\
\hline & & & $\begin{array}{l}\text { Environmen- } \\
\text { tal issues }\end{array}$ & $\begin{array}{l}\text { To be } \\
\text { determined }\end{array}$ & $\begin{array}{l}\text { To be } \\
\text { determined }\end{array}$ & $\begin{array}{l}\text { To be } \\
\text { determined }\end{array}$ & $\begin{array}{l}\text { To be } \\
\text { determined }\end{array}$ & $\begin{array}{l}\text { To be } \\
\text { determined }\end{array}$ \\
\hline & & & $\begin{array}{l}\text { Regulatory } \\
\text { aspects }\end{array}$ & No & Fines & $\begin{array}{l}\text { Threat of } \\
\text { banning } \\
\text { certain } \\
\text { activity } \\
\end{array}$ & $\begin{array}{l}\text { Organiza- } \\
\text { tion under } \\
\text { supervision }\end{array}$ & $\begin{array}{l}\text { Organization } \\
\text { losses license } \\
\text { to operate }\end{array}$ \\
\hline & & & Reputation & $\begin{array}{l}\text { Only local } \\
\text { impact. } \\
\text { Forgotten } \\
\text { quickly. }\end{array}$ & $\begin{array}{l}\text { Escalation } \\
\text { can be } \\
\text { prevented } \\
\text { by adequate } \\
\text { action to } \\
\text { local media }\end{array}$ & $\begin{array}{l}\text { Long term } \\
\text { impact on } \\
\text { brand of the } \\
\text { university }\end{array}$ & $\begin{array}{l}\text { Long term } \\
\text { impact and } \\
\text { intensive } \\
\text { political, } \\
\text { public, \& } \\
\text { media } \\
\text { attention }\end{array}$ & $\begin{array}{l}\text { International } \\
\text { concern, } \\
\text { Government } \\
\text { investigation }\end{array}$ \\
\hline & & & $\begin{array}{l}\text { Organization } \\
\text { processes \& } \\
\text { systems }\end{array}$ & $\begin{array}{l}\text { Minimal } \\
\text { impact on } \\
\text { core activities }\end{array}$ & $\begin{array}{l}\text { Small } \\
\text { impact on } \\
\text { core } \\
\text { activities }\end{array}$ & $\begin{array}{l}\text { Moderate } \\
\text { impact on } \\
\text { core } \\
\text { activities }\end{array}$ & $\begin{array}{l}\text { Serious } \\
\text { Impact on } \\
\text { core } \\
\text { activities } \\
\end{array}$ & $\begin{array}{l}\text { Serious } \\
\text { impact on } \\
\text { survival of } \\
\text { organisation }\end{array}$ \\
\hline & & & Finance & $\begin{array}{l}1 \% \text { of total } \\
\text { financial } \\
\text { budget }\end{array}$ & $\begin{array}{l}2-5 \% \text { on } \\
\text { financial } \\
\text { budget }\end{array}$ & $\begin{array}{l}5-10 \% \text { of } \\
\text { total } \\
\text { financial } \\
\text { budget }\end{array}$ & $\begin{array}{l}\geq 10 \% \text { of } \\
\text { total } \\
\text { financial } \\
\text { budget }\end{array}$ & $\begin{array}{l}\geq 30 \% \text { of } \\
\text { total } \\
\text { financial } \\
\text { budget }\end{array}$ \\
\hline & $\begin{array}{l}\text { Qualita- } \\
\text { tive } \\
\text { assess- } \\
\text { ment }\end{array}$ & $\begin{array}{l}\text { Historical } \\
\text { assessment }\end{array}$ & & insignificant & Negligible & Moderate & High & Fatal \\
\hline & $\begin{array}{l}\text { Very } \\
\text { High }\end{array}$ & $\begin{array}{l}\text { Happened } \\
\text { yearly }\end{array}$ & $\begin{array}{l}\text { Almost } \\
\text { certain }\end{array}$ & & & & & \\
\hline & High & $\begin{array}{l}\text { Happened } \\
\text { in the last } \\
\text { few years }\end{array}$ & Probably & & & & & \\
\hline & $\begin{array}{l}\text { Mode- } \\
\text { rate }\end{array}$ & $\begin{array}{l}\text { Happened } \\
\text { at least } \\
\text { once }\end{array}$ & Possible & & & & & \\
\hline 㝘 & Low & $\begin{array}{l}\text { Has not } \\
\text { happened } \\
\text { before }\end{array}$ & Unlikely & & & & & \\
\hline & $\begin{array}{l}\text { Very } \\
\text { Low }\end{array}$ & $\begin{array}{l}\text { Extremely } \\
\text { unlikely to } \\
\text { happen }\end{array}$ & Rare & & & & & \\
\hline
\end{tabular}




\section{B-A1.8. Platform IV-HO}

\section{Integrale Veiligheid Hoger Onderwijs, Handboek Integraal Veilig internationaliseren. Veiligheid bij interne- en externe mobiliteit van studenten en medewerkers in het hoger onderwijs. https://integraalveilig-ho.nl/wp- content/uploads/Handboek-internationalisering1.pdf 24 pp.}

This report describes the most common internal and external mobility risks for students and staff members at HEIs (Higher Education Institutes). Also the respective associated measures are described. In addition, a guide line for HEls is provided to develop a system to identify, assess, mitigate and manage Integral Safety risks which are related to internationalization activities.

The most common international incidents of Dutch students and staff members of HEls are:

- Violence: violent robbery, theft, rape and sexual harassment, sedated with drugs, kidnapping.

- Robberies: Laptop, personal property, money, information, research results

- Traffic accidents: involved in a traffic accident

- Health problems: hospitalization, sexually transmitted diseases, reaction to swallowing malaria pills, long-term illness.

- Psychic problems: psychic (in) stability, social isolation, culture shock, alcohol and drug abuse

- Political instability: riots, coup, violent change of power

- Natural disasters: earthquake, tsunami and flood

- Administrative problems: problems with visa and other travel documents.

- Medicines: the non-availability of medicines; medicines that are seen as drugs.

The most common incidents experienced by international students in The Netherlands are:

- Financial problems: PhD students lacks financial resources from home country, BSc and MSc student who do not receive scholarship from home country

- Administrative problems: administrative problems with social security number, bank account, accommodation and public transport with chip card.

- Health problems: the use of drugs

- Psychic problems: social isolation, home sickness, relationship problems

The report also provides an overview of measures that HEls can take and precautions that students and staff members can take themselves. A briefing provided by HEls is advised as an effective preventive measure to inform Dutch students as well as staff members. Such a briefing includes information about healthcare, insurance and required travel documents, finance, exchange of contact data and background information about the local circumstances of the country to visit. HEls may also consider to extend their collaboration with international universities, organize information session for those who stay at home, and organizing for adequate accommodation facilities. It is also advised to organize debriefing sessions to learn from past experiences for future travels and stays. Besides preventive measures, also repressive measures are recommended such as a 24/7 accessible emergency number, the setup of whatsapp or facebook groups to be able to effectively reach all students or staff members. Also the availability of an emergency protocol for worst case scenario's is recommended.

Also for foreign students travelling to the Netherlands it is recommended to take adequate preventive and repressive measures. Preventive measures include a suitable provision of relevant information about the administrative side of a stay and study in The Netherlands (e.g. BSN number, bank account, student card etc.) and adequate accommodation. During their stay in the Netherlands, a buddy system, the organization of social events and - if needed - psychic support are effective measures that can be taken. Exit interviews are helpful to improve the process of accommodating foreign students in The Netherlands. 
Important websites for students and staff members who have the intention to travel or stay abroad, are: the travel advises provided by the ministry of foreign affairs

(www.rijksoverheid.nl/ministeries/bz/reisadviezen), the Coordinating Office for student Placement Abroad (so called COSPA-netwok) www.nuffic.nl/promotie/cospa-network, the Iphone application SOS providing direct access to all relevant emergency numbers

www.sosinternational.nl/sos-nummers-op-reis, Radio Netherlands Worldwide, acting as an emergency transmitter www.corprate.rnw.nl and a website hosted by nuffic for students who are preparing for a study or internship abroad: www.wilweg.nl/landen.

A final observation concerns the importance for HEls to have an as complete as possible overview of all their students who are studying or travelling abroad. An example of how this can be organized can be found at the website of the University of Twente (https://www.utwente.nl/nl/studyabroad/praktisch/registratie-verzekering/).

\section{B-A1.9. Platform IV-HO (2019)}

Integrale Veiligheid Hoger Onderwijs, Handreiking voorbereiding op een ernstig geweldsdelict op instellingen van hoger onderwijs; https://integraalveilig-ho.nl/wp-content/uploads/Handreiking-ErnstigeGeweldsincidenten.pdf 22 pp.

This guide provides an elaboration on the necessary preparation and response of a potential serious violence incident at a higher education institution. With this guide a (higher) educational institution can prepare itself for a threat with, or actual committing of, a serious violence directed at people.

Various choices can be made which can be helpful to prevent a violence incident or to limit its impact. The choices that an institution for higher education can make can be divided into three categories:

- Measures to prevent a violence incident

- Measures to take during a violence incident

- Measures to take after a violence incident.

\section{Measures to prevent a serious violence incident}

- Worrying behavior

Often worrying behavior appears to be a manifestation of a student's healthcare issue. To prevent a violent incident, it is therefore recommendable to pursue a strong policy in the area of health care issues.

- Cooperate with the local health and safety chain.

A good cooperation with the local care and safety chain can help in cases when a rapid escalation is needed to organizations outside the institution. This is required when a student or staff member shows serious forms of worrying behavior.

- A well-performing crisis organization

The advantage of a well-functioning crisis organization is that it can be used for every conceivable crisis. A good crisis organization requires a well prepared and administratively approved crisis management plan. A good crisis organization also requires a clear overview of all the officials involved. It is also required to ensure that everyone involved knows exactly what role they play in the crisis organization. For this it is essential to regularly organize a crisis exercise. 


\section{Measures to taken during a violence incident}

- The most important measures to take during an attack are:

- Immediately inform the police

- Immediately inform anyone who is in the buildings or on the site through a system, including giving clear instructions on how to act, such as a phased evacuation or a lockdown procedure (although this information is never complete due to the acute threat of the incident)

- In case a lockdown procedure is effective at the institution, safeguard the persons in the building by following this procedure.

- Put emergency response (BHV) /Security organization into action

As soon as a normal incident occurs, the emergency response and / or security organization of the university will be deployed. However, in case of a violent incident, it is important to make a careful assessment of the role which these organizations may or may not play. In case it is decided to give the emergency response and/or security organization an explicit task, in the event of a violence incident, the organizations must be provided with the right resources to be able to act adequately.

- Awareness among students and personnel

To ensure that students and staff know how to act in the event of an violence incident, an awareness campaign could be envisaged. A clear message and a clear action perspective must be given so that students and staff are familiar with the established procedures.

Consideration must also be given to the degree of repetition and the manner in which communication takes place. In the case of an awareness campaign for an incident of violence, the effect of a campaign on the sense of security must also be considered. Some people will appreciate the campaign because they see the institution preparing, while others may think there is a reason to worry about incidents of violence.

- Lockdown procedure

During a violent incident, a lockdown procedure can prevent the perpetrator from spreading through the building. A lockdown can also enable students and staff to entrench themselves in (lecture) rooms. However a lockdown procedure requires in many cases also a thorough revision of the infrastructure of the buildings. Account must also be taken of the implementation of a reporting system that is not dependent on one central location. In addition, both the emergency response and/or security organization and the students and staff must regularly practice the lockdown procedure to ensure that the procedure is carried out correctly. The decision to implement such a procedure must therefore be well prepared.

\section{Measures to be taken after the violence incident}

- Psychosocial aftercare

When an incident of violence has occurred, this will have a major psychological impact on those involved. Although victim support is always offered by the government, it is also possible to offer psychosocial aftercare as an institution. This could include support for victims, parents of involved students, their own staff, etc.

In case the institution is considering offering psychosocial aftercare, it is good to determine in advance who will be deployed for this aftercare. Will it be done by professionals already employed at the university, or does the university needs to make use of external professionals?

- Legal and/or financial aftercare 
After the occurrence of a violent incident, it may be advisable to provide legal and / or financial aftercare to those involved. The consideration of which stakeholders can and to what extent claim legal and / or financial aftercare should be included in the crisis management approach.

\section{B-A1.10. Paul van Damme and Mitchell Remrev Handreiking Crisisorganisatie (Guide for a crisis organization), Platform Integrale Veiligheid in het Hoger Onderwijs, https://integraalveilig-ho.nl/wp- content/uploads/Handreiking-Crisisorganisatie-IV-HO.pdf 23 pp.}

The Management System for Integral Safety (MSIS) for Higher Education (see Hutter and Spit, 2014) focuses on the first two phases: the pre-action and prevention phase (see also figure 1). MSIS provides an action framework and approach to limit through pre-action and prevention the chance of incidents and crises.

- Pre-action: through structural prevention of risky situations. Risk analyzes are carried out to identify unsafe situations.

- Prevention: by taking measures to prevent incidents, calamities and crises arising, and keeping them manageable

The "Handreiking Crisisorganisatie" (Guide for a crisis organization) provides tools to get the organization prepared in the event of a crisis. Specific attention is paid to the set-up of a crisis management team and an efficient crisis organization.

In the total safety chain from pre-action to aftercare (see figure 1), the guide focuses on the preparation, the response, and the aftercare of crisis situations.

- Preparation: prepare for a possible calamity or crisis. Examples of this are drafting and practicing the safety plan with associated procedures, educating, training and practicing in crisis situations.

- Response: take decisions about acting or combating a calamity or crisis, on strategic level.

- Post-phase: dealing with the consequences of a disaster or crisis and taking measures to restore the normal course of events

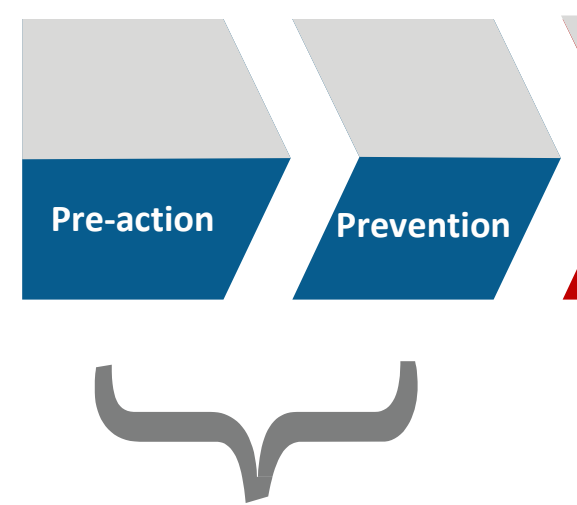

Risk management
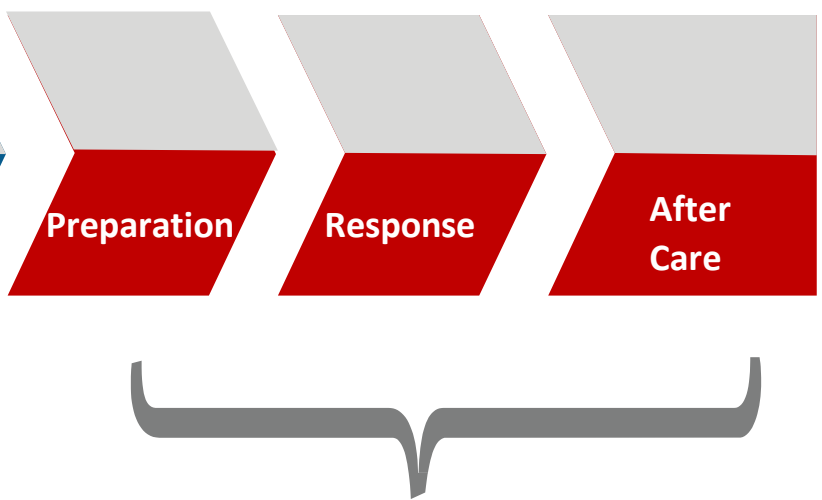

Crisis management

Figure B-2. A safety chain from Pre-action to aftercare

A crisis can be defined as: an unexpected event that poses a serious threat to the strategic goals, the reputation and possibly even the survival of the institution. In the event of a crisis, it is important to act quickly. Not all employees have to take immediate action, but a number of people do: they form the crisis organization. They must be prepared. Because when a crisis breaks out, there is no 
time to think about what needs to happen and who has what tasks. A crisis plan and a crisis organization are needed to handle a crisis situation effectively.

A crisis plan defines who takes the lead during a crisis (the response phase). The crisis plan also describes the crisis organization: when does it come into effect, who is responsible and how do they proceed? During a crisis, an institution works in a different way than under normal circumstances. The regular organization makes way for the crisis organization. The company emergency services (BHV) and security together form the operational side of the crisis organization. The policy, strategic side is in the hands of the crisis team. While the emergency response team has probably already taken action, the crisis team keeps an overview and makes decisions. A good crisis team is therefore crucial; the members must have certain competences to properly fulfill their role in the team.

The content of a typical crisis plan includes:

- The crisis organization

- Explanation of the situation

- Procedure for reporting and scaling up

- Accessibility, availability, picket service

- The functioning of a crisis team

- Attachments to a crisis plan

The purpose of a crisis team is to act quickly and adequately in the event of a disaster or crisis in order to minimize the consequences for the continuity of business operations. Combatting in the first hour after a disaster or crisis or in the event of an imminent event in the hours / days before is essential to minimize material and immaterial damage (business continuity and reputation). A crisis team is expected to:

- Decide on measures aimed at returning as quickly as possible to normal business operations;

- Ensure the strategic coordination of internal assistance, with the operational assistance from the in-house emergency response team (who may have already taken action) and if necessary external emergency services, such as the police and fire brigade, to assess the effects of the combat calamity or crisis.

- Maintain contacts at strategic level with stakeholders within the network of the institution: think of lenders, insurers or colleges in the area.

- Provides clear communication to employees, visitors, internal and external social workers and to the media;

- Order the business process after the calamity or crisis has ended to resume, to repair the material and non-material damage and to have an evaluation carried out perform on one's own functioning

The composition of a crisis team depends on the size of the institution. It is good to include employees from various disciplines / departments. After all, it is important that there is broad support within the institution. Moreover, expertise in various fields is often required. In most cases, someone from the board of the institution will also be part of the crisis team. It is recommended that at least the following departments are represented in the crisis team: Monitoring, security and safety (BHV); Facility, building management; and Publicity / press information.

Through a clear division of roles, the members of the crisis team know from each other who has which responsibilities and tasks. Every team member must be sufficiently trained and trained and must have been trained to fulfill his/her role(s). And members must be firm, that is to say, limit themselves to their own role or roles. Table 3 provides a clarification of the different roles in a crists team. 
Table B-5. Example of a division of tasks in a crisis team

\begin{tabular}{|c|c|}
\hline Role & Main task \\
\hline Crisis manager & $\begin{array}{l}\text { Chairs the crisis team; Coordinates the crisis management; Takes the } \\
\text { decisions. }\end{array}$ \\
\hline Secretary & Supports the crisis manager; Takes the notes; Time management \\
\hline $\begin{array}{l}\text { Communication } \\
\text { professional }\end{array}$ & $\begin{array}{l}\text { Advises about external and internal communication; Provides } \\
\text { information about media reputation }\end{array}$ \\
\hline $\begin{array}{l}\text { Information } \\
\text { coordinator }\end{array}$ & $\begin{array}{l}\text { Coordinates the internal and external information lines; maintains } \\
\text { contacts with the liaison officer (in case appointed) }\end{array}$ \\
\hline Content expert(s) & Advises are given about personnel, finance, facilities, safety and security. \\
\hline Liaison & $\begin{array}{l}\text { Represents institution in external crisis consultation; maintains contacts } \\
\text { with }\end{array}$ \\
\hline
\end{tabular}

\section{Situation report}

To keep an overview of the developments, the secretary of the crisis team can prepare a situation report, also known as a "sitrap". This is a "growth document" in which progress is always processed. By updating the sitrap for each crisis team consultation and giving the new information a different color, the team can follow the progress of the disaster or crisis.

\section{Crisis communication}

Communication is crucial during a disaster or crisis idea. There are two types of communication flows:

- Operational communication: How does the crisis team communicate with each other and with internal and external emergency services? During an emergency or crisis, the crisis manager, who is also chairman of the crisis team, has contact with the heads of the operational security services, BHV. The information coordinator and security maintain contact with external emergency services. If a COPI (Command Operation Place Incident) is set up in the event of a large-scale crisis, the institution may be asked to appoint a contact person. This "liaison" represents the institution in the COPI. The liaison maintains contact with the information coordinator.

- Communication to media and press: who informs the media and keeps up with the news on radio and TV, in newspapers and social media? This is about informing the media, adjusting the public perception of the disaster or crisis and limiting reputation damage. That is why it is important for the department to inform communication quickly in the event of an (imminent) calamity or crisis. The reporting to the media is coordinated in the crisis team (see the role of the communication advisor).

\section{Network: internal and external}

During a calamity or crisis, the crisis team deals with all kinds of internal and external parties. They belong to the integral safety plan, with the names and telephone numbers of contact persons, the overview of the agreements, the date of the agreements, responsibilities and liability, and the response time of the relevant authority.

\section{The Post-phase of a crisis: the aftercare}

As soon as the situation permits, the crisis organization is scaled down. This can be done gradually or in one go. The crisis manager decides for this, after consultation with the other members of the crisis team. Then the aftercare phase starts. This includes:

- Preparation for full scaling to the normal phase;

- Return to the normal phase;

- Determine the damage caused by the crisis; 
- Work on limiting or restoring the effects of the crisis (for example, providing aftercare to victims and those directly involved, commemorating);

- Communication about the crisis that has taken place.

- Evaluation An evaluation will take place as soon as the normal phase has returned. The evaluation has two goals: Prepare a report with accountability for the actions of the crisis organization, the decisions taken and how effective they have been for managing the crisis situation; Reflecting on the experience and lessons learned to improve the design and working methods of the crisis organization.

\section{B-A1.11 Boin, A. and Hart, Paul ' $t$ (2010) Organising for effective emergency management: Lessons from research, Australia Journal of Public Management, Vol. 69 (4), pp. 357-371.}

Crisis management can be defined as the preparing for and responding to unscheduled, undesirable, urgent and threatening contingencies. Examples pandemics, infrastructure breakdowns, terrorist attacks and outbursts of mass violence. Such contingencies are of the low probability but very high impact kind before they happen, posting challenges of risk management and preparedness.

Public organizations tend to prepare for known and expected contingencies, but the administrative toolbox for routine disturbances has only limited use in the face of a major crisis. The centralization of authority and added layers of coordination often foreseen in crisis plans do not necessarily improve operational response capacity. Effective crisis management depends on principles and processes that assure flexibility and a smooth flow of information; formal structures play a facilitative role at best.

In-depth studies of individual cases and a range of small- $N$ case comparisons have enabled scholars to identify the probable features of effective crisis planning and preparation. These are:

- A generic all-hazards approach combined with a suite of specific contingency plans

The generic functions that every crisis response network will need to perform: warning; mobilization; registration; evacuation; sheltering; crisis medical care and after care; search and rescue; protection of property; and information dissemination. These generic functions should be planned for, staffed by trained officials, ready to use, and updated through periodic testing.

- High-level policy-makers must be trained to deal with crises and disasters. They must learn the regularities of crisis management: the political and organizational issues that will emerge, the faltering information flows, the complex dilemmas and the impossible choices, the tolls of stress and the search for scapegoats and 'lessons'. They must learn to use simple checklists that will improve their crisis performance: balance short and long-term effects of a decision; make sure you hear contrarian views; leave operational decisions to the professionals; stick with the political decisions that must be made - and make them; facilitate emerging coordination rather than imposing ready-made designs; engage with the media in a proactive manner.

- Frequent and rigorous crisis exercises and simulations make for better crisis management performance. Regular simulation exercises nurture awareness of crisis management complexities, hone decision-making skills, and allow members of the response network to get to know, understand and respect each other. Not having this is one of the principal causes of crisis response failures.

- Effective crisis preparedness includes the forging of relationships among response agencies, as well as with media representatives, external stakeholders, and a variety of experts. Once a crisis has occurred there is usually no time to look for the right people and interact with them on a basis of trust. Effective crisis response relies strongly on pre-existing cooperative networks built and maintained painstakingly during the preceding years. Strategic policy-makers should do everything to foster the growth of such networks. They should not tolerate the persistence of 
non-contact, silo mentalities and bureaucratic turf wars in interorganizational relations within the crisis management domain.

- Policy-makers must prepare more intensively for the post-crisis phase, which is glaringly overlooked in most conventional disaster exercises. They must have in place a system that facilitates the accountability process that will most likely follow any major crisis. They should at least consider the involvement of external bodies of expertise that can manage their own organizational learning process (these bodies can also be involved in the study of smaller scale incidents and near misses).

- Crisis management systems should be audited on a regular basis by independent experts. The critical examination by outsiders is an essential quality assurance system. It introduces accountability in a normally obscure area that only comes under scrutiny after disasters have occurred. Audits as well as lesson-drawing exercises based on comparative analysis of experiences in other jurisdictions force the crisis management fraternity to explain why the system looks the way it does, and to reflect on the strengths and weak- nesses of current arrangements. They generate new insights that can make the system more effective.

- System-wide crisis preparedness will not happen without the active, continuous involvement and visible commitment of political-administrative elites. They must nurture a culture of inquiry, in which everybody is invited to consider vulnerabilities and propose bet- ter ways of organizing a resilient system. Their words and deeds must signal that crisis management is a crucial activity - all the time!

\section{B-A1.12 Garcia, H.F. (2006) Effective leadership response to crisis, Strategy \& Leadership, Vol. 34 (1), pp. 4-10.}

Garcia concludes his article with a checklist for crisis response preparedness:

- Know how to mobilize energy and resources quickly by:

- Developing an early warning mechanism/rapid response capability.

- Designating a senior executive as responsible for crisis preparedness and response.

- Making this executive accountable and provide sufficient resources to conduct a thorough analysis of vulnerabilities, crisis response strategies, and crisis implementation.

- Pre-authorize this executive to take initial response steps without going through usual corporate approval processes.

- Test the system with war games, table top exercises, and other processes that challenge leaders to make tough decisions and act quickly:

- Remember that the best plan won't help if executives don't know what to do.

- Recognize when business as usual needs to be suspended.

- Control the agenda: don't let the media, adversaries, or the rumor mill define your situation.

- Keep in mind the Golden Hour of crisis response: incremental delays cause greaterthan-incremental harm to reputation.

- Develop messages and tactics with a goal in mind: how do you want your key stakeholders to think and feel, and what do you want them to know and do?

- In a crisis, assure both self-awareness and situational awareness:

- Coordinate all functions of the crisis response with frequent meetings/conference calls.

- Correct mistakes early.

- Understand what your stakeholders, adversaries, the media, and others are saying about you.

- Keep your focus on the goal: influencing stakeholders. Decisions become clear when you keep stakeholders in mind.

Garcia also describes four avoidable missteps in leadership in crisis management: 
- Ignore the problem: management seems unaware and is surprised by a crisis that others saw coming, or that they themselves were warned about but chose not to take seriously.

- Tell misleading half-truths: management tries to misdirect attention by speaking literally true statements with the intention of misleading, which challenges adversaries or whistleblowers to uncover the full story.

- Lie: management tells a deliberate untruth with the intention of deceiving.

- Assign blame to others: rather than taking meaningful steps to solve the problem, management tries to redirect attention away from itself and to someone else.

\section{B-A1.13 Sapriel, C. (2003) Effective crisis management: Tools and best practice for the new millennium, Journal of Communication Management, Vol. 7 (4), pp. 1-8.}

A crisis is, by definition, 'an event, revelation, allegation or set of circumstances which threatens the integrity, reputation, or survival of an individual or organization'. Statistics show that most business crises today originate mostly with management inaction and/or neglect.

Therefore, there is a growing recognition among corporations that crisis management must be institutionalized and that all key business functions must address crisis prevention and management formally as part of business planning and establish slid business continuity plans (BCP). To be effective, crisis management must be embedded into the organization's corporate management system. The organization should be prepared to respond to new and unimagined risks as well as to manage the ever-growing number and diversity of stakeholders, many of whom have conflicting agendas.

With respect to leadership Sapriel states:

- In a crisis, 'leaders serve as a repository for people's fears. Leaders can also act as a mirror reflecting a group's anger, grief, resolve or joy on a much larger stage than is available to most. Leaders say in effect "I hear you".

- Managing a crisis by consensus does not work. Short time, threat and the surprise elements of most crises imply that tough decisions need to be made and made quickly. The crisis management team must command and control and not get lost in endless debates to make decisions.

- Regular crisis leadership workshops need to be organized to train crisis leaders and their Crisis Management Team (CMT) to be better prepared to lead under stress, and manage the situation proactively and strategically. During such workshops, executives are invited to experience the difference between consensus-based and command and control styles of management by working through scenarios. To enhance their strategic planning and proactive crisis management skills, CMT members are taught to work with stakeholder and issues/risk-mapping processes.

- Crisis leadersmust assign scenario planners on their team whose sole responsibility it is to generate scenario permutation based on the events and potential stakeholder reactions. This facilitates the decision-making process, helps prevent knee-jerk reactions and generally promotes proactive and strategic management. This reinforces the notion that an CMT should be made according to suitability and not mere functionality

- It is vital not to lose sight of stakeholder perceptions, and work with a solid communication strategy based on corporate values and principles, which are best captured in a crisis mission statement. This mission statement, which the CMT should formulate at the onset of the crisis, provides the organization with a guiding strength, a focus and a vision of the aftermath of the crisis. 
- Communicating with stakeholders is only half of the equation. Listening to them and their concerns is essential to ensure that the organization's internal operational view of the way the crisis is being managed is as close as possible to the external perceptual one of stakeholders.

\section{B-A1.14. European Confederation of Institutes of Internal Auditing, Risk in Focus 2020, Hot topics for internal auditors, https://www.eciia.eu/wp- content/uploads/2019/09/Risk-in-Focus.pdf 68 pp.}

This report is an annual barometer of what Chief Internal Auditors (CAEs) perceive as their organizations' highest risks and what is preoccupying their thinking as they prepare their forthcoming audit plans. The report is based on a quantitative survey among CAEs and with 528 full responses. In addition it draws upon qualitative interviews with 46 CAEs in Belgium, France, Germany, The Netherlands, Italy, Spain, Sweden the UK and Ireland who are working in a range of industries.

An important observation that is made in this report, concerns the fact that the identified risks do not exist in a vacuum, but overlap and impact upon each other. As figure 2 shows, Cyber and data security has firmly established itself as a top-of-mind issue for the majority of audit executives. The survey findings also show the way in which CAEs anticipate the risk profiles of their organizations developing over time. For the most part, there is a consistency between what are considered the top five risks today and what the priority risks are expected to be five years from now.

However, there are two notable outliers, both of which have a differential rate of more than ten percentage points. The first of these is 'Environment and climate change', which $14 \%$ of CAEs said is currently a priority risk their organization faces; this surges to $28 \%$ of CAEs who anticipate this being a top five risk by 2025 . This clearly demonstrates the rising prominence of this issue and suggests that internal audit should now be preparing itself to deliver relevant assurance on the risks and opportunities related to climate change. Secondly, 'Digitalization, disruptive technology and other innovation' is today a top five risk in the eyes of $58 \%$ of CAEs, rising to $75 \%$ who foresee it being a priority risk in five years' time. This would put digitalization on a roughly even footing with 'Cybersecurity and data security' (76\%) by 2025.

Although already a well-established item on board agendas and in the minds of senior executives, there is no room for complacency in managing and mitigating cybersecurity/information security risk. For organizations there is a need to remain diligent because:

1. the methods by which actors attempt to breach their targets are constantly evolving and increasing in sophistication, and;

2. organizations are not fixed or static entities: IT infrastructure migrates to the cloud and Internet of Things (IOT) and other digital capabilities are developed and expanded. 


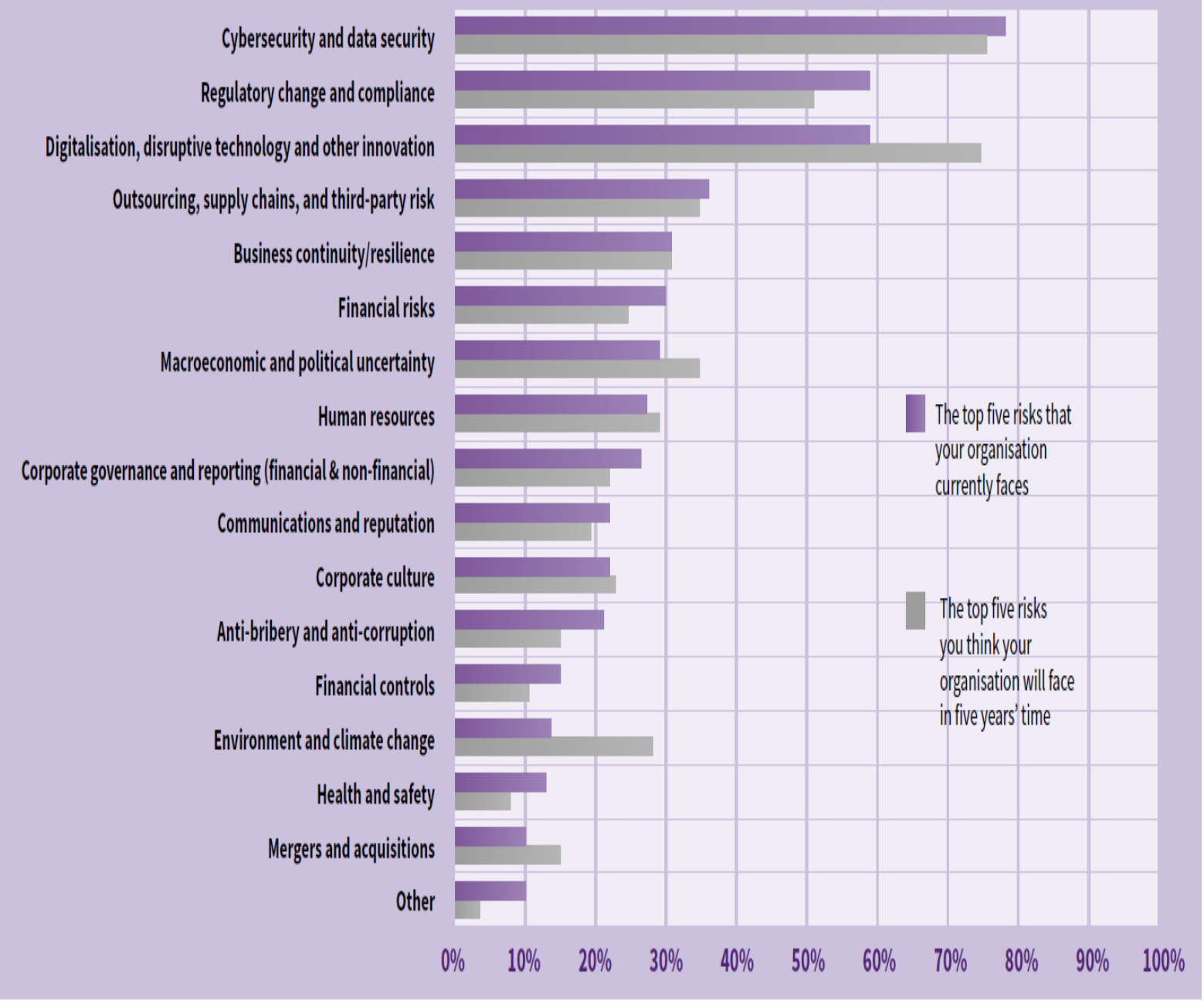

Figure B-3. The top five risks that according to CAEs organizations currently face versus the anticipated top five risks in five years' time

B-A1.15. García Herreo, S., Mariscal Saldaña, M.A., Manzanedo del Campo, M.A. \& Ritzel, D.O. (2002) From the traditional concept of safety management to safety integrated with quality, Journal of Safety Research, Vol 33, pp 1-20.

According to the authors, traditional Safety management programs do not always improve the results of safety because they are centered exclusively on the technical requirements and obtaining short term results. Another shortcoming of traditional safety management is that it is isolated and many times not integrated with the rest of the functions of an organization. The authors therefor recommend a "Total Safety Management approach" comparable to the existing "Total Quality Management approach". Ideally, the two approaches should be integrated in an organization.

B-A1.16. Stafford, D. \& Rittereiser, S. (2007) Community policing, crime prevention and comprehensive trainings programs: Key ingredients to reducing risk in campus public safety, In: Stetson College of Law, proceedings of the $28^{\text {th }}$ Annual National Conference on Law and Higher Education, February 17-21, 2007. 
Campus Security and Public Safety in the USA has seen an evolution that has brought about significant changes to the sector during the past thirty years. Campus public safety and police departments have had to focus on significant issues like violence related to war protests and an antiestablishment philosophy; an increase in the use of drugs like marijuana, cocaine and heroin by students; the continued challenges of alcohol abuse; sexual abuse and domestic violence between students, gang activity on and around the campuses; terrorism concerns; identity theft affecting students and employees; an increase in internal theft and fraud; and the increasing theft of high priced equipment from campus facilities.

Nowadays community policing on campuses in the USA means that members of the public safety department become involved in student orientation programs, work with housing and student affairs representatives to provide educational opportunities to improve safety for students, and building relationships with members of the campus community. It means analyzing campus crime trends and reported information, and subsequently, designing patrol strategies and activities to target those particular areas of concern. It may include meeting with a student disciplinary team to address particular behaviors before they become actual criminal activities. But most of all, it means that the public safety department and its officers are viewed as an integral part of the campus community. Through consistent visibility and being included as an active participant of campus problem solving team, the department and campus community develops trust and reliance upon one another.

An effective crime prevention program will increase positive officer contacts with the community, leading to more timely reports, increased solvability in cases, and show a commitment by the institution to protecting people and property. The Board of Directors of the International Association of Campus Law Enforcement Administrators (IACLEA), defined minimum levels of crime prevention programming, including:

- A rape awareness and education program, developed and offered to members of the campus community. Special emphasis should be placed upon student residents, student athletes and fraternity and sorority members as it relates to acquaintance or date rape.

- A crime prevention orientation program presented to all new faculty and staff as they become members of the institutional community. Program content should include issues related to personal security topics as well as those that relate directly to the institution such as access control, care and use of institutional equipment, and the security policies and procedures.

- All new students, new faculty and staff should be exposed to a campus security and personal safety- oriented program.

- Specialized crime prevention programs should be developed for presentation to various specialized campus constituencies. Among these groups are the following: commuter students, international students, students with disabilities, physical plant or maintenance staff, student residents, fraternity and sorority members, athletes, etc.

- The institution should employ both printed and electronic media to convey crime prevention and security information to the campus community. If the campus makes extensive use of electronic mail or bulletin boards, such facilities should be made available for this purpose.

- One or more effective methods should be developed for distributing warning notifications to members of the campus community regarding serious crime or security incidents. Such warnings or notifications should be published in a timely manner and in a way that permits access to the information by a significant percentage of the students, faculty and staff.

In 2006 IACLEA announced its accreditation program to campus public safety agencies, both sworn and non-sworn. IACLEA's approach to provide standards for all of campus public safety is unprecedented. The fact that standards have been adopted by IACLEA for the accreditation program also means that these standards are likely to be used as a benchmark. Even if campus departments do not seek to become accredited, they need to understand that for the first time ever, there are 
standards that have been adopted by IACLEA as best practices, and failure to meet those standards could cause liability problems in the future.

\section{B-A1.17 Ministerie van Binnenlandse Zaken en Koninkrijksrelaties, Algemene Inlichten- en Veiligheidsdienst, Kwetsbaarheidsanalyse spionage, Spionagerisico's en de nationale veiligheid (2010), \\ https://www.aivd.nl/documenten/publicaties/2010/04/01/kwetsbaarheidsanalyse- spionage, 56 pp.}

The Ministry of the Interior and Kingdom Relations (BZK) notes that economic, strategic and technical-scientific espionage is a current threat to Dutch national security. To get a better picture of this threat and to make recommendations on how to (further) reduce this threat, the General Intelligence and Security Service (AIVD) and the Directorate-General for Security (DGV) jointly investigated espionage risks in the field of economic well-being and scientific potential and of public administration and vital infrastructure. In its counterintelligence investigations, the AIVD observes that various sectors of foreign intelligence services are active in secretly gathering intelligence in sectors within these areas of attention.

This study shows that knowledge acquainted in The Netherlands, by foreign intelligence services or foreign governments, which potentially affects the Dutch national security, can be found in all sectors studied. These type of knowledge acquisitions can be roughly divided into the following categories:

- Data sets and blueprints: this concerns data files, designs and building plans present in organizations;

- Positions and strategy: for example policy positions, long-term visions and negotiation strategies;

- Emerging core interests and infrastructure: for example, scientific innovations that can make important contributions to the Dutch economy in concrete applications in the future.

Foreign intelligence services and governments try to obtain relevant information through people who have (indirect) access to this information or through the use of technical means such as hacking, tapping or eavesdropping. The different options for intercepting telecommunications traffic are important in this context. This research also shows that the increasing interdependence and complexity of computer systems as well as the linking of data storage systems makes sensitive data in systems vulnerable. The outsourcing of activities such as system and server management, data warehousing and data processing also entails espionage risks.

This research also shows that the promotion of knowledge migration to and from the Netherlands has the undesirable side-effect of intelligence officers who can hide relatively easily in the student population. Preventing such types of undesired intelligence activities requires that those at risk of being spied on are aware of the fact that they may be of interest to foreign services and that they also know how intelligence activities are carried out. The research shows that awareness of espionage in the sectors concerned is often low. The limited consciousness becomes visible on three levels:

- Value awareness: organizations and individual employees sometimes do not realize, or do not realize enough, the value of the information that they have or to which they can provide access;

- Security awareness: security and safety of core interests do not always receive sufficient attention within organizations; other considerations often get a higher priority;

- Weighing of interests: interests of the organization and/or government interests in the short term (often) prevail over the interests in the long term. Insufficient attention is being paid to the risk of leaking abroad strategic knowledge or activities that are relevant to Dutch national security in the long term. 
Three main recommendations are made for (further) reinforcement of the resilience to espionage in organizations:

- Actively strengthen the awareness (among managers and employees) of governments, companies and knowledge institutions with regard to the value of the information they have and the potential interest of foreign authorities in this information.

- Work on a culture change in the field of security. Users, the organization of data flows and databases and the techniques used for the detection of incidents are important points of attention.

- Pay particular attention to the protection of core interests and the effects of policy on the interests of the Dutch national security, also in a longer time perspective.

Based on chapters $3-7$ of the AIVD report, a summary has been made in table 4 of knowledge areas possessed at the University of Twente, that might be of potential interest for foreign intelligence services or foreign governments. Consequently, these need special attention. 
Table B-6. Knowledge areas possessed by University of Twente with high potential interest for foreign intelligence services or foreign governments.

\begin{tabular}{|c|c|}
\hline Pending patents & $\begin{array}{l}\text { Knowledge about patent applications provides insight into the direction in } \\
\text { which research by other countries / companies takes place. Although } \\
\text { patent information finally becomes public, the application takes } 18 \\
\text { months. This period provides an opportunity to adjust own R\&D, for } \\
\text { example, a year and a half earlier, based on the knowledge gained. That } \\
\text { makes espionage in this area profitable. }\end{array}$ \\
\hline Optical sciences & $\begin{array}{l}\text { Knowledge about optics is important for areas such as chip manufacturing } \\
\text { and advanced observation equipment. The latter development area can be } \\
\text { important at a strategic-military level. High-quality chip manufacturing } \\
\text { encompasses both economic and strategic-military interests, whereby the } \\
\text { economic interests are probably greater than the direct strategic-military } \\
\text { interests. } \\
\text { These economic and strategic-military applications explain the perceived } \\
\text { interest of foreign intelligence services in research in the field of high-end } \\
\text { optics and its fields of application. Half of all integrated circuits (ICs, chips) } \\
\text { in the world are made with Dutch photonics techniques. }\end{array}$ \\
\hline $\begin{array}{l}\text { High Tech Systems: } \\
\text { mechatronics and } \\
\text { robotics }\end{array}$ & $\begin{array}{l}\text { Mechatronics and robotics are considered the heart of motion \& control } \\
\text { systems and are important in almost all high-tech systems. The } \\
\text { Netherlands has a leading position in autonomous medical robotics and } \\
\text { mechatronics, and the customized application of robot technology. The } \\
\text { number granted patents for mechatronics in the Netherlands is far above } \\
\text { the European average and also that of the US. Various international top } \\
\text { players in the field of High Tech Systems work in the Netherlands. }\end{array}$ \\
\hline Radar technology & $\begin{array}{l}\text { Radar technology can have a great value for foreign intelligence services. } \\
\text { Radar technology has military applications as well as civilian applications. } \\
\text { From the point of view of national security, leakage of such knowledge } \\
\text { could therefore threaten both the economic well-being and the territorial } \\
\text { integrity of the Netherlands. }\end{array}$ \\
\hline $\begin{array}{l}\text { Aerospace } \\
\text { technology }\end{array}$ & $\begin{array}{l}\text { Important knowledge areas in aerospace technology in The Netherlands } \\
\text { are knowledge about innovative materials, (civil) avionics (hardware and } \\
\text { software) and satellite technology. Knowledge about (the application of) } \\
\text { aerospace technology is of economic importance for the Dutch industry, } \\
\text { which contributes to the development and production of components for } \\
\text { aircraft and satellites. The leakage of knowledge can also lead to the } \\
\text { production of high-quality defense material in countries of concern. In } \\
\text { addition, parties can derive information from such knowledge about Dutch } \\
\text { / European defense material and its potential weaknesses. This directly } \\
\text { affects national security. }\end{array}$ \\
\hline $\begin{array}{l}\text { Water technology } \\
\text { and management }\end{array}$ & $\begin{array}{l}\text { The Netherlands possesses valuable knowledge in the field of hydraulic } \\
\text { engineering. In addition, it has a unique position in the dredging industry. } \\
\text { Such knowledge represents great value for large (infrastructure) projects, } \\
\text { certainly for emerging economies that (want to) implement many of such } \\
\text { projects. The economic damage to Dutch business that can be suffered by } \\
\text { theft of such knowledge is substantial. }\end{array}$ \\
\hline
\end{tabular}


Table B-6. Knowledge areas possessed by University of Twente with high potential interest for foreign intelligence services or foreign governments (continued)

\begin{tabular}{|c|c|}
\hline Innovative materials & $\begin{array}{l}\text { The Netherlands is at the forefront of the development of innovative } \\
\text { materials. Knowledge about, for example, lightweight composite materials } \\
\text { or self-repairing materials can not only be used for more regular } \\
\text { applications, but is also of great importance for applications with a clear } \\
\text { strategic-military character. }\end{array}$ \\
\hline Bio technology & $\begin{array}{l}\text { Biotechnology is an economically relevant research field that is still } \\
\text { emerging. The Netherlands is historically at the forefront together with } \\
\text { Japan. The implications of advanced biotechnology applications are still } \\
\text { great. Given the great economic potential and possible dual-use } \\
\text { applications of biotechnology, Dutch knowledge in this field is valuable for } \\
\text { other governments. }\end{array}$ \\
\hline Bio-based economy & $\begin{array}{l}\text { The bio-based economy is an emerging concept in which the use of } \\
\text { agricultural / organic products as a raw material for all kinds of materials } \\
\text { for non-food applications is central. This concerns new applications and } \\
\text { especially changes in scale. For countries such as China and India, for } \\
\text { example, the bio-based economy is of vital importance in the light of the } \\
\text { growing appetite for energy and food in these countries. Due to the } \\
\text { worldwide shift that is anticipated in this direction, and the enormous } \\
\text { (financial) implications of 'greening the economy', it is of economic } \\
\text { importance for the Netherlands to protect its knowledge position in this } \\
\text { area }\end{array}$ \\
\hline Life sciences & $\begin{array}{l}\text { Research in the field of life sciences is a valuable part of the Dutch } \\
\text { knowledge economy. For life sciences, just as for many other core interests } \\
\text { in this area of interest, if the knowledge flows out just before it becomes } \\
\text { economically profitable, investments are made without the benefits of } \\
\text { being able to reap the benefits. }\end{array}$ \\
\hline Nano technology & $\begin{array}{l}\text { Nanotechnology has applications in many applied scientific areas such as } \\
\text { cryptology, biology (bio-nanotechnology), physics (photonics, quantum } \\
\text { computing), (bio) chemistry and medical technology / pharmacy. A leading } \\
\text { position in the field of nanotechnology can eventually result in spin-off } \\
\text { companies and patents that represent an even greater economic interest. } \\
\text { A cluster of high-quality nanotechnology companies in the Netherlands } \\
\text { would represent a major economic interest. In the international } \\
\text { competition to become a "Center of Excellence" in the field of } \\
\text { nanotechnology, the loss of information to other parties can therefore } \\
\text { have major consequences for the future position of Dutch business. A } \\
\text { second important notion is that technology not only represents economic } \\
\text { value, but also that numerous (military) strategic applications are } \\
\text { conceivable, which countries will see as vital to their national security. }\end{array}$ \\
\hline
\end{tabular}


Table B-6. Knowledge areas possessed by University of Twente with high potential interest for foreign intelligence services or foreign governments (continued)

\begin{tabular}{|l|l|}
\hline $\begin{array}{l}\text { Technologies for oil } \\
\text { and gas extraction }\end{array}$ & $\begin{array}{l}\text { The Netherlands has a strong knowledge position in the field of oil and gas } \\
\text { extraction such as offshore technology. Due to the size and duration of } \\
\text { such projects, the economic impact of participation is large. For other } \\
\text { countries, knowledge about these techniques is attractive from both a } \\
\text { financial and strategic point of view. Technical knowledge about oil and } \\
\text { gas extraction is a target of intelligence services. Extra attention is paid to } \\
\text { such techniques of intelligence services by countries that are subject to } \\
\text { embargo regimes. The knowledge and know-how from the energy sector } \\
\text { these regimes can only acquire through espionage or other covert ways. }\end{array}$ \\
\hline $\begin{array}{l}\text { Technologies for } \\
\text { transport, storage } \\
\text { and processing of oil } \\
\text { and gas }\end{array}$ & $\begin{array}{l}\text { This concerns knowledge about processes, such as techniques for } \\
\text { processing, transporting and storing oil and gas products. Knowledge in } \\
\text { the field of liquefaction, the handling and transport of Liquid Natural Gas } \\
\text { (LNG) is also valuable. In the Dutch ambition to be an international hub for } \\
\text { the transit of energy (products), such technologies can be an important } \\
\text { asset. Leakage of this knowledge weakens the Dutch position in the } \\
\text { international competition for achieving such an economic center of } \\
\text { gravity. }\end{array}$ \\
\hline $\begin{array}{l}\text { Technologies for } \\
\text { alternative energy } \\
\text { generation and } \mathrm{CO}_{2} \\
\text { storage }\end{array}$ & $\begin{array}{l}\text { A great deal of knowledge is also available in the Netherlands in the field } \\
\text { of alternative energy generation. The Netherlands occupies a leading } \\
\text { position in the research and production of solar cell technology. High- } \\
\text { quality innovative solutions, such as flexible films with solar cells and } \\
\text { efficient wind energy generation, have their origins in the Netherlands. }\end{array}$ \\
\hline $\begin{array}{l}\text { Alternative energy } \\
\text { sources }\end{array}$ & $\begin{array}{l}\text { The Netherlands has high-quality technological knowledge about } \\
\text { renewables, alternative energy sources and systems to make energy } \\
\text { consumption more efficient and efficient. Foreign governments are also } \\
\text { interested in this knowledge. Little attention is currently being paid in the } \\
\text { Netherlands to maintaining this potentially valuable competitive } \\
\text { knowledge position. }\end{array}$ \\
\hline
\end{tabular}

\section{B-A1.18. AIVD Jaarverslag 2018}

https://www.aivd.nl/documenten/jaarverslagen/2019/04/02/jaarverslag-aivd201828 pp.

In the annual report of The General Intelligence and Security Service (AIVD) of the Netherlands, also attention is paid on espionage. The economic espionage is of particular interest for HEls (Higher Education Institutes). The AIVD reports e.g. on page 8 of their annual report:

"In the field of espionage, the year 2018 was mainly characterized by the brutality with which intelligence officers have shown themselves. The attempt by the Russian military intelligence service GROE to gain access to the OPCW network in The Hague shows how far this service goes."

And: "More and more countries are focusing on political and / or economic espionage. We see in our investigations that China, Iran and Russia are at the forefront of political and economic espionage."

On page 9 of their annual report specific attention is paid to economic espionage:

"By far the biggest threat in the field of economic espionage comes from China. This espionage is fueled by Chinese economic policy plans, such as "Made in China 2025" and the "New Silk Roads", with which the country can increase its economic and geopolitical influence.

These plans not only lead to economic opportunities, but also to increasing competition with 
Western and therefore also Dutch companies. China uses a wide range of (covert) resources to undermine the earning capacity of Dutch companies and which may eventually result in economic and political dependencies. One of these means is (digital) economic espionage.

China is interested in Dutch companies from the sectors: high-tech, energy, maritime and life sciences \& health. Theft of research findings also takes place within legitimate partnerships between academic and knowledge institutions. Dutch innovations thus disappear across the border.

The safety awareness and resilience of Dutch business and knowledge institutions against these risks do not seem sufficient. This poses a risk to the economic security of our country."

On page 9-10 of the annual report attention is paid to covert political influence.

According to the AIVD report, China and Russia are actively engaged in covert political influence.

The AIVD reports specifically about China:

"We also see that there are states, including China, that try to influence opinions and publications about their own country through educational and knowledge institutions. This may concern countries with which, for example, scientific cooperation is relatively fruitful. The only risk is that a dependency on the government in question arises, for example when investigations are funded by China or when research is conducted about developments in China and one therefore needs to travel to this country. This provides the possibility that a country can sometimes abuse its dominant position. Journalists also face opposition in a similar way. In the case of unpleasant publications, for example, there may be a threat of withholding work permits."

\section{B-A1.19. Van Gelder, P. and Focke-Bakker, E., TU Delft, TBM/Dsys \& Delft Safety and Security Institute, Veiligheidsprofiel (VP 2019) TU Delft 2019, 22pp.}

The publication of an annual Safety Risk Profile (VP) TU Delft started in 2013. Two types of measurements are used in the VP 2019:

- An objective measurement with a Comparison Test, in which the number of incidents at TU Delft are, as far as possible, compared with other (national) sources;

- A subjective measurement with a Benchmark, in which respondent groups from TU Delft, the municipality and the Delft police and other Dutch higher education institutions were asked about their perception of risk by using the TU Delft risk list.

For the objective measurement, the safety incidents that were reported and registered in 2018 were used. The following sources were used:

- The incidents registered at the control room (iG4S)

- The reports made by Integral Safety for the Board of the University

- Incident reports made by CBS and the Police

- TNW reports about dangerous substances

- ICT/FM incident reports

- $\quad$ The Safety report 2018

- The annual report 2018 made by TU confidential counselor

- Radar; Power failures

- Start Global database and Wikipedia 2017

- National Risk profile made by RIVM

- The "Boasatlas van de veiligheid"

The threat by an unknown person with an object similar to a firearm, the loss of a TU student in Benin and the suicide of a TU student were the incidents with a very large impact in 2018.

Incidents with a (much) smaller impact that were registered include issues such as a relative high number of EHBO incidents, damage to traffic signs, lampposts and traffic lights, car accidents, vandalism, threats and heated arguments, network and wifi outage, power failures, heavy weather damages, leakages, elevator locks, small fires and false fire alarms. A relative high rise is noted with 
respect to undesirable behavior (intimidation), ICT spam and pollution. In cases of robbery, the thefts that are mostly reported is the theft of laptops.

The subjective measurement reports the 13 highest perceived risks. See table 5.

Table B-7. A subjective assessment of potential risks at TU Delft $(n=47)$.

\begin{tabular}{|c|c|c|c|c|}
\hline Risk category & Undesired incident & 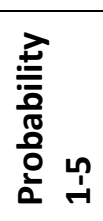 & 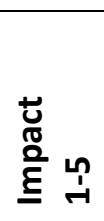 & 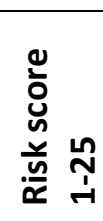 \\
\hline ICT & Cyber attack & 3 & 4 & 12 \\
\hline ICT & ICT failure & 3 & 4 & 12 \\
\hline Accident & A traffic accident & 4 & 3 & 12 \\
\hline $\mathrm{ICT}$ & Infected/ compromised system & 3 & 3 & 9 \\
\hline Integrity & Unacceptable behavior & 3 & 3 & 9 \\
\hline Off campus & Incident at a student club & 3 & 3 & 9 \\
\hline Power failure & Power failure & 3 & 3 & 9 \\
\hline Fire & Big fire & 1 & 5 & 5 \\
\hline Lab unsafety & Robbery of nuclear material & 1 & 5 & 5 \\
\hline Reporting system & No safe fled in case of a calamity & 1 & 5 & 5 \\
\hline Undesired behavior & Radicalization & 1 & 5 & 5 \\
\hline Undesired behavior & Terrorist action & 1 & 5 & 5 \\
\hline
\end{tabular}

\section{B-A1.19. Universiteit Utrecht (31 januari 2020) Integrale Veiligheid, een Overzicht, Centraal Integraal Risicomanagement (CIRM), 11 pp.}

This document provides an outline of the method by which risks are managed at Utrecht University (UU). UU has formulated a minimum standard for Integral Safety Management. This standard describes the basic principles, the organization and the way how safety risks will be identified, analyzed, mitigated and evaluated. The management system for Integral Safety follows a "Plan-docheck-act" approach. UU defined 11 pillars for Integral Risk management (Integral Safety; Buildings and BHV; Social safety; Alarming behavior and radicalization; Internationalization; Integrity; Arbo and environment; Knowledge safety; Privacy and Cyber security; Image and reputation management; Crisis management.

For the risk management process a number of risk management tools are used. These are:

- Determining the Risk appetite

- Apply the ALARP (As Low A Reasonable and Practical) principle

- Classify the risks by plotting the risks into a risk matrix

- Mitigate identified risks by using the BowTie model

- Register and analyze the incidents

- Monitor the identified risks and the effectiveness of the mitigating actions 
APPENDIX 2:

A SUMMARY OF THE CONSULTATIONS WITH EXTERNAL EXPERTS ON SAFETY AND SECURITY

\section{B-A.2.1. Consultation with Linda Krom, Director Security at TNO on 19th December 2019}

\section{Internationalization}

Because of her strong position in the Defense industry, TNO takes special security precautions when employees visit or want to collaborate with countries that have been labeled by the Ministry of Defense as high-risk countries. TNO employees are briefed in advance before an international trip to a high-risk countries takes place. When traveling to countries that are registered as "unsafe", employees need to make use of an empty "TNO loan laptop". This Laptop will be destroyed after an employee's return to The Netherlands.

In a similar way security precautions are taken when people from high-risk countries visit TNO. The whole process takes place in close consultation with the Ministry of Defense. All visitors from highrisk countries are required to register in advance. Since it is a TNO policy to protect its "Crown Jewels", foreign visitors are also not allowed to visit specific locations at TNO. This sensitive information concerns innovations, patents and other types of sensitive knowledge possessed by TNO. To this end, information is classified in "Public" and "Non-public". Since 2014, no more business has been done with Russia. Also for Iran, Turkey, China, and Saudi Arabia, the topics are carefully considered: where to place or not to place a "red flag". Israel is also seen as a "risk country". In the meantime, espionage policy with regard to high-risk countries such as China, Iran and Russia has been scaled up to the EU level. A complicating factor is the fact that thirty percent of TNO employees come from abroad. This creates an increased risk of potential espionage related activities.

The increasing migration flow to the Netherlands of students from countries such as China and Iran is estimated by TNO to be one of the greatest risks for universities. Many Chinese students study in The Netherlands with scholarships awarded by China. These students are considered a potential source of espionage. In the report "Picking flowers making honey; the Chinese military's collaboration with foreign universities", TU Delft is even listed among the TOP 10 of universities outside of China for PLA (People's Liberation Army of China) collaboration. Inherent in Chinese culture, students must unconditionally contribute to requests from the Chinese State. Chinese counselors are in direct contact with students from China. We will have to take actions how this "vacuum cleaner effect" (the retrieval of much relevant information by Chinese students) can be eliminated.

As far as Russia is concerned, the goal of the Russian State for many decades has been not only to detect relevant information, but also to influence the domestic climate in the Netherlands (and in other foreign countries) in favor of Russia. This policy has intensified with the increasing digitization. Iran does both: through cyber-espionage, information that might be relevant to Iran is detected and collected, and through deploying Iranian students additional relevant information is collected.

\section{Organization:}

TNO has become increasingly strict in the past few years when it comes to matters related to safety and security. It is important to be compliant with current regulations in the Netherlands, the EU, but also the USA (given the working relationships of TNO in the USA). As far as the USA is concerned, it is 
important to meet the requirements set in regulations such as the ITAR compliance (International Traffic in Arms Regulations), OFAC (Office of Foreign Assets Control with the sanctions list) and US Customs. In view of the importance of TNO's defense branch in the Netherlands, TNO must also comply with ABDO regulations (General Security for Defense Missions regulations). See also:

https://www.defensie.nl/onderwerpen/militaire-inlichtingen-en-veiligheid/downloads/beleidsnotas/2020/02/04/abdo-2019

With regard to cyber security in the organization, next to the use of laptop, also the mobile phone can be considered as a potential source for hackers. Employees must be made aware of the potential risks associated with using their mobile phone and how to deal with it. It is important e.g., both for laptops and mobile phones to install software updates in time.

\section{Selection and hiring of employees}

When selecting or hiring staff, TNO as a standard always asks for a certificate of good conduct (VOG). This statement shows whether or not a person's past is a risk for performing a specific function or task. A VOG is issued if no offense has been committed in the past that is important for the position. Screening is also applied for all integrity-sensitive positions such as managers, employees who handle money and goods, and employees who have access to sensitive information, or vital infrastructure (energy, IT, water safety). TNO also requests a declaration of no objection (VGB). This screening is standard for persons in the government or in the business world who are going to perform a function that may harm the national security or other important interests of the State. To this end, a screening is conducted by the General Intelligence and Security Service (AIVD) and the Military Intelligence and Security Service (MIVD). These services carry out a so-called safety investigation. Criteria are honesty, independence, loyalty and integrity. If the result is positive, the employee will receive a Declaration of No Objection (VGB).

\section{Burn-out}

Burn-out is a serious problem at TNO (see also: https://www.mt.nl/worklife/vitaal-leiderschap/zozet-tno-eigen-kennis-in-om-burn-out-en-ziekteverzuim-aan-To tackle / 578190 ) TNO therefore offers its staff a variety of options to prevent burnout. These include:

- A "Fit for your future" vitality program developed by TNO

- The consultation of a physiotherapist

- The free use gyms

- Personal councilors

- The deployment of "ambassadors" who speak about this.

\section{Future developments}

There is an increasing trend towards further digitization. Innovative IT options such as using the cloud and the Internet of Things offer, in addition to new options, increases the chance of unforeseen, complex security risks. Cybercrime is becoming a more common issue. In this context, a system of $24 / 7$ security monitoring is of great importance. This is to anticipate new vulnerabilities and better intercept possible cyber attacks 


\section{B-A.2.2. Consultation at Thales with Ronald Brinkman (Tactical Information Security Officer) and with Henk Schutte (Director Security) on 22 November 2019}

Thales Nederland is specialized in the development, production and integration of complex high-tech systems for the defense, transport and security industries. Examples of high-tech systems include equipment such as radar, command \& control, communication systems and cyber security but also a product such as the public transport chip card used by National Roadways (NS) in The Netherlands.

Thales works in the defense industry. A requirement within this industry branch is that an organization must realize a high maturity level of cyber security (CMMC level: Cyber security Maturity Model Certification), see also Table 8 . With a high maturity level an organization can demonstrate how well it prepared and organized to prevent for possible cybercrime actions to occur.

Table B-8 CMMD (Cybersecurity Maturity Model Certification) maturity levels

\begin{tabular}{|c|c|c|}
\hline Level & Description of Practices & Description of processes \\
\hline Level 1 & $\begin{array}{ll}\text { - } & \text { Basic cyber security } \\
\text { - } & \text { Achievable for small companies } \\
\text { - } & \text { Subset of universally accepted common practices } \\
\text { - } & \text { Limited resistance against data exfiltration } \\
\text { - } & \text { Limited resilience against malicious actions }\end{array}$ & $\begin{array}{l}\text { - } \quad \text { Practices are performed at } \\
\text { least in an ad-hoc way }\end{array}$ \\
\hline Level 2 & $\begin{array}{ll}\text { - } & \text { Inclusive of universally accepted cyber security best } \\
\text { - } & \text { Resilient against unskilled threat actors } \\
\text { - } & \text { Minor resistance against data exfiltration } \\
\text { - } & \text { Minor resilience against malicious actions } \\
\end{array}$ & - $\quad$ Practices are documented \\
\hline Level 3 & $\begin{array}{l}\text { - } \text { Coverage of all NIST SP } 800-171 \text { rev } 1 \text { controls } \\
\text { - } \quad \text { Additional practices beyond the scope of CUI } \\
\text { - } \quad \text { Resilient against moderately skilled threat actors } \\
\text { - } \quad \text { Moderate resistance against data exfiltration } \\
\text { - } \quad \text { Moderate resilience against malicious actions } \\
\text { - } \quad \text { Comprehensive knowledge of cyber assets }\end{array}$ & $\begin{array}{l}\text { - Processes are maintained and } \\
\text { followed }\end{array}$ \\
\hline Level 4 & 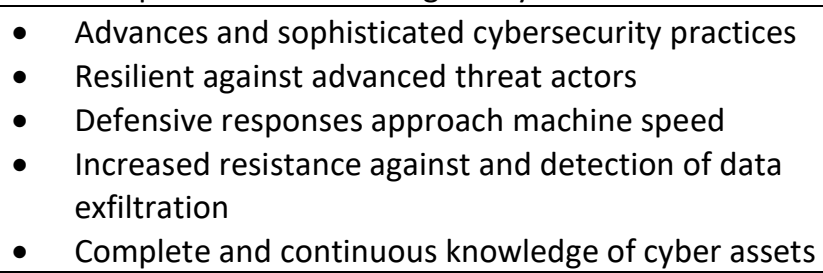 & $\begin{array}{l}\text { - Processes are periodically } \\
\text { reviewed, properly } \\
\text { resourced, and improved } \\
\text { across the enterprise }\end{array}$ \\
\hline Level 5 & $\begin{array}{ll}\text { - } & \text { Highly advances cybersecurity practices } \\
\text { - } & \text { Reserved for the most critical systems } \\
\text { - } & \text { Resilient against the most-advanced threat actors } \\
\text { - } & \text { Defensive responses performed at machine speed } \\
\text { - } & \text { Machine performed analytics and defensive actions } \\
\text { - } & \text { Resistance against and detection of data exfiltration } \\
\text { - } & \text { Autonomous knowledge of cyber assets }\end{array}$ & $\begin{array}{l}\text { - Continuous improvement } \\
\text { across the enterprise }\end{array}$ \\
\hline
\end{tabular}

It is important for an organization such as Thales to be proactive in detecting potential deviant behavior: "Intelligence driven security". Thales has built up expertise in the field of pattern recognition. Pattern recognition takes place with the help of models. This helps to recognize and predict abnormal behavior. In addition to pattern recognition within their own organization, Thales 
also provides consultancy services in this area to third parties. For example, Thales has trained attendants at the "Nachtwacht" of the Rijksmuseum to detect abnormal behavior of visitors.

\section{Promoting Safety \& Security awareness at Thales}

To promote security awareness at Thales, the organization schedules, on a monthly basis, a new security theme. In addition, Thales applies a"10 golden rules" protocol (a few of these rules are: employees always their employee card visibly; clear rules about the use of a mobile phone; and what to do in case your password has been hacked).

Thales, called in the consultancy firm "Awareways" (see also: https://www.awareways.com/) to perform a first baseline measurement to map the existing level of security awareness. Partly based on this baseline measurement, Awareways subsequently set up a communication campaign for Thales and deployed it to raise the awareness of cybrrisks within Thales.

According to the Awareways website, psychology, communication and didactics form the basis of their approach to achieve important behavioral changes in individuals. This approach is aimed at detecting vulnerabilities, offering possible solutions to these vulnerabilities and rewarding safer behavior. With the help of experts in the field of psychology, communication, didactics and information security, Awareways aims to raise awareness in the field of safety and security. Awareways has a number of "products" to realize this aim:

- A baseline measurement to chart the level of awareness in the field of safety and security

- A communication campaign to raise awareness

- A security awareness engine

- E-learning security programs

- A phishing simulation

- An "Awareways escape room"

- Interactive sessions.

\section{The impact of Hacking}

Being hacked can seriously harm the continuity of any organization. Four examples of organizations that have been severely damaged by a serious form of hacking are:

- In November 2016, the Australian Signals Directorate (ASD) was alerted by a "partner organization" that an attacker had gained access to the network of a 50-person aerospace engineering firm that subcontracts to the Department of Defense. Restricted technical information on the F-35 Joint Strike Fighter, the P-8 Poseidon maritime patrol aircraft, the C-130 transport aircraft, the Joint Direct Attack Munition (JDAM) smart bomb kit, and "a few Australian naval vessels" was among the sensitive data stolen from a small Australian defense contractor. Around $30 \mathrm{~GB}$ of ITAR-restricted aerospace and commercial data was exfiltrated by an unknown malicious actor during the months-long 'Alf's Mystery Happy Fun Time' attack.

- NonPetya ransomware forced Maersk, a Danish container ship and supply vessel operator to reinstall 4000 servers and 45000 of their PCs. The whole resulted in a loss of 300 million dollars.

- A former National Security Agency contractor was sentenced in 2019 in the USA to nine years in prison for stealing huge amounts of classified material from U.S. intelligence agencies such as NSA, CIA, U.S. Cyber Command and national Reconnaissance Office over two decades. It is generally considered to be the biggest breach of U.S. classified information. on record, Martin was accused of stealing from the NSA, CIA, U.S. Cyber Command and National Reconnaissance Office.

- In 2018 China used a tiny chip, installed on computer motherboards to infiltrate U.S. companies, including companies such as Amazon and Apple. With the help of this secret chip it became possible for China to gain access to the network of organizations that used the motherboards 
supplied. Delivery of these motherboards has taken place to organizations such as the $\mathrm{ClA}$, the DoD and warships of the USA

\section{Leaks of confidential information due to employees}

Thales pointed out that the loss of confidential information may also be caused by the company's own employees (see also Figure 4). The source can be either a permanent or a temporary employee:

- 74 percent of the organizations report feeling vulnerable to data breaches by internal employees

- 60 percent of the organizations report having been confronted with attempts by their own employees to steal sensitive data.

- In 2016, the cost of theft of sensitive information by employees of the organization was 1.2 million dollars, excluding reputation damage.

- In 2002 the Computing Center of the University of Twente was hit in 2002 by a fire that was deliberately ignited by a UT employee. The damage amounted to more than 50 million euros.

Gates

\begin{tabular}{|c|}
\hline Human \\
\hline Physical \\
\hline Tech/Cyber \\
\hline Operations \\
\hline
\end{tabular}

Mechanism

\begin{tabular}{|c|}
\hline Subversion \\
\hline Sedition \\
\hline Sabotage \\
\hline Espionage \\
\hline (org.) crime \\
\hline Cyber \\
\hline Activism \\
\hline Extremism \\
\hline Terrorism \\
\hline
\end{tabular}

Threat Agents

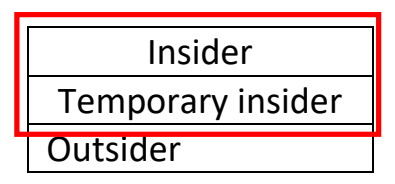

Threat Actors

\begin{tabular}{|c|}
\hline Nation State Actors \\
\hline Organizations \\
\hline Competitors \\
\hline Suppliers \\
\hline Individuals \\
\hline
\end{tabular}

Figure B-4. Security threats in the defense industry (Thales, 2019)

Thales also advised to seriously consider also how to prevent a potential threat of loss of confidential information due to criminal actions by employees. Research shows that:

- 80 percent of the internal perpetrators, prior to committing their crime, already show deviant behavior;

- Prior to committing their crime, 58 percent of the perpetrators spoke negatively about their own organization, and expressed the intention of damaging the organization or an employee within the organization;

- In 31 percent of the cases, other people were aware of the evil intentions the perpetrator. This concerned 64 percent of his colleagues, 21 percent of his friends and 14 percent of family members. 


\section{B-A.2.3. Consultation at TU Delft with met Ron Massink, Manager Integral Safety TU Delft and with Paul Hillman, Director CIO \& Facilities at TU Delft, 9 January 2020.}

There are countless examples to give about unsafe situations at a university. Consider, for example: The security of the nuclear reactor on the TU Delft campus, a serious phishing attack by a hacker group, theft of laptops, unsafe working conditions, unsafe car and bicycle traffic. When considering possible actions that can be made with respect to Safety and Security, TU Delft makes a distinction between Preventive, Repressive and Innovative actions (see Table 1)

Table B-9: Repressive, Preventive and Innovative actions with respect to Safety en Security

\begin{tabular}{|c|c|c|c|}
\hline $\begin{array}{l}\text { Action } \\
\text { (not limitative) }\end{array}$ & Safety & Security & Cyber Security \\
\hline Repressive & $\begin{array}{l}\text { - Work accident } \\
\text { investigation } \\
\text { - Hazardous substances } \\
\text { leakage } \\
\text { - Occupational diseases } \\
\text { and pandemic } \\
\text { - Incident response }\end{array}$ & $\begin{array}{l}\text { - Incident handling } \\
\text { - Theft response } \\
\text { - Burglary response } \\
\text { - Violence response } \\
\text { - Criminal Investigation } \\
\text { - Cameras }\end{array}$ & $\begin{array}{l}\text { - } \text { Abuse CERT team } \\
\text { - SIEM/SOC } \\
\text { - Intrusion detection }\end{array}$ \\
\hline Preventive & $\begin{array}{l}\text { - Inspection machines } \\
\text { - Risk Inventory \& } \\
\text { Evaluation } \\
\text { - Lab Servant } \\
\text { - BHV audit } \\
\text { - Trend Analysis } \\
\text { - Awareness training } \\
\text { and education }\end{array}$ & $\begin{array}{l}\text { - Campus monitoring } \\
\text { - Fire and closing rounds } \\
\text { - Surveillance buildings } \\
\text { - Awareness } \\
\text { - Cameras } \\
\text { - Access control } \\
\text { - Pre-employment } \\
\text { screening }\end{array}$ & $\begin{array}{l}\text { - Architecture } \\
\text { - Defense \& detection } \\
\text { software } \\
\text { - Awareness } \\
\text { - } \text { Timely Patch mgt. } \\
\text { - Current real system } \\
\text { knowledge } \\
\text { - Pre-employment } \\
\text { screening } \\
\end{array}$ \\
\hline Innovative & $\begin{array}{l}\text { - Integration with other } \\
\text { domains } \\
\text { - Trend recognition } \\
\text { - Maturity development } \\
\text { - TU wide } \\
\text { standardization }\end{array}$ & $\begin{array}{l}\text { - Hotspot recognition } \\
\text { - Crime analysis } \\
\text { - Culture and behavior } \\
\text { measurement } \\
\text { - Predictive security }\end{array}$ & $\begin{array}{l}\text {-Trend and incident } \\
\text { analysis } \\
\text { - Risk management in } \\
\text { relation to core } \\
\text { objectives } \\
\text { - Predictive security }\end{array}$ \\
\hline
\end{tabular}

In the organization process to realize Integral Safety, one may distinguish sub-areas, risk types, care tasks, reporting forms, and Hotspots.

- Sub-areas of Safety \& Security are: the Campus, the buildings, people, processes and data / knowledge.

- Important care tasks are to ensure that students and employees can study, work, research, experiment, travel, party, relax, exercise and relax safely.

- The management and governance of Integral Safety also requires registering, recording and monitoring the status of Integral Safety. To this end, TU Delft has the following reports: Memorandum R\&P (Risk \& Protection); the Crisis Plan, BNO; Safety profile TU Delft; S\&S vision; CRE (Corporate Real Estate) plans; HSE (Health, Safety \& Environment) plans. 
- A number of "top risks" can be distinguished within the totality of potential risks. In the latest report from the TU Delft "Security profile 2019", the Top risks are counted as: IT risks; Incidents of violence; Fire; Accidents; Radicalization and / or espionage; and the power outage.

- The TU Delft campus has a number of so-called "Hotspots". These are locations where a large number of people gather together. This requires specific attention for monitoring safety and security. These Hotspots are the Aula and lecture halls, the laboratories, the "Bouwcampus", the sports facilities and the car and bicycle traffic flows on the campus.

Integral Safety can also be categorized into Strategic, Tactical and Operational areas of attention. TU Delft has made the following order for this:

Strategy: Crisis management, Safety risk management, IV Governance, Pre-employment screening policy, Fraud prevention policy

Tactics: $\quad$ OWEE / KMT (Reception week for new students and Introduction time), Events, Safety in faculty and management, Incident management, crime and investigations, safety systems, injury and social safety, hotspots, RID safety \& security (hazardous substances), Risk inventory and evaluation, safety audits.

Operations: Security officers, BHV, Emergency room, Safe PC use, Safe working, Occupational safety

For the implementation of the above mentioned strategic, tactical and operational areas of attention, TU Delft has defined the following organic structure. See table 10.

Tablel B-10. Organizational set up for Safety \& Security management at TU Delft

\begin{tabular}{|c|c|}
\hline $\begin{array}{l}\text { Strategic level } \\
\text { IV Board } \\
\text { Frequency of deliberation: } 1-2 \\
\text { times per year }\end{array}$ & $\begin{array}{l}\text { Composition: } \\
\text { CvB portfolio holder Integral Safety (chair); Manager IV; } \\
\text { Secretary CvB; two deans (rotating); Staff directors; } \\
\text { Educational Affairs; HR; ICT; Campus; Operations; Legal } \\
\text { services. }\end{array}$ \\
\hline $\begin{array}{l}\text { Tactic level } \\
\text { IV Deliberation } \\
\text { Frequency of deliberation: } 4 \\
\text { times per year }\end{array}$ & $\begin{array}{l}\text { Composition: } \\
\text { Manager IV (chair); Manager Facilities; Manager HSE (Health, } \\
\text { Safety \& Environment); Head ICT architecture; Press officer; } \\
\text { Manager Library; Two Faculty directors (rotating) Manager } \\
\text { Campus \& Real Estate }\end{array}$ \\
\hline $\begin{array}{l}\text { Operational level } \\
\text { Faculties and services } \\
\text { Frequency of deliberation per } \\
\text { Faculty or Service: monthly }\end{array}$ & $\begin{array}{l}\text { Composition: } \\
\text { Faculty director (chair); HSE advisor; FM security; ICT } \\
\text { Information manager; CRE building safety. }\end{array}$ \\
\hline
\end{tabular}

TU Delft has compiled a comprehensive Safety Mindmap in which all important safety and security aspects and their organizational relationships are shown. See figure 5. 


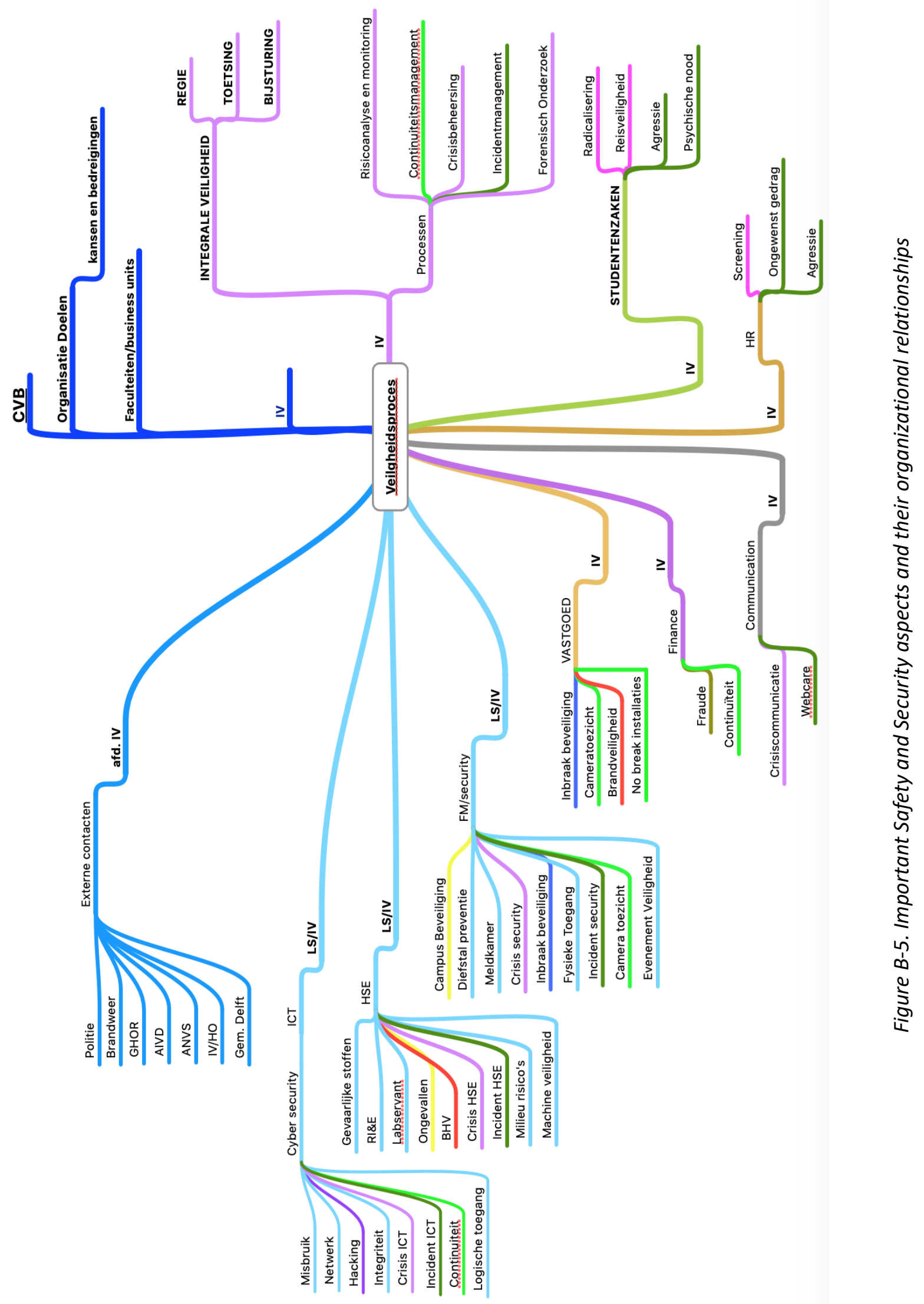


The portfolio holder for Integral Safety in the Executive Board of TU Delft (also chairing the IV-Board) informs the other members of the Executive Board about important matters concerning Integral Safety. In addition, the TU Delft Executive Board receives weekly a report of incidents that have occurred. This report is provided by the control room and from the IT department. Usually about 1012 incidents are reported per week.

The IV-Board proposes every year an updated Annual Plan for Integral Safety to the Executive Board. Important chapters of this annual plan are the respective integrated programs in the areas of Cyber security, HSE (Health, Safety \& Environment), Knowledge safety (knowledge migration and dual use; Fraud prevention; travel safety employees), Real estate and Campus security (including access to buildings), Student affairs (radicalization, espionage, aggression, psychological distress and travel safety), HR (screening, undesirable behavior, aggression), Relevant External contacts in the field of Safety \& Security, the process of risk management and crisis management and the IV plans of the respective faculties and services.

Important input in compiling the annual plan IV is the "improvement agenda" that is drawn up based on the experiences of the previous year. Incidents that have happened, and crises that may or may not have occurred, are monitored and registered. Additional input for the improvement agenda, are a yearly performed Benchmark in which Safety and Security performance is compared with similar types of activities at other universities and the yearly VRP report (Safety, Risk \& Protection).

Each faculty and service department at TU Delft also draw up their own safety and security improvement plan and an annual plan for integral safety. These are discussed and approved in the IV meetings.

\section{Crisis management}

TU Delft also has a Crisis Management Policy Plan. Important ingredients of this policy plan are the TU Delft crisis organization and the description of the crisis management process. Three levels of crisis management are distinguished (see also table 11): the Central Crisis Team (CCT) for TU Delft as a whole; a Decentral Crisis team (DCT) determined per faculty or building complex; and a Local Crisis Team (LT).

The Integral Safety Manager acts for all three levels, as coordinator of the process and as a liaison between the levels. Depending on the nature, extent and impact of the crisis, TU Delft drafted a scaling up matrix that provides for scaling up I three phases.

Phase 1

Minor incidents are dealt with directly at the operational level by the Local Team (LT) and only reported (in writing) to the tactical level. In the event of an accident / injury, the incident is handled by the TU Delft Emergency Response Team. The incident is also registered in the incident registration system (Infrahelp) according to the incident registration process by the person responsible for it.

\section{Phase 2}

Scaled up incidents are handled by the concerned faculty / building complex responsible person. The Local Team (LT) alerts and informs the Decentral Crisis Team (DCT) about the crisis event.

Phase 3

In the event of serious incidents of a faculty or a complex transcending nature, the Central Crisis Team is alerted and informed by the Decentral Crisis Team. 
Table B-11. Distinguished levels of crisis management (roles and functions)

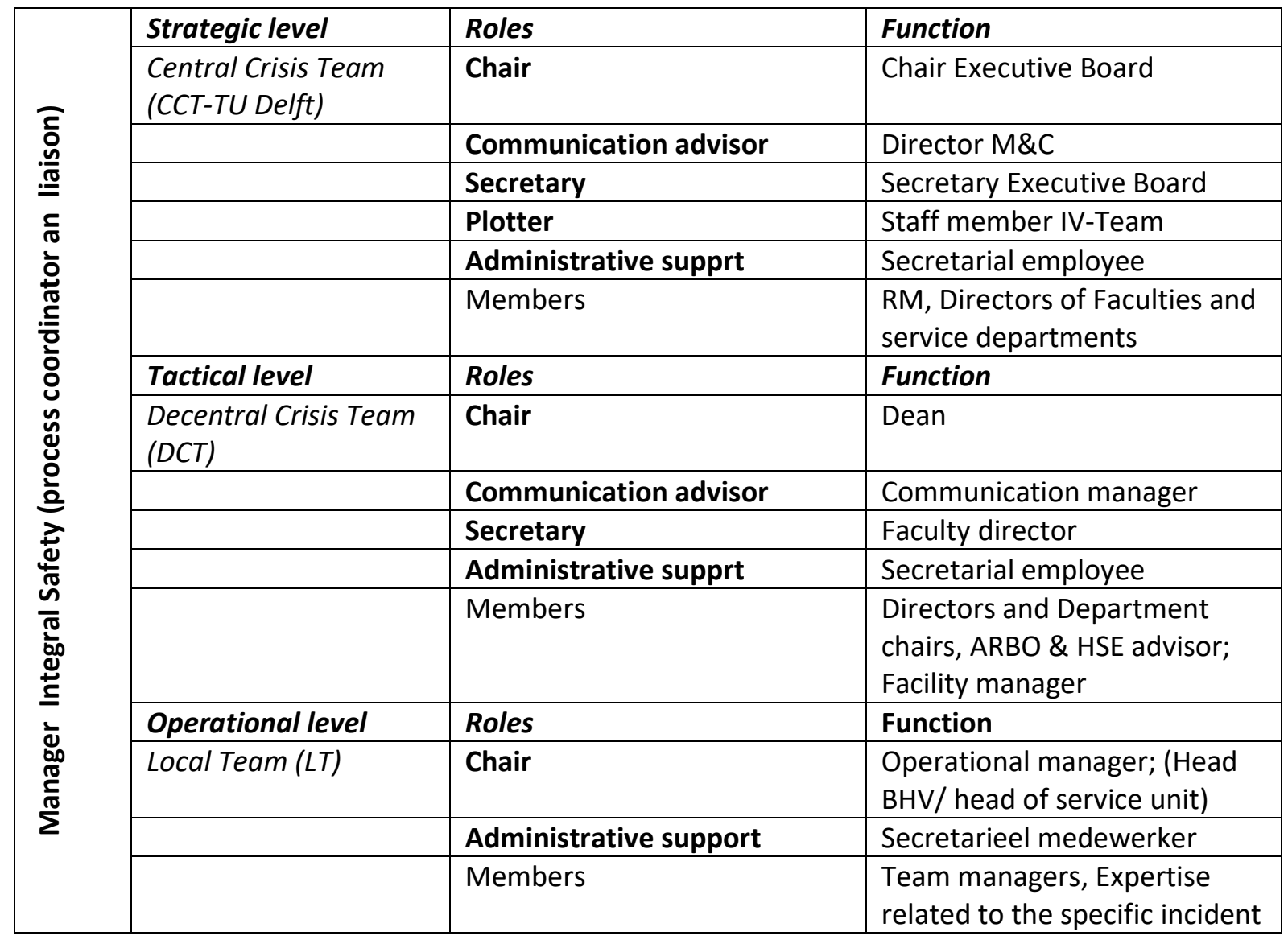

Please note: Roles in bold form the core team of the respective CCT, DCT and LT. 


\section{REFERENCES}

Adelerhof, G. (2018) Bewust omgaan met gevaarlijke stoffen, University of Twente, Master thesis Risk Management, $58 \mathrm{pp}$.

American Chemical Society (2012) Creating Safety cultures in academic institutions: a report of the safety culture task force of the ACS committee on chemical safety, Washington DC, $58 \mathrm{pp}$.

Azough, N. (2017) Weerbare jongeren, weerbare professionals, Ministerie van Onderwijs Cultuur en Wetenschap \& Ministerie van Volksgezondheid, Welzijn \& Spot, Den Haag, 56 pp.

Bakker, E., Donker, A., Eysink Smeets, M., Gelder, P. van, Helsloot, I., Hoepman, J., Khonraad, S. , Massink, R., Advies over veiligheid in het hoger onderwijs, $2 \mathrm{pp}$.

Boin, A. and Hart, Paul 't (2010) Organising for effective emergency management: Lessons from research, Australia Journal of Public Management, Vol. 69 (4), pp. 357-371.

Borgman, C.L. (2018) Open data, grey data and Stewardship: Universities at the privacy frontier, Berkeley Technology Law Journal, Vol. 33, pp. 365-412.

Bormans, R. (red.) Handreiking 'voorbereiding op een ernstig geweldsincident' op instellingen voor (hoger) onderwijs, Stuurgroep Programma Integrale Veiligheid Hoger Onderwijs, 22 pp.

Brinkman, R. (2019) Export control and IT systems, Thales, slide presentation, 7 November 2019, $12 \mathrm{pp}$.

Brinkman, R. (2019) Security update, changing regulations US DoD 2019-2020, Thales, 12 pp.

Chua, E.C. (2018) Managing risk to managing safety, University of Twente, 19 pp.

Clark, A. \& Kouri, R. (2009) Choosing an appropriate university or college environmental management system, Journal of Cleaner Production Vol. 17 pp. 971-984.

Damme, P. van \& Remrev, M. Handreiking Crisisorganisatie (Guide for a crisis organization), Platform Integrale Veiligheid in het Hoger Onderwijs, https://integraalveilig-ho.nl/wpcontent/uploads/Handreiking-Crisisorganisatie-IV-HO.pdf 23 pp.

Dowding, M.R. (2011) Interpreting privacy on campus: the freedom of information and personal privacy and Ontario universities, Canadian Journal of Communication, Vol 36 pp. 11-30.

European Confederation of Institutes of Internal Auditing, Risk in Focus 2020'Hot topics for internal auditors, https://www.eciia.eu/wp-content/uploads/2019/09/Risk-in-Focus.pdf 68 pp.

Fletcher, P.C. \& Bryden, P.J. (2009) Preliminary examination of safety issues on a university campus: personam safety practices, beliefs \& attitudes of female faculty \& staff, College Student Journal, Vol. 43, no. 1, pp 181-195.

Focke-Bakker, E.G.A., Kaouass, A., Koning, R.W.J. de \& Mansvelt, W.M. (2012) Integrale Veiligheid in governance en bedrijfsvoering in het hoger onderwijs, Handleiding voor de implementatie van integrale veiligheid, Ministerie OCW, https://integraalveilig-ho.nl/wpcontent/uploads/Integrale-veiligheid-in-governance-en-bedrijfsvoering-ho.pdf, pp. 50.

Garcia, H.F. (2006) Effective leadership response to crisis, Strategy \& Leadership, Vol. 34 (1), pp. 4-10.

García Herreo, S., Mariscal Saldaña, M.A., Manzanedo del Campo, M.A. \& Ritzel, D.O. (2002) From the traditional concept of safety management to safety integrated with quality, Journal of Safety Research, Vol. 33, pp. 1-20

Gearon, L. (2017) The counter-terrorist campus: Securisation theory and university securisation: Three models, Transformation in Higher Education, https://doi.org/10.4102/the.v2i0.13, $13 p p$.

Gelder, P. van \& Focker-Bakker, E., Veiligheidsprofiel (VP 2019), TU Delft, TBM/Dsys \& Delft Safety and Security Institute, $22 \mathrm{pp}$.

Gilley, A. \& Gilley, J.W. (2006) ERPA: What do Faculty know? What van universities do? College and University Journal, Vol. 82 (1) pp $17-26$.

Grote, G. \& Künzler, C. (2000) Diagnosis of safety culture in safety management audits, Safety Science, Vol. 34, pp. 131-150.

Joske, A. (2018) Picking flowers, making honey. The Chinese military's collaboration with foreign 
universities, Australian Strategic Policy Institute, International Cyber Policy Centre, Policy

Brief report No 10/2018, 25pp

Justis, de screeningsautoriteit van het Ministerie van Justitie en Veiligheid, April 2019,

https://www.justis.nl/binaries/Brochure\%20Screening\%20van\%20personeel tcm34381945.pdf $34 \mathrm{pp}$

Halman, J.I.M. (2019) Plan tot implementeren van Integraal Veiligheidsmanagement op de UT. $1^{e}$ Fase: Rapportage uitgevoerde Quick Scan, UT-intern rapport, 15 pp.

Helsloot, I., Vlagsma, J. \& Kraaijenbrink, S. (2017) Risk analysis higher education institutions, An integral analysis of the higher educational institutions, Program IV-HO, https://integraalveilig-ho.nl/wp-content/uploads/Risk-analysis-HEls.pdf, 31pp.

Hutter, J. \& Spit, M. (2014) Management Systeem Integrale Veiligheid, Integrale Veiligheid Hoger Onderwijs, $93 \mathrm{pp}$.

Joshi, C. \& Singh, U.K. (2017) Information security risks management framework: A step towards mitigating risks in university network, Journal of Information Security and Applications, Vol. 35, pp. $128-137$.

Kapucu, N. \& Khosa, S. (2012) Disaster resiliency and culture of preparedness for university and college campuses, Administration \& Society, Vol. 45, no. 1, pp. 3-27.

Ministerie van Binnenlandse Zaken en Koninkrijksrelaties, (2019) AIVD Jaarverslag 2018, Den Haag, $27 \mathrm{pp}$.

Ministerie van Binnenlandse Zaken en Koninkrijksrelaties, Algemene Inlichtingen- en Veiligheidsdienst (2010) Kwetsbaarheidsanalyse spionage, Spionagerisico's en de nationale veiligheid, Den Haag, 53 pp.

Neufeldt, T. (2009) Formalizing privacy protection: FIPPA, Ontario universities, and unsupervised records management, Faculty of Information Management Quarterly, pp. 1-12.

Orrick, D.M. (2003) An examination of online privacy issues for students of American universities, International Conference on Internet Computing, 6pp.

Platform IV-HO (2018), Advies over Veiligheid in het Hoger Onderwijs, Raad van Advies, kenmerk B.07.06B https://integraalveilig-ho.nl/wp-content/uploads/Advies-RvA.pdf 14 pp.

Platform IV-HO, Integrale Veiligheid Hoger Onderwijs, Handboek Integraal Veilig internationaliseren. Veiligheid bij interne- en externe mobiliteit van studenten en medewerkers in het hoger onderwijs. https://integraalveilig-ho.nl/wp-content/uploads/Handboekinternationalisering1.pdf $24 \mathrm{pp}$.

Platform IV-HO (2019) Integrale Veiligheid Hoger Onderwijs, Handreiking voorbereiding op een ernstig geweldsdelict op instellingen van hoger onderwijs. https://integraalveilig-ho.nl/wpcontent/uploads/Handreiking-Ernstige-Geweldsincidenten.pdf $22 \mathrm{pp}$.

Ministerie van Binnenlandse Zaken en Koninkrijksrelaties, AIVD Jaarverslag 2018 https://www.aivd.nl/documenten/iaarverslagen/2019/04/02/jaarverslag-aivd-2018 28 pp.

Ministerie van Binnenlandse Zaken en Koninkrijksrelaties, Algemene Inlichtingen- en Veiligheidsdienst (2010) Kwetsbaarheidsanalyse spionage, Spionagerisico's en de nationale veiligheid https://www.aivd.nl/documenten/publicaties/2010/04/01/kwetsbaarheidsanalyse-spionage, $56 \mathrm{pp}$.

Ministerie van Defensie, Algemene Beveiligingseisen voor Defensieopdrachten (ABDO, 2019, uitgegeven februari 2020, https://www.defensie.nl/onderwerpen/militaire-inlichtingen-enveiligheid/downloads/beleidsnota-s/2020/02/04/abdo-2019 132pp.

Radboud Universiteit (2019) Regeling bescherming persoonsgegevens, Nijmegen, 14pp.

Rajabalinejad, M., Bonnema, G.M. \& Houten, F.J.A.M. (2015) An integral safety approach for design of high risk products, In: Proceedings of the European Safety and Reliability conference, ESREL 2015 - ETH, the Swiss Federal Institute of Technology, Zurich, Switzerland, 7-10 Sep 2015.

Rouwette, E., Leeuwen, R. van \& Vennix, J. (2003) Beleidsplannen Integrale Veiligheid: Elektronische besluitvorming, Het Tijdschrift voor de Politie, Vol. 65, no. 3, pp. 22-26.

Sapriel, C. (2003) Effective crisis management: Tools and best practice for the new millennium, 
Journal of Communication Management, Vol. 7 (4), pp. 1-8.

Schermer, B.W., Hagenauw, D \& Falot, N. (2018) Handleiding Algemene Verordening

Gegevensbescherming en Uitvoeringswet Algemene Verordening Gegevensbescherming, Ministerie van Justitie en Veiligheid, 98. Pp.

Sloan, J.J., Lanier, M.M. \& Beer, D.L. (2000) Policing the contemporary university campus: Challenging traditional organizational models, Journal of Security Administration, Vol. 23, no 1, pp 1-20.

Stafford, D. \& Rittereiser, S. (2007) Community policing, crime prevention and comprehensive training programs: Key ingredients to reducing risk in campus public safety, In: Stetson College of Law, Proceedings of the $28^{\text {th }}$ Annual National Conference on Law and Higher Education, February 17-21, 2007.

Steur, H.G.J., (2012) Rapportage (sociale) veiligheid \& integriteit hoger Onderwijs, Ministerie van Onderwijs, Cultuur en Wetenschap, Inspectie van het Onderwijs, Den Haag, 7pp.

Stol, W., Rijpma, J., Tielenburg, C., Melching, G. \& Roest, M. (2008) Basisboek Integrale Veiligheid, Studiehulp, Coutinho, Bussum, $91 \mathrm{pp}$.

U.S. Department of Education [DOE]. (2009). Action guide for emergency management at institutions of higher education.

Thales (2019) Country security management, OR Meeting, Insider Threat, slide presentation 14 pp.

Toolkit Integrale Veiligheid in het Hoger Onderwijs (2012) Ministerie OCW, projectgroep Integrale Veiligheid, https://integraalveilig-ho.nl/wp-content/uploads/Toolkit-IV-HO-2012.pdf, pp. 51.

Williams, B.N., LePere-Schloop, M., Silk, P.D. \& Hebdon, A. (2016) The co-production of campus safety and security: a case study at the University of Georgia, International Review Administrative Sciences Vol. 82, no 1, pp. 110-130.

Zdziarski, E. L., Dunkel, N. W., \& Rollo, J. M., \& Associates. (2007). Campus crisis management: A comprehensive guide to planning, prevention, response and recovery. San Francisco, CA: Jossey-Bass. 